\title{
A proposed method for evaluation of morphological changes in the condyle and glenoid fossa by cone beam computed tomography
}

\author{
Michael R. Munn \\ West Virginia University
}

Follow this and additional works at: https://researchrepository.wvu.edu/etd

\section{Recommended Citation}

Munn, Michael R., "A proposed method for evaluation of morphological changes in the condyle and glenoid fossa by cone beam computed tomography" (2010). Graduate Theses, Dissertations, and Problem Reports. 2971.

https://researchrepository.wvu.edu/etd/2971

This Thesis is protected by copyright and/or related rights. It has been brought to you by the The Research Repository @WVU with permission from the rights-holder(s). You are free to use this Thesis in any way that is permitted by the copyright and related rights legislation that applies to your use. For other uses you must obtain permission from the rights-holder(s) directly, unless additional rights are indicated by a Creative Commons license in the record and/ or on the work itself. This Thesis has been accepted for inclusion in WVU Graduate Theses, Dissertations, and Problem Reports collection by an authorized administrator of The Research Repository @ WVU. For more information, please contact researchrepository@mail.wvu.edu. 


\title{
A PROPOSED METHOD FOR EVALUATION OF MORPHOLOGICAL CHANGES IN THE CONDYLE AND GLENOID FOSSA BY CONE BEAM COMPUTED TOMOGRAPHY
}

Michael R. Munn, D.M.D.

\section{A THESIS}

\author{
Submitted to: \\ The School of Dentistry \\ at West Virginia University \\ in partial fulfillment of the requirements \\ for the degree of \\ Master of Science \\ In \\ Orthodontics
}

Peter Ngan, D.M.D., Chair

Chris Martin, D.D.S., M.S.

Thomas Razmus, D.D.S., M.S.

West Virginia University

Department of Orthodontics

Morgantown, West Virginia

2010 


\title{
ABSTRACT \\ A PROPOSED METHOD FOR EVALUATION OF MORPHOLOGICAL CHANGES \\ IN THE CONDYLE AND GLENOID FOSSA BY CONE BEAM COMPUTED TOMOGRAPHY
}

\begin{abstract}
Michael R. Munn, D.M.D.
The difficulty with three-dimensional analyses remains with the myriad of data that is possible to derive from a volume. The goal of this study is to report 3D changes in the temporomandibular joint in a reliable and quantifiable way. The approach included plotting specific referents on the mandibular condyle and tracking them in magnitude $(\mathrm{mm})$ and direction $\left({ }^{\circ}\right)$ on a reference plane after superimposing the cone beams threedimensionally on the inferior alveolar nerve canal and the lower contour of the third molar tooth germ. Two sets of measurements were compared for reliability and each measurement showed varied correlation. Linear measurements tended to be more reliable than component and angular measurements. Angular measurements were generally the least reliable. The varied reliability results are likely due to the difficulty in superimposing limited field of view (FOV) cone beam radiographs because of inadequate structures that are able to be superimposed.
\end{abstract}




\section{DEDICATION}

I dedicate this thesis to my beautiful wife, Emily Munn, who has been there for me and encouraged me from the beginning. You are wonderful in ways that I cannot find words to express. You are an incredibly loving individual who seeks out the needs of others. I do not know how I could have completed this chapter in my life without your support. I love you!

Also to my parents, Willie and Chun Ja Munn, whose wisdom and support have always guided me throughout my life. You are my role models both in work and in how to live life. You have always supported me in whatever I chose to do.

Also to Loring Ross, my mentor, friend, and brother-in-law. You have contributed a great deal to my life as a person and a clinician. I don't know if you realize how much of a direct impact you have had on my life. I look forward to the opportunities in the future as we work in practice together.

And to God, who has provided me with abundant joy and blessing... so much more than I deserve. It is He who I give all of the glory and honor. 


\section{ACKNOWLEDGEMENTS}

I would like to take this opportunity to thank the following individuals who have contributed and assisted me throughout my specialty training.

Dr. Peter Ngan, for his excellent wisdom both in life and in education. Your dedication to teaching is extraordinary.

Dr. Chris Martin, for his commitment to education in full-time teaching. You have provided me with much knowledge about practice management and patient care. My vocabulary has greatly increased since doing crossword puzzles with you.

Dr. Thomas Razmus, for his advice and encouragement and expertise in radiology.

Dr. Erdogan Gunel, for your expertise (and patience) in assisting me with the statistics in this study.

Dr. Loring Ross, for providing radiographs used in this study.

Drs. Tim Tremont, Joseph Bonello, Edward McFarland, Jeff Gilmore, Thomas Jarrett, Kerry Kirsch, John Dempsey, Mike Hazey, Jennifer Hamilton, and Dan Foley, for your leadership and advice both in and out of the classroom. The contributions you have made to this program are so numerous they cannot be measured.

Pam, Charlotte, Vivian, Karen, and Leona, for your part in my education and the fun times in the clinic.

Joyce, Carrie, and Hillary, for your hard work and also for your friendship.

Dr. Dean Heinrichs and Dr. Kolin Weaver, my co-residents, for the lifelong friendship we have forged together and all the great memories in residency. I consider myself truly blessed to have gotten to know you two. I look forward to interacting with you and your families in the future. Holler!

Tim, Lindsay, Nikia, Mike, Rajia, Thuy, Rob, Maggie, Erica, Ronnie, Jung Mee, and Holly, my fellow residents, for their friendship, guidance, and fun throughout the program. 


\section{TABLE OF CONTENTS}

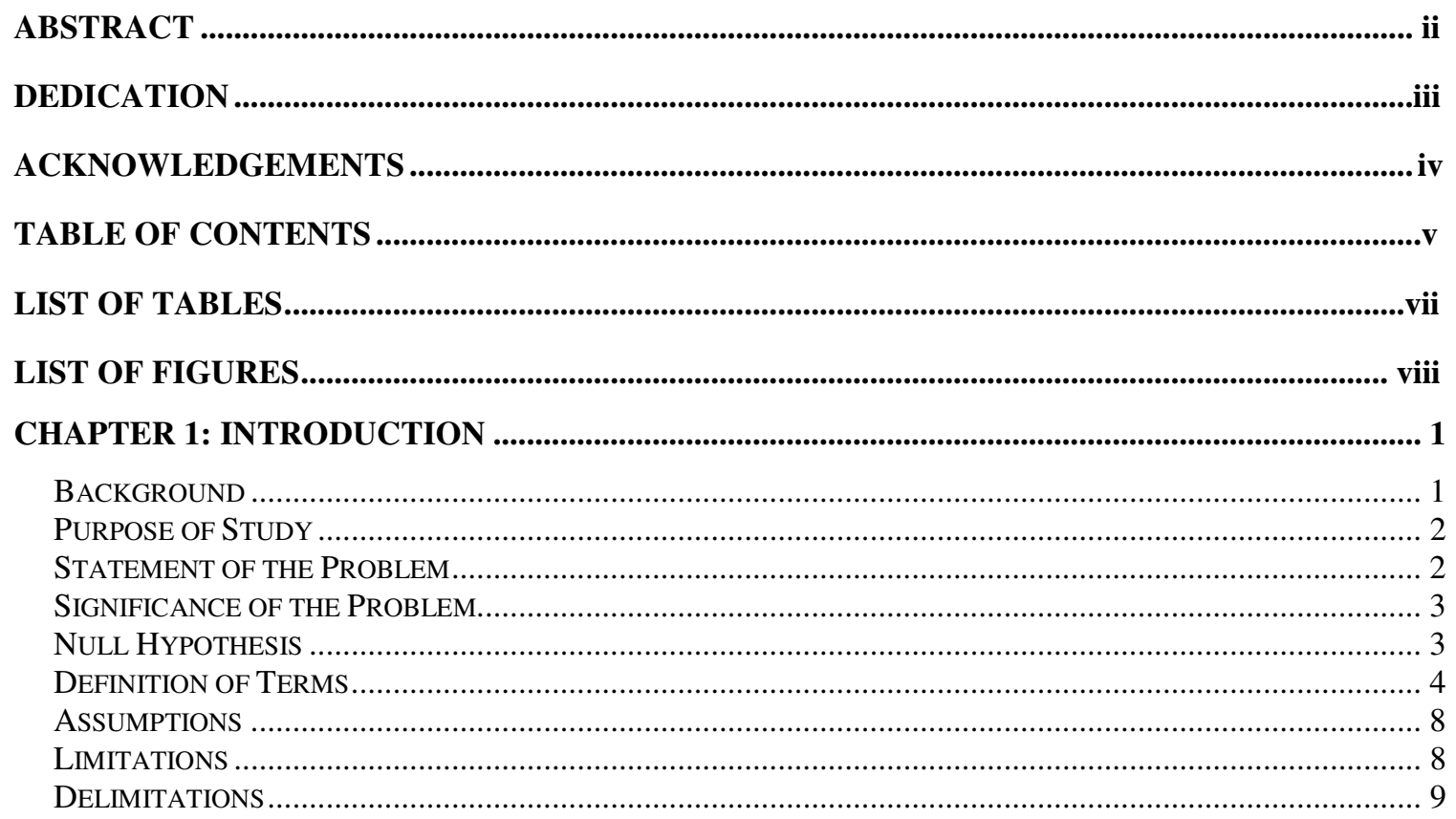

CHAPTER 2: REVIEW OF LITERATURE ........................................................................................10

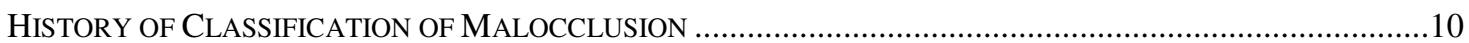

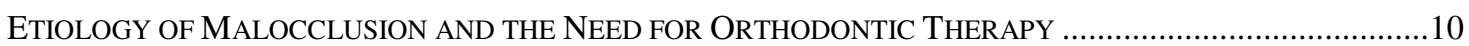

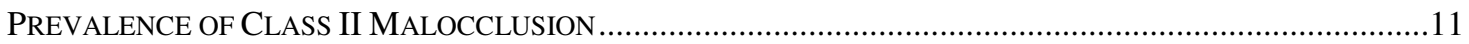

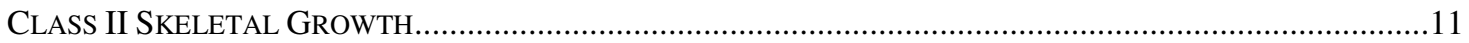

TREATMENT OF CLASS II MALOCCLUSION ............................................................................... 13

FunCTIONAL APPLIANCES USED TO TREAT ClASS II MALOCCLUSION ............................................15

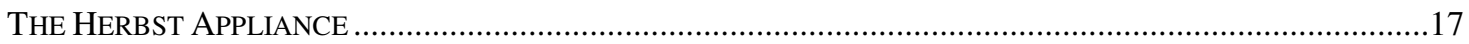

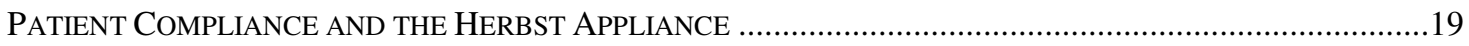

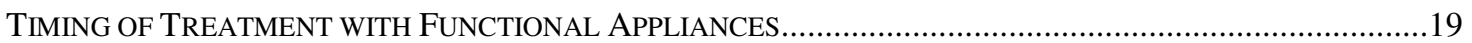

SKELETAL TREATMENT EFFECTS OF THE HERBST APPLIANCE ....................................................21

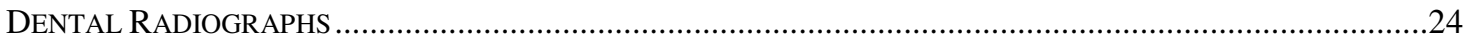

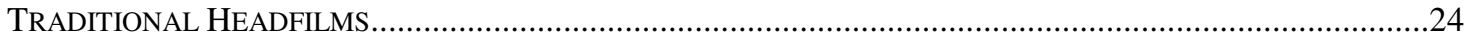

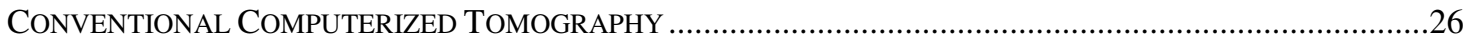

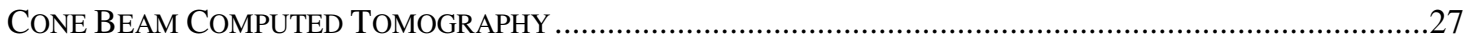

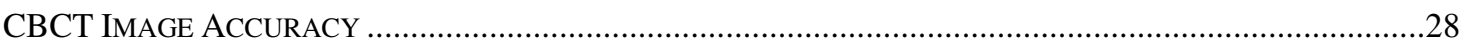

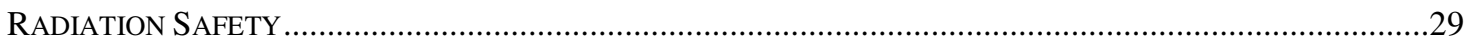

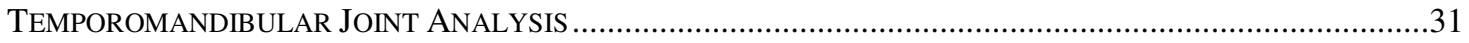

CHAPTER 3: MATERIALS AND METHODS ..............................................................................33

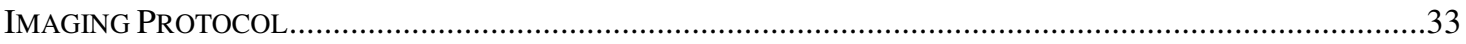

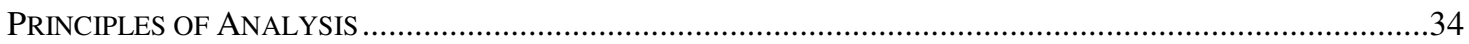

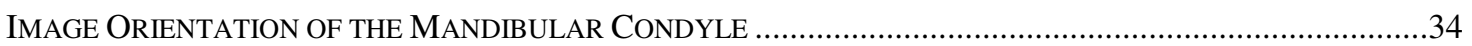

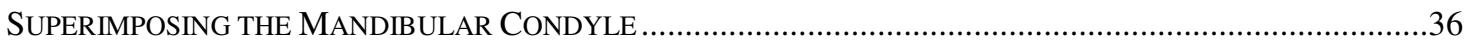

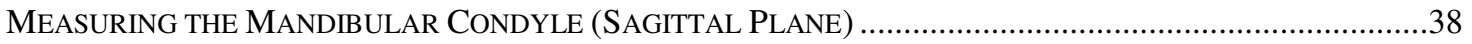

MEASURING THE MANDIBULAR CONDYLE (CORONAL PlanE) ....................................................40

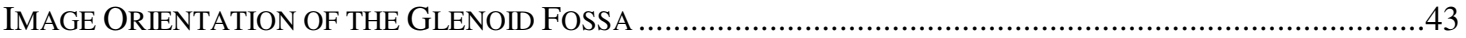

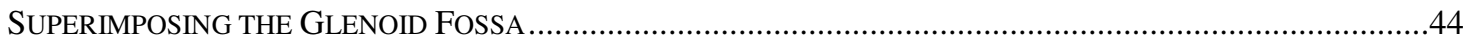

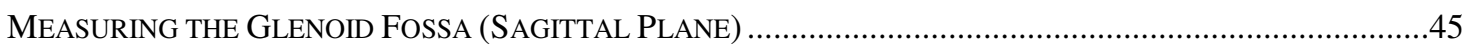

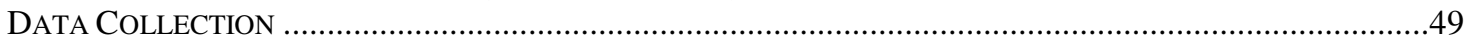

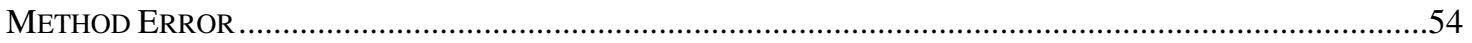




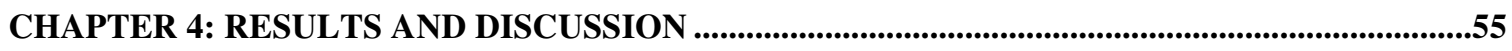

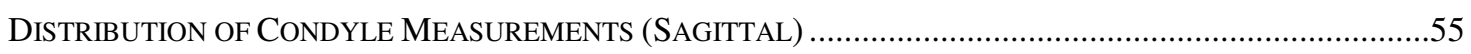

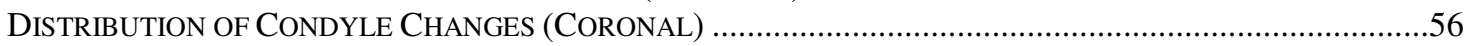

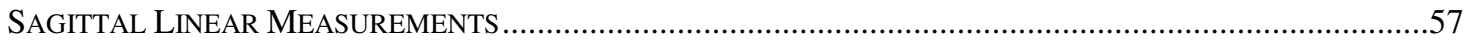

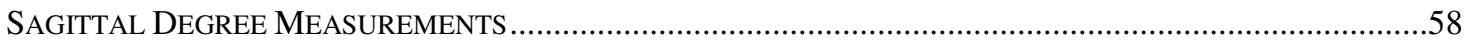

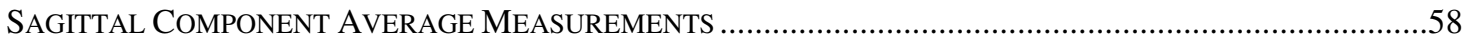

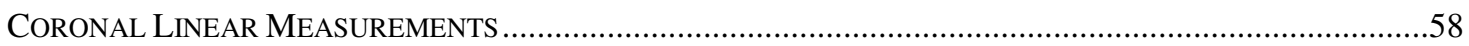

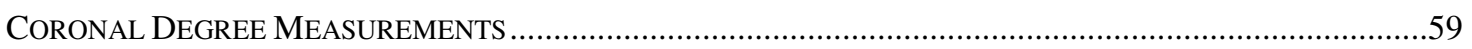

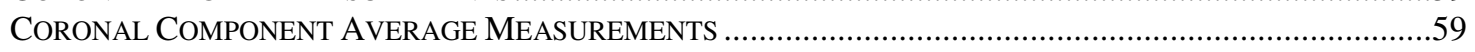

CHAPTER 5: SUMMARY, CONCLUSIONS, AND RECOMMENDATIONS.....................................61

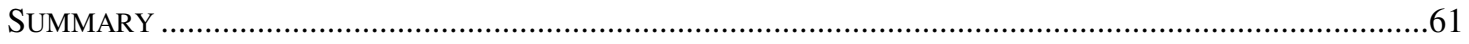

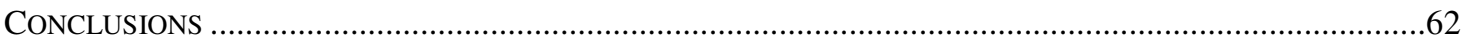

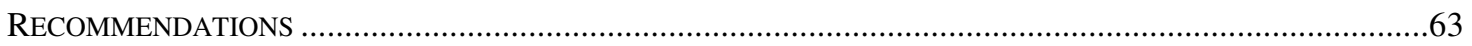

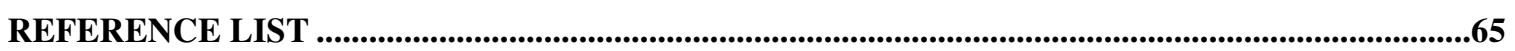

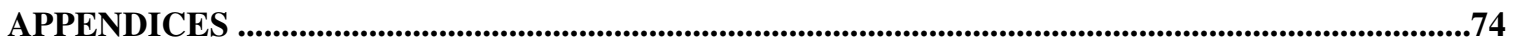

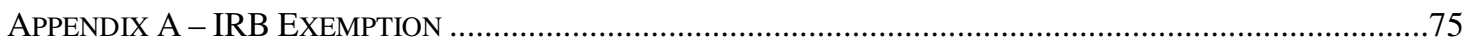

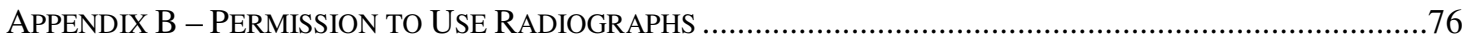

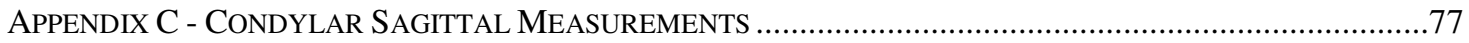

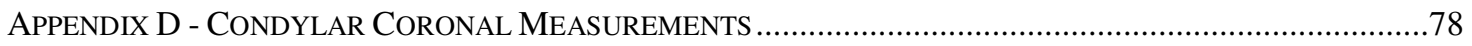

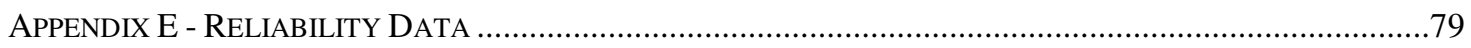

CURRICULUM VITAE ....................................................................................................................................80 


\section{LIST OF TABLES}

Table 1. Summary of radiograph exposure comparison $(\mathrm{mSv})$.................................. 30

Table 2. Data collection table for the mandibular condyle (coronal plane).................... 49

Table 3. Data collection table for the mandibular condyle (sagittal plane) ..................... 49

Table 4. Data collection table for the glenoid fossa (medial sample)............................ 50

Table 5. Data collection table for the glenoid fossa (center sample) .............................. 50

Table 6. Data collection table for the glenoid fossa (lateral sample) ...............................50

Table 7. Microsoft Excel ${ }^{\mathrm{TM}}$ formula for summarizing direction of movement in the

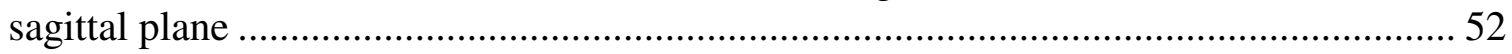

Table 8. Microsoft Excel ${ }^{\mathrm{TM}}$ formula for summarizing direction of movement in the

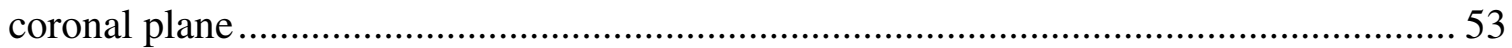

Table 9. Distribution of condyle measurements (sagittal plane) ....................................56

Table 10. Distribution of condyle measurements (coronal plane) ................................. 57

Table 11. Reliability of condylar sagittal linear measurements ...................................5 57

Table 12. Reliability of condylar sagittal directional measurements..............................58

Table 13. Reliability of condylar sagittal component average measurements................. 58

Table 14. Reliability of condylar coronal linear measurements ....................................59

Table 15. Reliability of coronal directional measurements .............................................59

Table 16. Reliability of condylar coronal component average measurements .................60 60

Table 17. Reliability of variables, ordered from least to most correlated........................ 60 


\section{LIST OF FIGURES}

Figure 1. Pixel and voxel components of a computerized tomographic radiograph. ........ 8

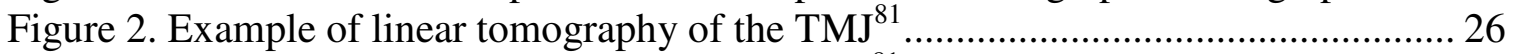

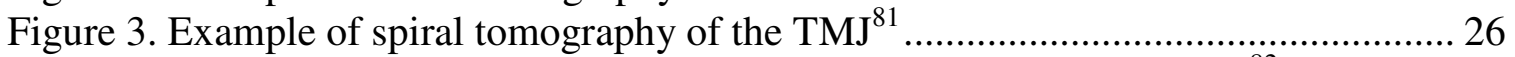

Figure 4. Example of horizontal cross-section of right TMJ in a CT image. ${ }^{82}$................ 27

Figure 5. Example of a cone beam computerized tomography radiograph of a TMJ

(Planmeca Promax 3D, Romexis ${ }^{\mathrm{TM}}$ software) ............................................................ 28

Figure 6. Illustration of the radiograph field of view used in this study (blue cylinder

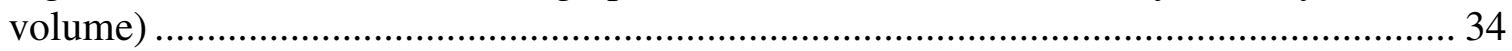

Figure 7. Standardizing the orientation of the T0 image for superimposition of the

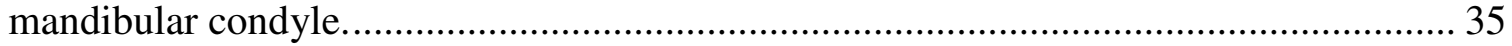

Figure 8. Auto-registration interference from radiographic artifact .............................. 36

Figure 9. Auto-registration for superimposing the mandibular condyle......................... 37

Figure 10. Visual inspection of the mandibular condyle superimposition (inferior alveolar

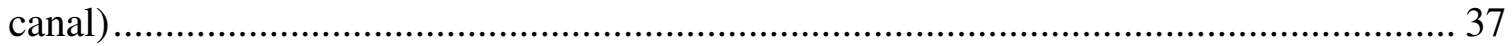

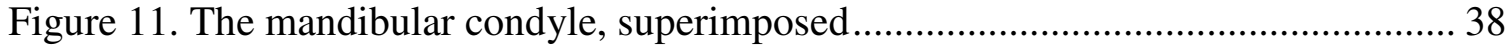

Figure 12. (A) Line \#1 parallel to vertical of FOV with Point \#2 on superior referent (sagittal) of T0 condyle. (B) Lines \#1 and \#2 and Points \#1 and \#2 and an arbitrary Point \#3. (C) Point \#3 moved to superior referent of T1 condyle. Degree measurement and

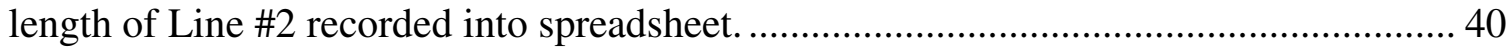

Figure 13. Demonstration of anterior referent (sagittal). Left, T0; Right, T1 ................ 40

Figure 14. Demonstration of posterior referent (sagittal). Left, T0; Right, T1............... 40

Figure 15. Demonstration of superior referent (coronal). Left, T0; Right, T1 ............... 42

Figure 16. Demonstration of medial referent (coronal). Left, T0; Right, T1 ................. 42

Figure 17. Demonstration of lateral referent (coronal). Left, T0; Right, T1 ................... 42

Figure 18. Standardizing the orientation of the T0 image for superimposition of the glenoid fossa. Arrows indicate the most superior aspect ............................................. 43

Figure 19. Orienting the sagittal plane to be parallel with the long axis of the upper fossa

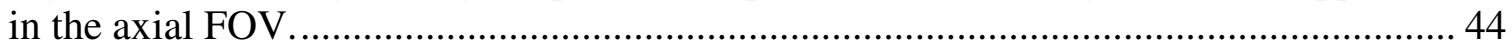

Figure 20. Auto-registration for superimposing the glenoid fossa .............................. 45

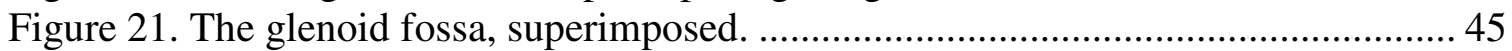

Figure 22. Axial FOV of fossa bisected with sagittal and coronal planes ...................... 46

Figure 23. (A) Posterior bisection; (B) superior aspect of the fossa; (C) anterior bisection

Figure 24. (A) Glenoid fossa at the most inferior level with bone still circumferential. Bisect medial (a) and lateral (b) halves for measurement sampling. (B) Axial plane too inferior, where bone does not completely surround the fossa (arrows)......................... 48 Figure 25. (A) Line \#1 parallel to vertical of FOV with Point \#2 on superior referent (sagittal) of T0 fossa. (B) Lines \#1 and \#2 and Points \#1 and \#2 and an arbitrary Point \#3. (C) Point \#3 moved to superior referent of T1 fossa. Degree measurement and length of Line \#2 recorded into spreadsheet. .................................................................... 49

Figure 26. Compass view of directions in the sagittal plane ....................................... 51

Figure 27. Compass view of directions in the coronal plane ...................................... 51

Figure 28. Compass diagram of the above example ................................................. 54 


\section{CHAPTER 1: INTRODUCTION}

\section{Background}

Bite jumping appliances such as the Herbst, MARA, or twin block appliance utilize forward lower jaw positioning to correct Class II malocclusions with a retrusive mandible. These appliances intentionally disarticulate the condyle from the glenoid fossa to stimulate condylar growth-contributing skeletally to Class II correction. The introduction of the Herbst appliance which utilizes anterior mandibular repositioning ${ }^{1}$ ("bite-jumping") has been blamed for increasing the risk of developing TMD. ${ }^{1,2}$ However, there are clinically insignificant structural bony changes to the TMJ detected after treatment with these appliances using traditional cephalometric analysis., 3,4

In the past, researchers were limited to cephalometric analysis on lateral and frontal headfilms. These measurements are largely oversimplified because information is lost (or assumed) when data from a three-dimensional object is transferred into a twodimensional image. Even now that volumetric radiology has become more practical to use in practice and in research, manipulating, measuring, and comparing threedimensional images can be difficult.

According to Popowich, et al, current published studies do not provide quantitative data in evaluating morphological changes of the condyle and glenoid fossa ${ }^{5}$. Studies utilizing magnetic resonance imaging (MRI) only provide data based upon visual inspection $^{6}$ of the radiographs with little information regarding operator standardization and method error. Attempts to create a quantitative analysis using MRI technology were abandoned because of changes in plane orientation between imaging acquisitions. ${ }^{5}$ Since 
the advent of Cone Beam Computed Tomography (CBCT), a number of companies have produced software, including InVivoDental ${ }^{\mathrm{TM}}$ by Anatomage USA, which allow for manipulation and comparisons of volumetric images. Now high-resolution threedimensional scans can be studied quantitatively to revisit the question of morphological changes of the condyle and glenoid fossa during functional appliance therapy.

\section{Purpose of Study}

This study investigated the changes in the condyle and glenoid fossa with Herbst treatment in three planes of space using a novel three-plane superimposition. Intraoperator reliability was evaluated and the results of this study will provide researchers with information regarding the usage of three-dimensional analysis to quantitatively determine morphological changes in the TMJ.

\section{Statement of the Problem}

Several problems arise when performing analysis in three dimensions. In prior research involving lateral cephalometric radiographs, angular and linear measurements are relatively easy to produce after mastering identification of radiographic anatomy. Three-dimensional analysis is more difficult because of the introduction of a third plane of space that must be carefully considered when analyzing. This is further complicated when comparing two volumes by superimposing them in three dimensions. The first of which is access (technologically or financially) to software capable of making threedimensional superimpositions. The second problem is inter- and intra-operator reliability. Because superimposing in three dimensions requires practice and attention to detail, there can be a high degree of variability within the same operator or between 
different operators carrying out a three-dimensional analysis. ${ }^{5}$ There is little documentation on the reliability and method error of three-dimensional analyses studying the morphology of the growing condyle and glenoid fossa during Class II treatment with the Herbst appliance.

\section{Significance of the Problem}

While research indicates that the Herbst appliance is successful in correcting Class II anterior-posterior discrepancies, little information is known about the developing structure of the TMJ during treatment (upon which this form of Class II correction has a major impact). Inadequate resolution of traditional head films and magnetic resonance imaging (MRI) make evaluation of the condyle and glenoid fossa difficult and imprecise. Due to the availability of a CBCT machine in a private office or in an academic institution, cone beam technology provides a precise and practical perspective in evaluating the morphology and development of the growing condyle in three dimensions. Overall, this makes the clinician more informed when planning and executing treatment.

\section{Null Hypothesis}

1. Changes in the condyle and glenoid fossa with Herbst treatment in three planes of space can be quantified using a three-planes superimposition technique.

2. There are no significant differences in intra-operator variability with the proposed superimposition technique. 


\section{Definition of Terms}

- Bite-jumping (mandibular anterior repositioning)

○ A change in the sagittal inter-maxillary jaw relationship by anterior displacement of the mandible

- Cephalogram

○ Synonym for a cephalometric radiograph

- Cephalometric analysis

- An analysis made on a radiograph of the head (cephalometric radiograph) comprised of referents and landmarks used to describe relationships of skeletal and dental components, usually compared to a norm.

- Cephalometric radiograph

- A radiograph of the head made with reproducible relationships between the x-ray source, the subject, and the film.

- Class II malocclusion

- A type of malocclusion in which the mesiobuccal cusp of the maxillary first molar is located mesial to the buccal groove of the mandibular first molar when the teeth are in centric occlusion.

- Class II skeletal pattern

- A type of skeletal discrepancy in which the mandible is retrusive, relative to the maxilla. 
- Compliance

- The ability of a patient to consistently follow instructions relating to treatment, even if following the instructions may be unpleasant or inconvenient.

- Computed tomography (CT)

- A series of radiographs (flat, two-dimensional grayscale images) that are analyzed and rendered via computer to produce a three-dimensional volumetric or surface mapped image.

- Cone Beam Computed Tomography (CBCT)

- A computed tomography scan utilizing an x-ray beam in the shape of a cone to provide images of bony structures. Data is captured by a flat receiver that detects pulses of cone shaped beam radiation. The result is a stack of two-dimensional grayscale images of the anatomy which can be rendered into volumetric data to visualize anatomical structures in three dimensions. Also known as Cone Beam Volumetric Tomography (CBVT)

- Digital Imaging and Communications in Medicine (DICOM)

- DICOM is a standard for handling, storing, printing, and transmitting medical images. It includes a file format in which data from volumetric radiographs are stored.

- Fixed functional appliance

- An appliance that is placed in the patient's mouth that utilizes forces of function (e.g. mastication) in order to provide a therapeutic force. This appliance cannot be removed from the mouth by the patient. 
- Herbst appliance

- A type of functional appliance that protrudes the mandible into a forward position to therapeutically stimulate mandibular growth and inhibit maxillary growth in the anterior-posterior dimension.

- Image intensifier

- Allows real time image feed to an analog or digital receiver for compilation or viewing of live radiographic images.

- Landmark

- A fixed, reproducible (anatomical) point of reference on a radiograph.

- Referent

- A variable, reproducible (anatomical) point related to a landmark on a radiograph.

- Resolution

- The smallest distance between two points at which the viewer can still distinguish the two points as separate entities. Higher resolutions provide finer detail.

- Retrognathic

- A term used to define the position or relationship of a skeletal component in an anterior-posterior dimension that is more posterior than normal.

- $\quad$ Sievert $(\mathrm{Sv})$

- SI unit of radiation dose equivalent. This unit of measure reflects the biological effects of radiation (as opposed to the physical aspects which are characterized by absorbed dose measured in Grays). 
- Temporomandibular Dysfunction (TMD)

- TMD is a blanket term for the acute or chronic dysfunction, disorder, or inflammation of the temporomandibular joint (TMJ). This joint derangement can be evidenced by popping, clicking, or pain symptoms or a combination.

- Temporomandibular Joint (TMJ)

- The joint at which the mandible articulates with the cranial base with a fibrocartilage articular disc interposed in a joint capsule.

- Tomogram

○ A radiograph representing a "slice" or sectioned focal area by moving an X-ray source and the film in opposite directions during exposure.

Structures in the focal plane appear sharp, while structures in front of and behind the plane are blurred.

- Volumetric

$\circ$ Visual representation of an image in three dimensional space

- Voxel

- The smallest element in building a three-dimensional image. Similar to a "pixel" in a two-dimensional image dispaly. Voxel size is important in defining the resolution of a volumetric image (smaller voxel size $=$ higher resolution). The voxel size of a CBCT image can be as small as 0.16 cubic millimeters while the voxel size of a traditional CT image is 0.32 cubic millimeters 


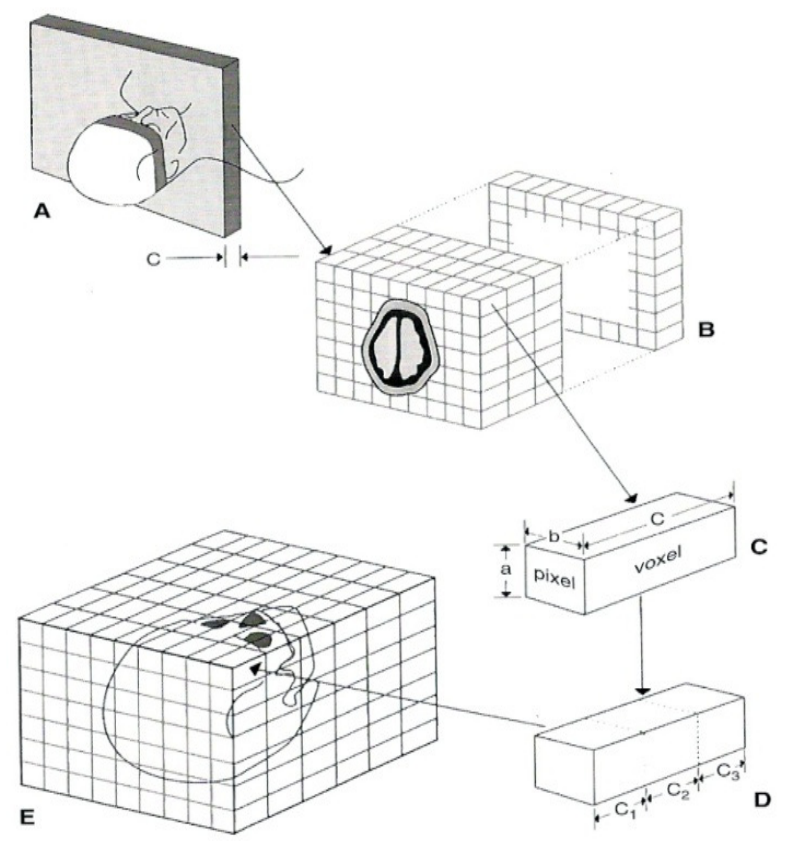

Figure 1. Pixel and voxel components of a computerized tomographic radiograph.

\section{Assumptions}

1. The CBCT scans are of sufficient quality with no patient movement contributing to the introduction of radiographic artifacts.

2. Herbst appliance treatment was effective at resolving the Class II discrepancy in part by producing morphological changes in the glenoid fossa and mandibular condyle.

3. The operator in this study has a working knowledge of computer technology.

\section{Limitations}

1. Growth patterns and growth periods (peak pubertal growth period) are not available for the individuals in this study

2. Skeletal ages of the patients comprising the sample cannot be determined 
3. There will be gender, ethnicity, and medical history differences among the subjects.

4. Volume of imaging field is a cylinder with an $8 \mathrm{~cm}$ diameter with a length of $8 \mathrm{~cm}$ capturing the cranial base/glenoid fossa and posterior mandible

5. Scan may contain artifacts depending on patient movement and machine calibration

6. Accuracy is limited to the operator's ability to manipulate the CBCT image

7. The participants of this study are limited to WVU Department of Orthodontics residents and faculty

8. The CBCT images utilized in this study are limited to patients in the practice of Dr. Loring Ross (Myrtle Beach, SC)

9. The appliance utilized in Class II correction for subjects in this study is the banded Herbst design.

\section{Delimitations}

1. The sample subjects were treated consecutively by one clinician

2. Criteria of sample selection included patients with no previous orthodontic treatment and an overjet greater than $5 \mathrm{~mm}$.

3. All patients in the sample were treated with the banded Herbst appliance to a position in which the maxillary cuspid was in an end-to-end relationship with the mandibular first premolar. This position was achieved in increments and the final increment held for 3 months. 


\section{CHAPTER 2: REVIEW OF LITERATURE}

\section{History of Classification of Malocclusion}

Throughout the last 1000 years of recorded history, crowded or otherwise malaligned teeth have been a problem for humankind. ${ }^{7}$ In 1850, Norman Kingsley was likely among the first to use force application to correct mal-aligned teeth. ${ }^{8}$ It wasn't until Edward Angle developed the first classification of malocclusion in his published work, Treatment of malocclusion of teeth and fractures of the maxillae in the 1890 's. ${ }^{9} \mathrm{He}$ described three malocclusions:

- Class I

- The mesiobuccal cusp of the maxillary first molar occludes with the buccal groove of the mandibular first molar, with there being a discrepancy in the line of occlusion.

- Class II

- The mesiobuccal cusp of the maxillary first molar is located mesial to the buccal groove of the mandibular first molar.

- Class III

- The mesiobuccal cusp of the maxillary first molar is located distal to the buccal groove of the mandibular first molar.

\section{Etiology of Malocclusion and the Need for Orthodontic Therapy}

In most cases, malocclusion and dentofacial deformity is the result of distortions in the normal growing process. The primary etiologic factors associated with orthodontic problems have been cited as hereditary influences, environmental influences, and specific 
causes such as embryologic developmental and skeletal growth disturbances, muscle dysfunction, acromegaly and hemimandibular hypertrophy. Without proper orthodontic treatment, these dentofacial irregularities can lead to difficulty for the individuals involved including: psychosocial problems associated with discrimination because of facial appearance; problems with the stomatognathic system including decreased jaw function, temporomandibular joint dysfunction, and speech difficulty; and increased risk of periodontal disease, tooth decay, and trauma. ${ }^{10}$ The need for orthodontic therapy continues to grow and it has assumed an important role in improving self-esteem and overall quality of life in our society.

\section{Prevalence of Class II Malocclusion}

Class II malocclusions affect nearly $30 \%$ to $40 \%$ of people of Northern European descent than other ethnic populations. ${ }^{11-13}$

\section{Class II Skeletal Growth}

Genetics, function, deformities, size, and position of bones of the craniofacial complex are all factors that can lead to Class II skeletal growth. ${ }^{14}$ Ultimately, Class II malocclusions are the result of either deficient mandibular growth, excessive maxillary growth, or a combination of the two. In people of Northern European descent, Class II patients usually present with a convex facial profile due to a retrognathic mandible. A prognathic maxilla can be present, but this is less common. 
Enlow divided the facial bones that contribute to a Class II skeletal pattern into segments ${ }^{14}$ including:

- the anterior and posterior cranial base

- nasomaxillary complex

- the ramus and corpus of the mandible

The orientation of these segments to one another and their interactions during the growth process determine the final dentofacial form of an individual.

The primary growth of the cranial base occurs as a result of bone deposition on its outer cortex and endochondral growth at the spheno-occipital synchondrosis. A pressure adaptive growth mechanism provides a bi-directional growth direction causing displacement of facial bones. ${ }^{14}$

The growth of the nasomaxillary complex is the result of two mechanisms. Passive displacement, resulting from growth in the cranial base pushing the maxilla downward and forward, is an important growth mechanism during the primary dentition years, but becomes less important as the growth in the synchondrosis slows around seven years of age. Active growth of the maxillary sutures and nose is responsible for the majority of forward movement of the maxilla from ages seven to fifteen. ${ }^{10}$ The normal growth of the maxilla is usually 1 to $2 \mathrm{~mm}$ a year, ${ }^{10,15}$ and there is a direct relationship between the effective maxillary length and mandibular length. Cephalometric analysis showed that the position of the maxilla was normal in the majority of Class II situations. In cases that were not normal, the maxilla tended to be in a retrusive position more frequently than in a protrusive position indicating that the maxilla was not the major contributing factor to a Class II malocclusion. ${ }^{16}$ 
Growth in the mandible is important in the establishment of a Class II malocclusion. Deposition and resorption of bone are responsible for directing growth in a posterior and superior direction. As the condyle grows directly towards its articular contact within the glenoid fossa, the entire mandible is displaced in the opposite direction to a more forward and downward position. ${ }^{17}$ The growth of the mandible occurs at a relatively stable rate before puberty with an average ramus height increase of 1 to $2 \mathrm{~mm}$

per year and an average body length increase of 2 to $3 \mathrm{~mm}$ per year. ${ }^{10}$ Growth changes in the region of the glenoid fossa have a significant effect of the prominence of the chin. Any mandibular length increase to improve the prominence of the chin is usually minimized by a posterior shift in the TMJ. To effectively increase the prominence of the chin, the TMJ must shift to the anterior or remain in the same anterior-posterior position with an increase in mandibular length. These properties of mandibular growth allow the clinician to alter growth patterns to provide therapy for Class II malocclusions with a retrognathic mandible.

\section{Treatment of Class II Malocclusion}

The amount of growth remaining for an individual is an important consideration for the treatment of a Class II malocclusion. The treatment options for a non-growing Class II patient are somewhat limited. Growth modification is not a treatment option; clinicians have to rely on tooth movement to compensate for the skeletal disharmony. Camouflage treatment including extractions, distal movement of maxillary teeth, and surgery are used. Often in cases where extraction and surgical treatment are not feasable, a non-extraction approach is implemented in which the an excess overjet is left after teeth in each arch are straightened. In cases with moderate to severe crowding, extractions are 
often indicated in patients with Class II malocclusions in order to provide space to align crowded incisors while avoiding excessive protrusion. Extractions are also recommended to camouflage a moderate skeletal discrepancy when modification by growth is not possible. In minor Class II malocclusions, the option of distalizing the maxillary molars exists. A maximum of 1-2 mm of distal movement is all that can be expected when using this approach. ${ }^{18}$ In recent years, the Herbst appliance has been shown to be an effective treatment option for Class II malocclusions in non-growing adults. ${ }^{19}$ Adults have been shown to exhibit the same condylar growth and remodeling of the glenoid fossa that occurs in children and adolescents. ${ }^{20}$ Orthognathic surgery is by far the most invasive and expensive treatment for non-growing patients with Class II malocclusion. The surgical movement of the maxilla, mandible, or both allows the upper and lower arches to be aligned into maximum intercuspation. This treatment option is often the most effective in obtaining an ideal occlusion.

More options for the treatment of Class II malocclusion are available when the patient is still growing. Treatment is often administered around an individual's peak pubertal growth period which occurs around age $13.9 \pm 1.0$ in males and age $11.7 \pm 1.0$ in females. $^{21}$ Non-extraction, extractions, and functional appliances are among the treatment options for these individuals.

Although more options exist for the orthodontist when treating growing individuals, ideal occlusion cannot always be achieved. Many parents dislike the alternatives of surgery or extraction for their children, and choose only to have the teeth aligned. In these cases, the patient will almost certainly still have an overjet due to size discrepancies between the maxilla and mandible. In growing patients, extraction is an 
option only when space is needed due to severe crowding of the anterior teeth.

Extractions with the intent of camouflaging skeletal disharmony are contraindicated in growing patients because of the unpredictable growth of the maxilla and mandible.

When teeth are aligned and an acceptable result in unachievable, the skeletal discrepancies must be corrected. Surgery is an option, however most patients prefer an alternative method that is non-invasive and less expensive. Because of these concerns, functional appliances were introduced to correct problems of skeletal disharmony without surgery in patients with a retrognathic mandible.

\section{Functional Appliances Used to Treat Class II Malocclusion}

In 1877, Norman W. Kingsley was the first to introduce an appliance designed to stimulate sagittal mandibular growth. ${ }^{22}$ The bite jumping appliance consisted of an upper plate with an inclined plane which caught the lower incisors and forced the mandible anteriorly. The rationale behind "bite jumping" was that forcing the mandible forward during function would stimulate condylar growth, thereby correcting the Class II malocclusion. Carl Breitner, with his experiments on rhesus monkeys, was the first to show that bite jumping led to condylar growth by means of

1. Bone apposition at the distal wall of the articular fossa and resorption at the mesial wall

2. Apposition of cartilage at the posterior margin of the condylar head and resorption at the anterior margin ${ }^{23}$

The principle of bite jumping encouraged the development of several removable functional appliances that are used today for stimulating mandibular growth in Class II patients with a deficient mandible. The activator ${ }^{24}$ was designed as a block of plastic that 
covered the teeth of both arches and the palate and was made to fit loose to allow advancement of the mandible several millimeters and open the bite 3-4 mm. The Bionator $^{25}$ is described as a cut-down activator with palatal coverage eliminated. The Frankel appliance ${ }^{26}$ is a tissue-borne functional appliance that consists of a small pad against the lingual mucosa beneath the lower incisors to stimulate mandibular repositioning. The Herbst appliance ${ }^{27}$ is a fixed functional appliance that forces the mandible forward by means of a pin and tube apparatus that runs between the arches.

The effect of the functional appliances have been debated with some studies showing alteration of mandibular growth ${ }^{28-30}$ and other studies showing no effect. ${ }^{31,32}$ Evaluating the treatment results of removable functional appliances can be difficult because

1. The appliance is used only part of the day and in certain individuals the threshold for condylar growth adaptation to forward displacement may never be reached

2. Patient compliance is a problem and undetected insufficient appliance wear could produce erratic results

3. Treatment time is on the order of two to four years which is relatively long and thus a suitable control group is often unattainable.

The fixed Herbst appliance offers several advantages in that it works continuously, patient cooperation is not a factor, and active treatment time is relatively short (on the order of six to nine months). ${ }^{27}$ A review of the literature by Aelbers and Dermaut found that the Herbst appliance was the only functional appliance that could effectively alter mandibular growth to a clinically significant extent. ${ }^{32}$ A randomized, controlled trial by O'Brien et al. ${ }^{33}$ concluded that the Herbst appliance had several advantages over 
functional appliances such as the twin block including better patient cooperation and decreased phase I treatment times.

\section{The Herbst Appliance}

The Herbst appliance comes in multiple variations: banded, ${ }^{34-36}$ cast splints, ${ }^{4,27}$ acrylic splints, ${ }^{37}$ or stainless steel crowns. ${ }^{38-40}$ Emil Herbst introduced a fixed bite jumping appliance called the "Scharnier" at the International Dental Congress in Berlin in 1909. The appliance was designed to alter mandibular jaw and muscle function by keeping the mandible in a continuously protruded position on both jaw closure and eccentric movements. ${ }^{41}$ Its design included a bilateral telescope mechanism attached by orthodontic bands to the lower first premolars and upper first molars. In 1934, Herbst published a series of articles in which he described the appliance to be most useful in:

1. Class II malocclusions with a retrognathic mandible

2. Mandibular ramus fractures

3. Condylectomies (used as an artificial joint)

4. TMJ problems including crepitus and bruxism ${ }^{42}$

After 1934, however, little was published about the Herbst appliance and the treatment method was more or less forgotten.

Hans Pancherz reintroduced the Herbst appliance as an experimental tool in clinical research in 1977 , and in 1979 , he published a paper calling attention to the possibilities of stimulating mandibular growth with the appliance. ${ }^{36}$ The popularity of the appliance increased after this time and the effects of the Herbst appliance on the occlusion, dentofacial complex, and masticatory apparatus began to be evaluated. 
The Herbst appliance employs a bilateral telescope mechanism consisting of a tube, a plunger, two pivots, and two locking screws, which function to keep the mandible in a continuously anterior position. The pivot for the tube is usually located on the maxillary first molar and the pivot for the plunger is usually attached to the mandibular first premolar. The length of the tube determines the amount of anterior displacement of the mandible and usually achieves an incisal end-to-end relationship.

The anchorage system of the Herbst appliance has evolved since its reintroduction by Pancherz in 1979. Originally, a partial anchorage system was used in which the maxillary first premolars and first molars were banded and connected to the other side with a lingual or buccal sectional arch wire and the mandibular first premolars were banded and interconnected with a lingual sectional arch wire. Later, a total anchorage system was used in which a labial arch wire was ligated to brackets on the maxillary first premolars, canines, and incisors and a lingual sectional arch wire was extended to the first permanent molars which were also banded. Bands were eventually replaced by cobalt chromium alloy casted splints that were cemented with glass ionomer cement ensuring a precise fit on the teeth. In 1988, McNamara and Howe presented the removable acrylic splint Herbst appliance, with occlusal coverage extending posteriorly from the canines to the first molars on the maxillary arch and full occlusal coverage on the mandibular arch. ${ }^{37}$ The crowned Herbst appliance consisting of stainless steel crowns cemented to the mandibular first premolars and maxillary first molars was introduced in the late 1980's and early 1990's to compensate for the inadequacies of the banded Herbst appliance. ${ }^{39}$ The crowned appliance offers several advantages over conventional anchorage including having no removable parts, eliminating the need for patient 
cooperation, having a streamlined design which facilitates hygienic procedures, and the ease of recementation in the event of a loosened crown. ${ }^{39}$

\section{Patient Compliance and the Herbst Appliance}

The Herbst appliance, being a fixed functional appliance, virtually eliminates the compliance factor. Being a fixed appliance, the patient has no choice in removing the appliance as it is cemented with stainless steel bands or crowns. Even though the appliance is fixed, however, there still exists the possibility that the patient can damage the appliance and forcefully remove it. Non-compliance is a problem with considerable challenge in orthodontic patient management. ${ }^{43,44}$ Typically, interpersonal factors such as a warm relationship between clinician and patient and good communication has a positive influence on patient compliance. ${ }^{45-47}$

\section{Timing of Treatment with Functional Appliances}

The timing of orthopedic intervention with functional appliances has been the subject of intense controversy within the profession of orthodontics. The decision to treat in the early mixed, late mixed, or permanent dentition has been debated and many questions remain unresolved. Two phase treatment with functional appliances became justifiable with the emergence of the functional matrix theory proposed by Moss in the 1960s. ${ }^{48,49}$ A shift from Brodie's genomic hypothesis that suggested craniofacial growth was established by three months old and could not be altered; ${ }^{50}$ the functional matrix paradigm exposed the possibility of correcting skeletal problems in a growing child with dentofacial orthopedics. The decision of when to begin Class II orthopedic treatment is 
made more difficult by individual variability between patients and uncertainty about growth and treatment response.

Successful treatment of Class II malocclusions with functional appliances have been reported in both the early mixed dentition ${ }^{18,51}$ and the late mixed dentition. ${ }^{52,53} \mathrm{~A}$ systematic review of mandibular changes produced by functional appliances in Class II malocclusions reported that the amount of supplementary mandibular growth appears to be significantly larger if the functional treatment is performed at the pubertal peak in skeletal maturation. ${ }^{54}$ The majority of the literature supports the idea that Class II correction can be successfully achieved in both the mixed dentition and the permanent dentition. The current debate seems to revolve around the effectiveness and the efficiency of the Class II correction. With respect to both duration and outcome, Pancherz found that late treatment of Class II Division I malocclusion (in the permanent dentition) was more efficient than earlier treatment (in the early or late mixed dentition). ${ }^{55}$ In a review of the data from a randomized controlled clinical trial, Tulloch et al. concluded that for children with moderate to severe Class II problems, early treatment followed by later treatment does not produce major differences in jaw relationship or dental occlusion, compared with later one-stage treatment. ${ }^{56}$ According to the same study, early treatment appeared to be less efficient, in that it did not reduce the amount of time a child was in fixed appliances in a second phase of treatment, and it did not decrease the proportion of complex treatments in phase II involving extractions or orthognathic surgery. ${ }^{57}$ Other clinical studies have shown that early treatment can lead to more relapse, reduced patient motivation in the second phase of orthodontic treatment, and other potential hazards. ${ }^{58-62}$ 
Despite these arguments against early treatment, many practitioners have published their opinions based on clinical experience suggesting that early treatment has many advantages. The ability to utilize all potential growth, increased probability of incisor fracture in untreated Class II patients, the development of improper swallowing patterns, incomplete lip function, temporomandibular joint dysfunction, and psychosocial considerations are all factors that support the concept of early treatment. Psychological studies have shown that younger children are good candidates for phase I orthodontics and expect orthodontics to lead to improvements in their lives. ${ }^{63}$ Another study showed that early treatment with Twin-block appliances resulted in an increase in self-concept and a reduction of negative social experiences. ${ }^{64}$ Surveys have shown that practice characteristics tend to affect orthodontists' decisions regarding orthodontic treatment and a wide range of acceptable treatment timing exists. Ultimately, the decision to initiate early phase orthodontics or orthopedic treatment should include a conversation with the parents and the child and the individual circumstances for each patient should be considered.

\section{Skeletal Treatment Effects of the Herbst Appliance}

The treatment effects of the Herbst appliance on the dentofacial complex are difficult to describe. The Herbst appliance directly or indirectly applies force in all three planes of space to the maxilla, the mandible, the maxillary and mandibular dental units, and the temporomandibular region. Evaluating the changes in the individual anatomic components and understanding the interaction between them becomes very complicated. In addition, treatment is usually performed on growing patients with variable growth patterns and rates. Although the Herbst appliance is considered a functional orthopedic 
appliance, the effects of treatment are not limited to the skeletal components. Anchorage on the dental units produces both desirable and undesirable side effects on the dentition. Changes in the angular position of the palatal plane, occlusal plane, and mandibular plane are important and should be considered. The temporomandibular joint, a ginglymodiarthrodial joint that allows both hinging and translational movement, is directly affected by treatment with the Herbst appliance and changes within the joint are very difficult to identify and quantify.

Many animal studies have shown that skeletal mandibular changes can be produced with functional appliances, ${ }^{65-67}$ however the effects on humans are more controversial. A systematic review of the literature limited to randomized controlled clinical trials from 1966 to 1999 on the efficiency of functional appliances on mandibular growth by Chen et al. ${ }^{68}$ reported that there is no difference in overall mandibular change in the horizontal or vertical direction. Another systematic review by Cozza et al. ${ }^{54}$ analyzed 22 studies that met inclusion criteria in an attempt to assess the scientific evidence of functional appliances in enhancing mandibular growth in Class II subjects. Two-thirds of the samples in the 22 studies reported a clinically significant supplementary elongation in total mandibular length compared to controls (a change of greater than $2 \mathrm{~mm}$ in the treated groups compared to the control groups) as a result of treatment with functional appliances. However, none of the four randomized clinical trials included in the study reported a clinically significant change in mandibular length with treatment. The results were attributed to treatment timing due to the fact that three of the four randomized clinical trials described outcomes of treatment at a pre-pubertal stage of skeletal maturity. 
Pancherz ${ }^{69,70}$ has reported that sagittal condylar growth is increased while vertical condylar growth is unaffected by Herbst treatment. Ruf and Pancherz ${ }^{20}$ analyzed temporomandibular joint remodeling with magnetic resonance imaging during Herbst treatment and reported signs of condylar remodeling at the posterior-superior border. Voudouris et al. ${ }^{71}$ performed radiographic investigations superimposing on metallic implants in nonhuman primates and showed increases in condylar length in response to treatment with functional appliances. In the same study, histological analysis using undecalcified sections and tetracycline vital staining with fluorescence microscopy also confirmed the increased condylar response. Another implant study by Araujo et al. ${ }^{72}$ on twenty five patients treated with the bionator appliance showed significant changes in the direction (more posterior) but not in overall amount of condylar growth. Despite these findings, a systematic review of the literature by Popowich et al. ${ }^{5}$ evaluating the effects of Herbst treatment on temporomandibular joint morphology did not provide conclusive evidence of osseous remodeling or condyle position change.

The response of the temporomandibular joint to mandibular forward repositioning has been very controversial in both experimental and clinical studies. Some researchers believe that the main effect of functional appliance therapy is increased condylar growth; others feel that the main effect is due to remodeling of the glenoid fossa, and others contend that little to no structural changes occur in response to treatment. Remodeling of the temporomandibular joint has been described to occur both within the glenoid fossa and the condyles of the mandible, with new bone formation on the posterior aspect of the condylar head and the roof of the fossa. ${ }^{20,73,74}$ Ruf and Pancherz ${ }^{20}$ have noted glenoid fossa remodeling six to twelve weeks after the initiation of Herbst treatment. In a study 
on rats, Rabie et al. ${ }^{75-77}$ reported that a forward positioning of the mandible leads to increased new bone formation in the glenoid fossa of the temporal bone with the highest levels of bone deposition occurring in the posterior region of the glenoid fossa. From a study on nonhuman primates treated with the Herbst appliance, Voudouris et al. ${ }^{71}$ reported that the growth modification measured in the glenoid fossa was in an inferior and anterior direction. In addition, he noted that restriction of the downward and backward growth of the fossa observed in the control subjects might additionally contribute to the Class II correction.

\section{Dental Radiographs}

Radiographs are necessary when diagnosing an orthodontic patient. Most commonly found in orthodontic practices are panoramic, cephalometric, and transcranial radiographs which provide a magnified, two-dimensional, projected view of a threedimensional structure subject to distortion. When analyzing the temporomandibular joint (TMJ), these traditional radiographs may be utilized as well as more specialized types of radiographs. More specialized radiographs include magnetic resonance imaging (MRI) and computed tomography (CT) which can be quite expensive for the patient. Specialized radiographs suitable for the dental practice include linear tomography optimized for the TMJ and cone beam computed tomography (CBCT). ${ }^{78}$

\section{Traditional Headfilms}

Panoramic, transcranial projections, and tomography are most commonly used in an orthodontic practice because of its availability, relatively low cost, and radiation dosage. Panoramic radiographs are principally used by many investigators to assess 
changes in the condyles from functional appliances ${ }^{3}$ and other orthodontic treatments. ${ }^{79,80}$ However, with more accurate radiographic tools available to the clinician, ${ }^{78}$ the complex anatomical structure of the TMJ can be better suited for study with one of these modern methods of tomography.

Most modern pan/ceph x-ray machines allow the capability of exposing tomographic radiographs (also called "body section radiography"). When a radiograph is taken at a particular plane in space, objects distal and proximal to the plane from the xray source are blurred as the x-ray source moves around the region of interest. These radiographs have been superseded in diagnostic equality by conventional CT and cone beam CT radiographs, but are still useful in areas of high-contrast anatomy such as the temporomandibular joint and the dental arches. ${ }^{81}$ The further the structure lies from the focal plane, the greater the blurring. Therefore, structures that are closer to the focal plane and have similar density as the region of interest can create interferences or artifacts on the tomogram. Image quality can be enhanced with the type of motion of the x-ray source (e.g. linear, circular, spiral, etc...) to attain the visibility of structures within the focal plane and to blur the structures outside of the focal plane (Figure 2 and Figure 3). 


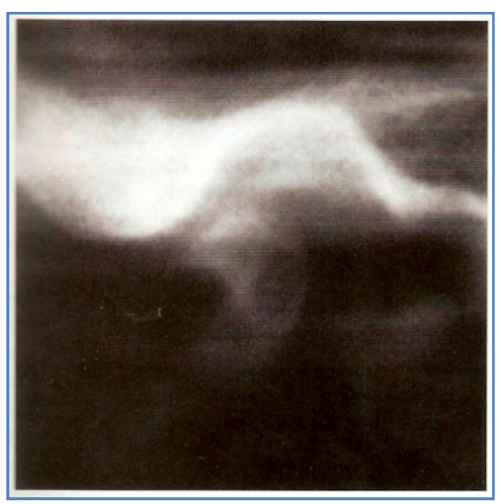

Figure 2. Example of linear tomography of the $\mathbf{T M J} \mathbf{J}^{81}$

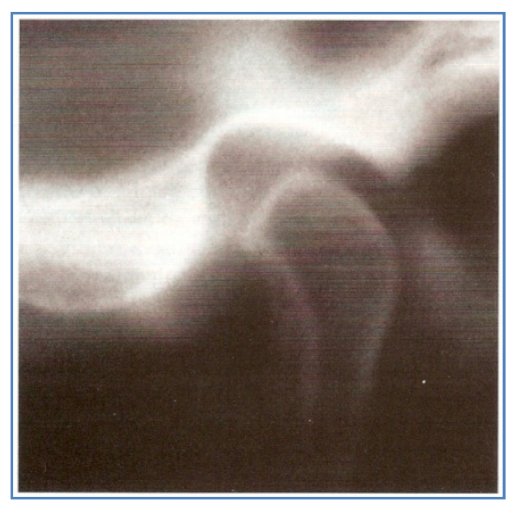

Figure 3. Example of spiral tomography of the $\mathbf{T M J} \mathbf{J}^{81}$

\section{Conventional Computerized Tomography}

Computerized tomography began as "computerized axial transverse scanning" by Godfrey Hounsfield in 1972. Hounsfield produced an axial cross-section of an image of the head using a narrow, moving x-ray beam. The signal was then fed into a computer and analyzed using a mathematical algorithm. The data was then reconstructed into a tomographic image. This revolutionary radiographic system claimed to be 100 times more sensitive than conventional $\mathrm{x}$-ray systems and had demonstrated diagnostic quality that had never been seen before in radiology. ${ }^{81}$ (Figure 4)

The CT scanner consists of an x-ray tube that emits a finely collimated, fanshaped beam. Some x-ray units, called incremental scanners, have x-ray tubes and detectors that move in a circle simultaneously around the subject. These produce many contiguous or overlapping images. Modern CT scanners collect data in a spiral or helical pattern from a gantry while the patient is positioned on a flat table and moves continuously through the gantry. 


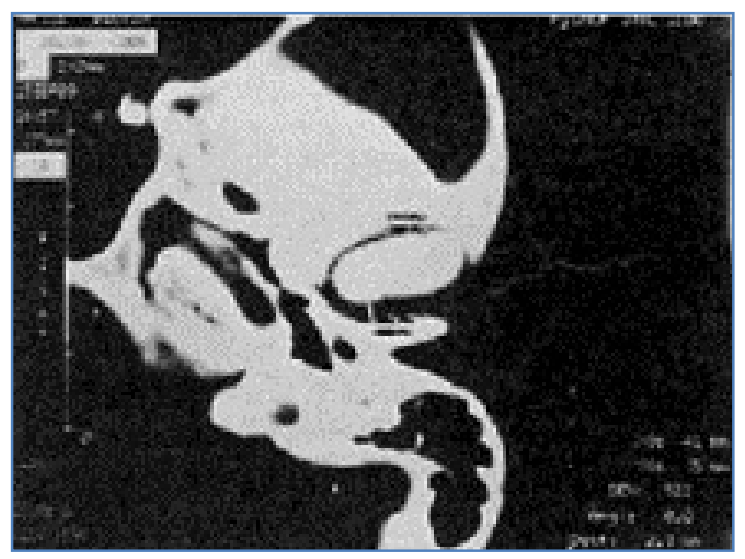

Figure 4. Example of horizontal cross-section of right TMJ in a CT image. ${ }^{82}$

\section{Cone Beam Computed Tomography}

Cone beam computed tomography utilizes a flat panel detector instead of an image intensifier (intensifiers have been traditionally used to produce "live" radiographic images for analog or digital capture). ${ }^{83,84} \mathrm{CBCT}$ scanners have been available for craniofacial imaging since 1999 in Europe and since 2001 in the United States. The scanner utilizes a round or rectangular cone-shaped x-ray beam that pulses on and off as the scan is executed in 360 degrees around the subject's head. Scan times range from 17 seconds to more than a minute depending on the size and resolution of the volume. The pulsing action reduces radiation exposure to the patient and shortens scan time. The cone beam scan produces raw data that requires the use of software on board a rendering computer in order to reconstruct volumetric data. This is in contrast to a conventional CT scanner that provides a set of consecutive slices of the imaged area. ${ }^{85}$ This reconstruction allows any three dimensional or two dimensional view in any selected plane of space. The visual resolution of a CBCT image varies but can be four times than that of a CT. ${ }^{81}$ 
CBCT equipment is typically less expensive than a traditional CT machine and is also less maintenance intensive.

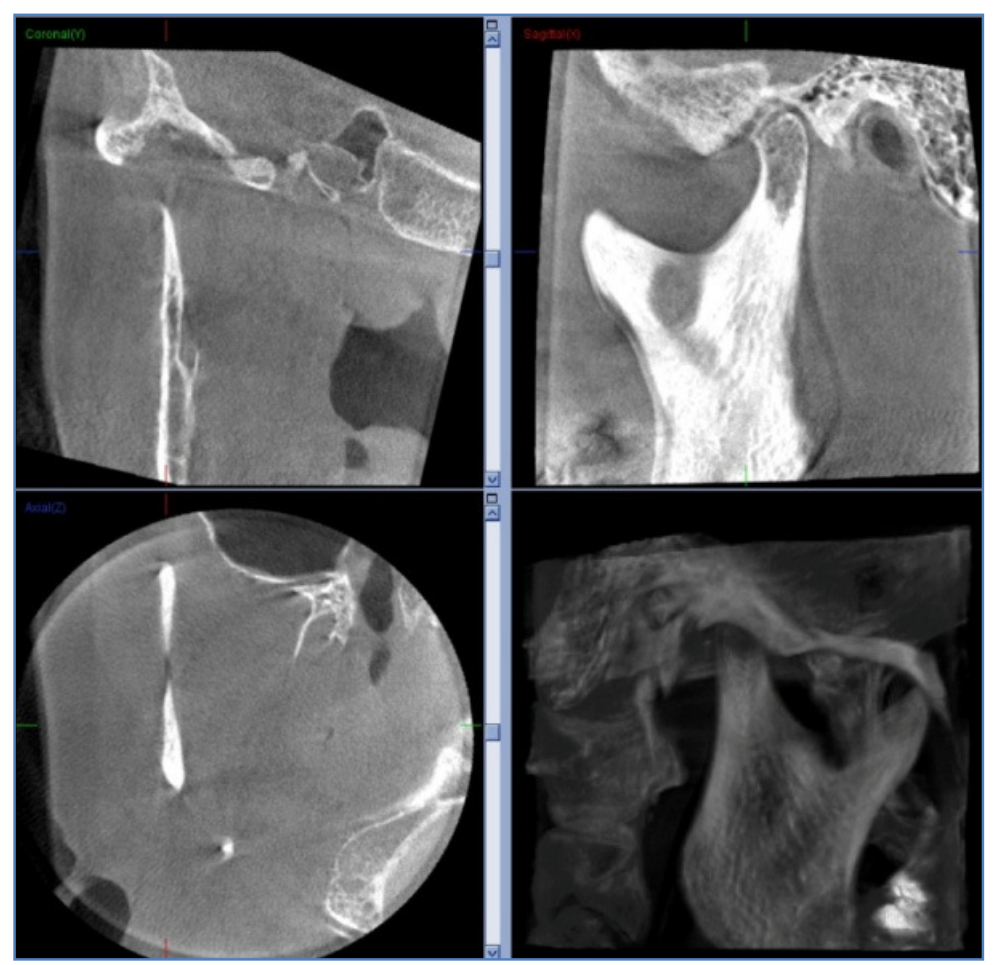

Figure 5. Example of a cone beam computerized tomography radiograph of a TMJ (Planmeca Promax 3D, Romexis ${ }^{\mathrm{TM}}$ software)

\section{CBCT Image Accuracy}

In a study conducted by Honey, et al. ${ }^{78}$ five types of radiographs were taken of 37 dry skull TMJ articulations and were reviewed by independent observers. The five categories of radiographs are as follows:

1. Corrected angle linear tomography

2. Standard panoramic radiograph

3. TMJ-specific panoramic radiograph

4. Cone beam computed tomography (static image)

5. Cone beam computed tomography (interactive image) 
The findings indicate that CBCT images provide more accuracy and reliability than the other types of radiographs studied. The interactive CBCT images were statistically more accurate and reliable than the static CBCT images. And both CBCT image types were more reliable than the panoramic radiographs and tomograms. ${ }^{78}$

In 2007, Moshiri et al. ${ }^{86}$ studied the accuracy of linear measurements from both CBCT images and traditional cephalometric headfilms. The study found that lateral cephalometric images constructed as slices from three-dimensional CBCT volumetric data were more accurate than traditional lateral cephalometric headfilms. ${ }^{86}$

Final images from a CBCT volume may be printed on a 1:1 scale with a margin of error in geometric accuracy reported to be $2 \%$ or less. ${ }^{81}$

\section{Radiation Safety}

With recent medical awareness of the general public, concern rises in the area of radiation safety with regards to radiographic imaging. The amount of radiation one receives from an $\mathrm{x}$-ray source depends on the field of view, the current multiplied by the scan time (mA), and the voltage $(\mathrm{kVp})$ chosen. A 2004 study by Rustemeyer et al. ${ }^{87}$ compared radiation dose between a low-dose dental CT protocol, a standard CT protocol, and CBCT. Standard dental CT protocols have an effective dose of approximately 3.4 $\mathrm{mSv}$ and a low-dose protocol can be up to nine times less radiation (approximately 0.37 $\mathrm{mSv}$ ). CBCT effective dose is approximately 0.11 to $0.5 \mathrm{mSv}$. However, some low-dose dental CT protocols might be superior to CBCT because the conventional CT can be used to evaluate soft tissue instead of high contrast, bony structures. ${ }^{88}$ A 2006 review article by Scarfe, et al. ${ }^{89}$ summarized that the radiation dose from CBCT scanners have been reported to be 15 times lower than those of conventional CT scanners (a range from 0.04 
to $0.05 \mathrm{mSv}$ ) which is a reduction of up to $98 \%$ compared with conventional dental CT scans (1.3 to $3.3 \mathrm{mSv}$ for imaging the mandible and 1.0 to $1.4 \mathrm{mSv}$ for imaging the maxilla). Ultimately, the CBCT image volume requires much less radiation than that of a conventional dental CT scan but more radiation than that of a typical panoramic or cephalometric radiograph. The low radiation requirements are attributed to the digital mechanism of image acquisition as well as pulse behavior of the $\mathrm{x}$-ray beam in acquiring a cone beam image. ${ }^{88}$ For reference, a full-mouth series (approximately 19 films) requires an estimated $0.15 \mathrm{mSv}$ dose of radiation. Digital panoramic and cephalometric headfilms require even less radiation (usually $70-80 \%$ or more) ${ }^{90}$ at $0.016 \mathrm{mSv}$.

CBCT radiation dosages are not an industry standard depending on several variables including the manufacturer of the x-ray machine, the scan volume size, and the scan resolution. Higher resolution scans require more radiation and/or longer scanning times as does a larger volume size. Current published radiation dosages will continue to vary as manufacturers make strides in the continued development and refinement of CBCT imaging.

\begin{tabular}{|l|l|}
\hline Source Type & Estimated Radiation Dosage (mSv) \\
\hline Traditional panoramic headfilm & 0.016 \\
\hline Full mouth series (19 films) & 0.150 \\
\hline Low-dose Dental CT & 0.370 (reported as low as 0.040 in one study) \\
\hline Traditional Dental CT & 1.300 to 3.400 \\
\hline Cone beam CT & 0.110 to 0.500 \\
\hline $\begin{array}{l}\text { Average radiation in the United States } \\
\text { from Natural sources (per year) }\end{array}$ & 3.000 \\
\hline \multicolumn{2}{|c|}{ Table 1. Summary of radiograph exposure comparison (mSv) } \\
\hline
\end{tabular}




\section{Temporomandibular Joint Analysis}

With Class II treatment, clinicians are interested in how much of the anteriorposterior bite correction is due to skeletal change. Since the advent of modern cephalometrics using headfilms and radiology, there are many methods that can be used to study joint morphology before after treatment that involves the TMJ. In the 1950's, Robert Ricketts popularized cephalometric laminagraphy ${ }^{92}$ as a technique to capture clear TMJ anatomy for analysis on a cephalometric headfilm. While laminagraphy employs certain tomographic principles that modern x-ray machines can accomplish, it only shows one sagittal slice. Tomograms carry us further than a traditional headfilm, but still stop short of attaining the goal of visualizing the temporomandibular joint in three dimensions. Before three-dimensional radiology became available, all measurements had to be done on traditional headfilms in various orientations of the subject and the x-ray source (e.g. open or closed lateral oblique view, Towne's AP axial view, etc.). This introduced the major, inherent limitation that a three dimensional structure is being compressed into a two dimensional film. The film itself becomes a singular plane of space with questions regarding the orientation, magnification, and distortion present in the projection of the subject onto the film.

As three dimensional radiography became available, the potential amount of information that could be derived from a 3D view was realized. Many researchers have contributed to the development of methods to evaluate the TMJ in three dimensions. Seren, et al., used conventional CT scans to evaluate differences in TMJ morphology in

Class III patients ${ }^{82}$ however joint changes or superimposing was not investigated. Arat, et al., studied TMJ morphology using MRI scans of Class II division 1 patients before 
and after activator therapy. The study identified changes in the joint space from a sagittal slice through the TMJ, but specific morphological changes in the condyle or fossa were not investigated. In particular, the study was not three-dimensional. As Popwich, et al. concluded, if a three-dimensional TMJ analysis exists, rarely is any data published on method error and operator reliability for analysis done in three dimensions. Furthermore, most published TMJ studies only investigate the condyle or the disc, but not the glenoid fossa. ${ }^{5}$ With the exception of MRI, all other forms of precise, high-resolution threedimensional imaging comes in the form of ionizing radiation. This presents ethical issues of irradiating patients who are untreated to establish a baseline or control group. Since there are no three-dimensional norms, it is difficult to attribute morphological changes to treatment or natural growth. 


\section{CHAPTER 3: MATERIALS AND METHODS}

\section{Imaging Protocol}

The imaging protocol involved $0.16 \mathrm{~mm}$ resolution cone beam volume with an $8 \mathrm{~cm}$ by $8 \mathrm{~cm}$ cylindrical field of view (Figure 6) taken by a Planmeca Promax 3D scanner (PLANMECA USA). Radiographs of twenty patients (11 male, 9 female) treated with the banded Herbst appliance were selected from the private practice of Dr. Loring L. Ross (Myrtle Beach, SC). Each of these patients underwent Class II correction with the Herbst appliance and had cone beam radiographs taken pre-treatment and immediately after Herbst appliance removal. Cone beam volumes were separated into right and left joints ( $\mathrm{R}$ and $\mathrm{L}$ ) and two time points (T0 and $\mathrm{T} 1)$. $\mathrm{T} 0$ indicated a pre-treatment radiograph and T1 indicated a radiograph taken immediately after Herbst removal. Exclusion criteria removed radiographs that were not of sufficient quality, radiographs that had subsequent missing joint scans, and radiographs that did not capture adequate anatomical structures of the TMJ and posterior mandible. Cone beam radiographs used in this study and the experimental design were reviewed and exempted by the Institutional Review Board of West Virginia University (Appendix A) and were then analyzed using the Anatomage InVivoDental ${ }^{\mathrm{TM}}$ software version 4.1. 


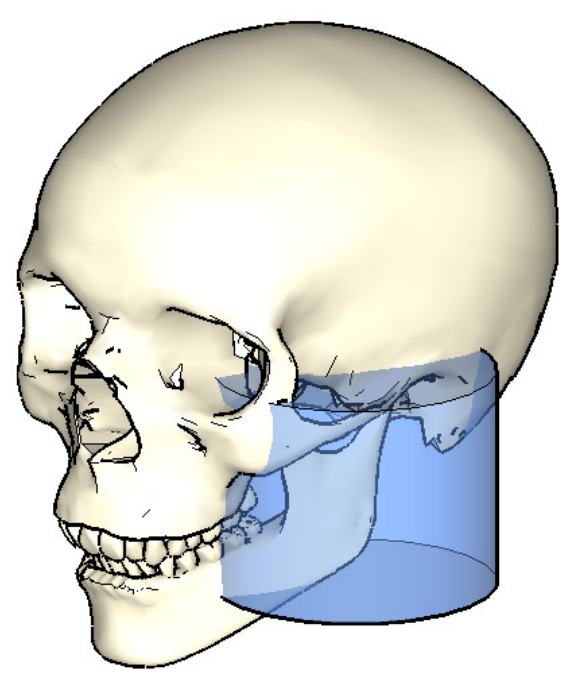

Figure 6. Illustration of the radiograph field of view used in this study (blue cylinder volume)

\section{Principles of Analysis}

The condyle is measured in the coronal and sagittal planes while the glenoid fossa is measured in the sagittal plane. Within each plane, two dimensions can be measured as a vector (magnitude and direction) of change. To simplify the measurements, all angular measurements are taken from a line parallel to the vertical axis of the field of view (FOV) after standardizing the orientation of the scan. A single operator (an orthodontic resident) was trained for measuring changes in dimensions on cone beam scans not used in this study. The operators were then randomly assigned a set of 10 cone beam volumes (right TMJ scans) to analyze twice. Results will be statistically analyzed to compare intraoperator reliability.

\section{Image Orientation of the Mandibular Condyle}

To prepare for superimposition of the mandibular condyle, a specific and repeatable volume orientation will be used for standardization of the T0 image (Figure 7). 
Note that this is not necessary in the $\mathrm{T} 1$ image because the $\mathrm{T} 1$ image will adopt the orientation of the $\mathrm{T} 0$ image automatically during image the superimposition procedure. The $\mathrm{T} 0$ radiographs were standardized by orienting the coronal plane tangent to the posterior surface of the condyle and gonial angle. The sagittal plane was oriented to the long axis of the condyle. Finally, the axial plane was aligned to be perpendicular with the coronal and sagittal planes.

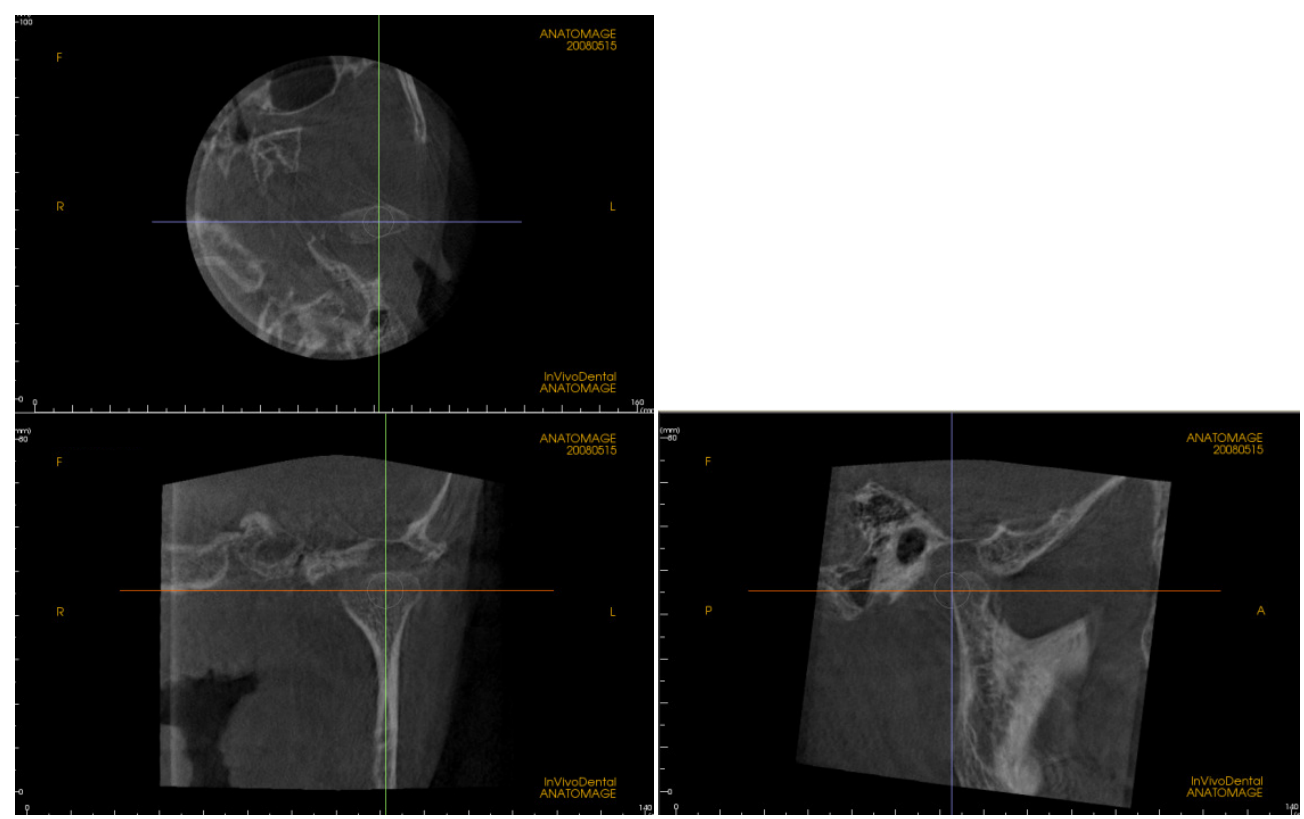

Figure 7. Standardizing the orientation of the T0 image for superimposition of the mandibular condyle.

The $\mathrm{T} 0$ and $\mathrm{T} 1$ images for the subject will be superimposed three-dimensionally using the superimposition tool in InVivoDental ${ }^{\mathrm{TM}}$ 4.1. The software allows automatic registration of superimpositions by marking anatomical landmarks that are similar in both scans. Depending on the availability of anatomical landmarks in the field of view and the presence of artifacts within the scan (Figure 8), fine tuning of the superimposition must be performed by the investigator to ensure proper superimposition and precise measurement. 


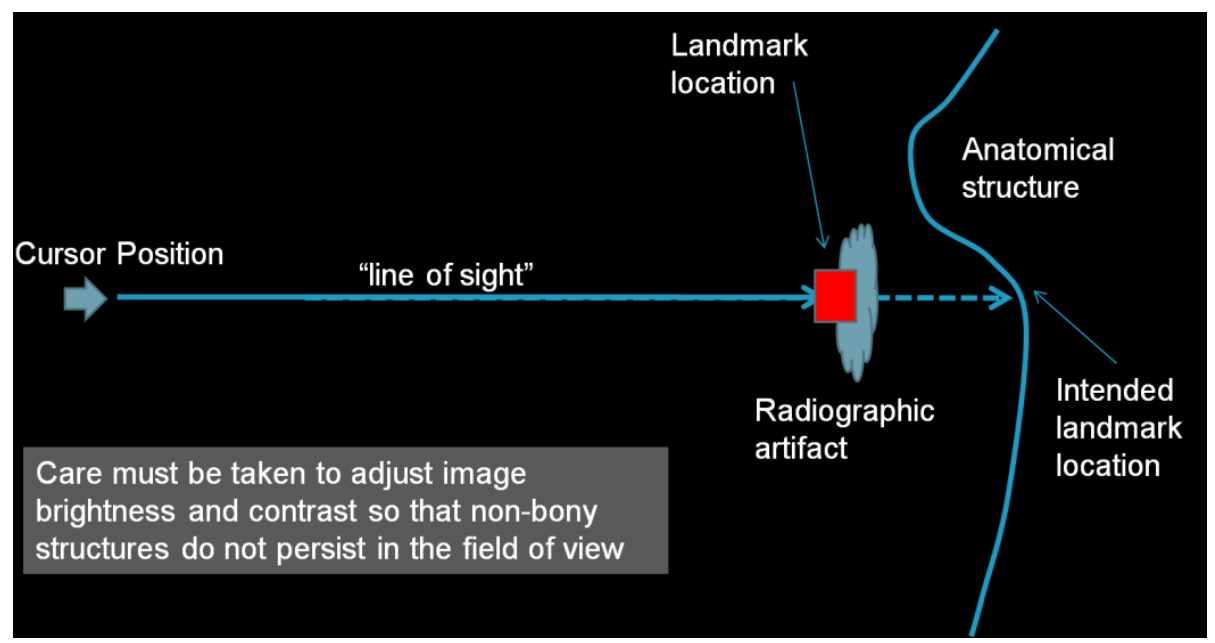

Figure 8. Auto-registration interference from radiographic artifact

\section{Superimposing the Mandibular Condyle}

The condyle, sigmoid notch, coronoid process, ramus, and gonial angle are used to auto-register the superimpositions. Auto-registration (Figure 9) is limited in its accuracy depending on the quality of the image, thickness of cortical bone, and accuracy of the operator to select similar anatomical locations. Therefore, further manipulation of the image is required to accurately superimpose the two scans. This is accomplished by many tools provided by InVivoDental ${ }^{\mathrm{TM}}$. Linear and rotational movements in each plane (coronal, sagittal, and axial) can be used to fine tune the position of the T1 scan over the T0 scan. A sliding switch allows the computer to alter opacity of the T1 scan so that either scan is showing or a blend of the two to allow the operator to visually verify that the superimposition has been done correctly. Visual verification (Figure 10) can be accomplished by inspecting the inferior third molar crypt and inferior alveolar canal ${ }^{93}$ are overlaid perfectly (Figure 11). 


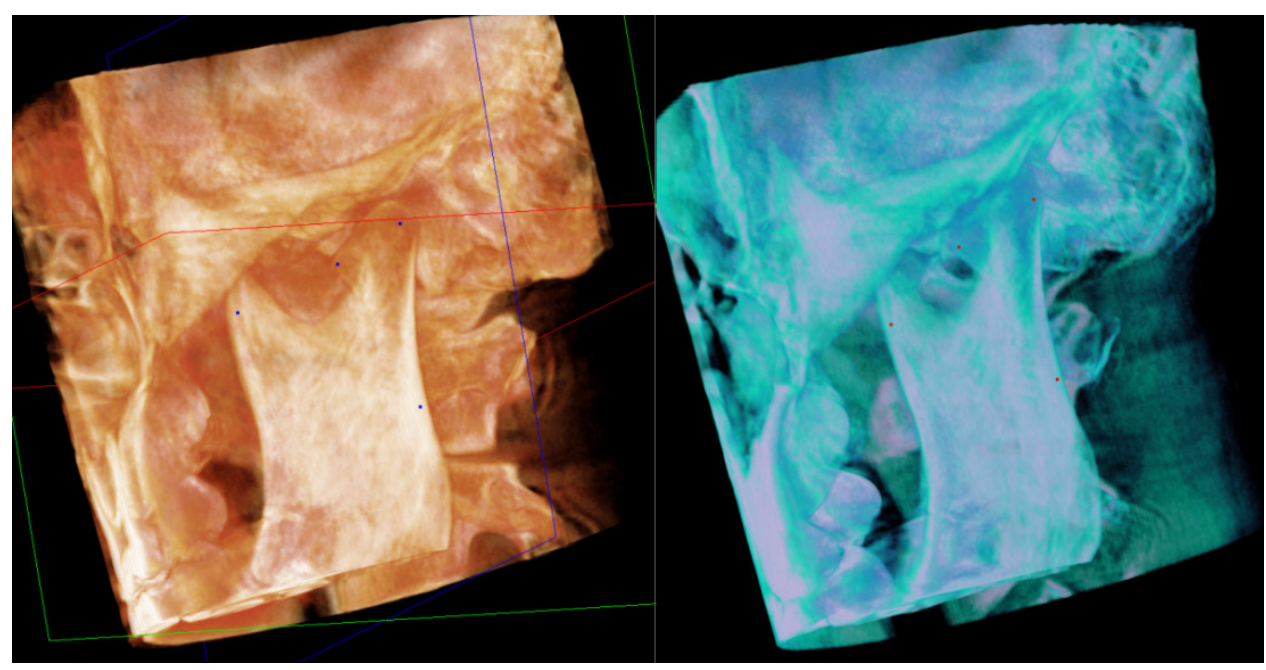

Figure 9. Auto-registration for superimposing the mandibular condyle

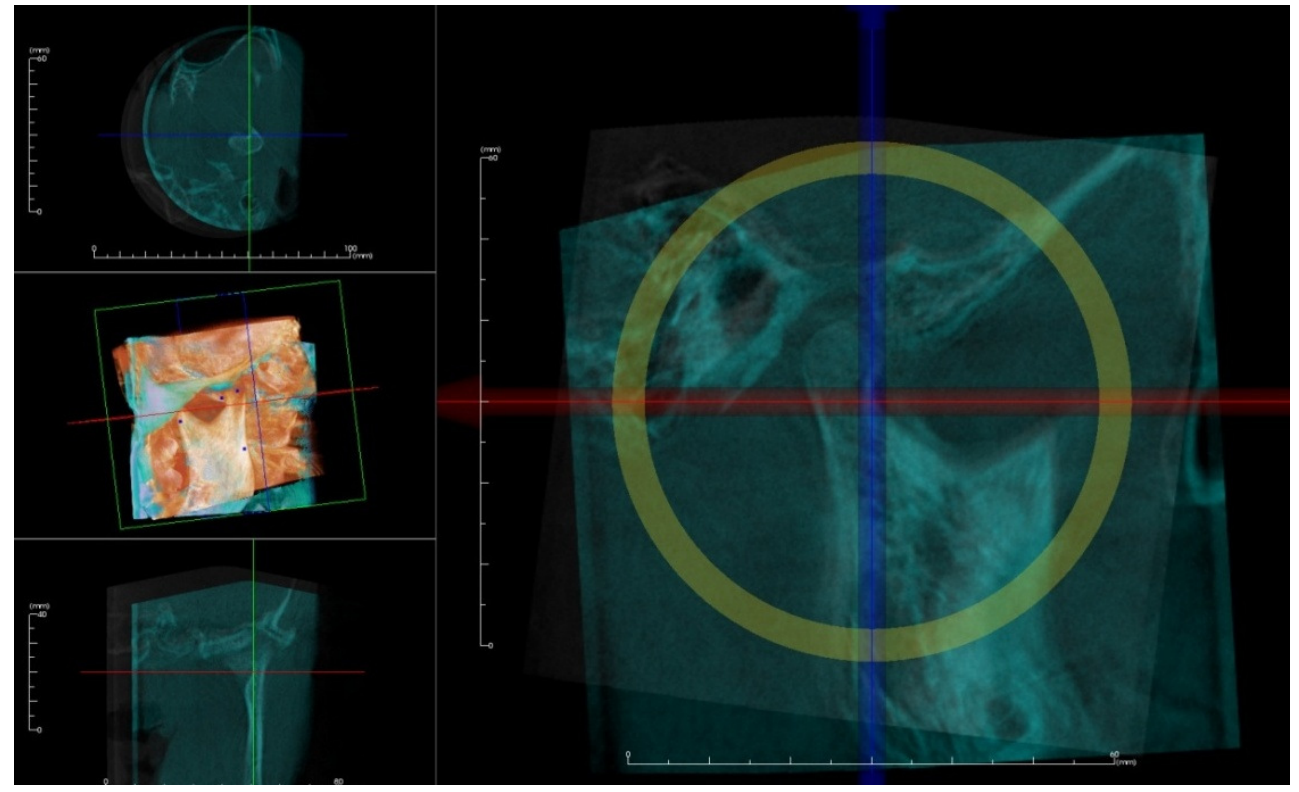

Figure 10. Visual inspection of the mandibular condyle superimposition (inferior alveolar canal) 


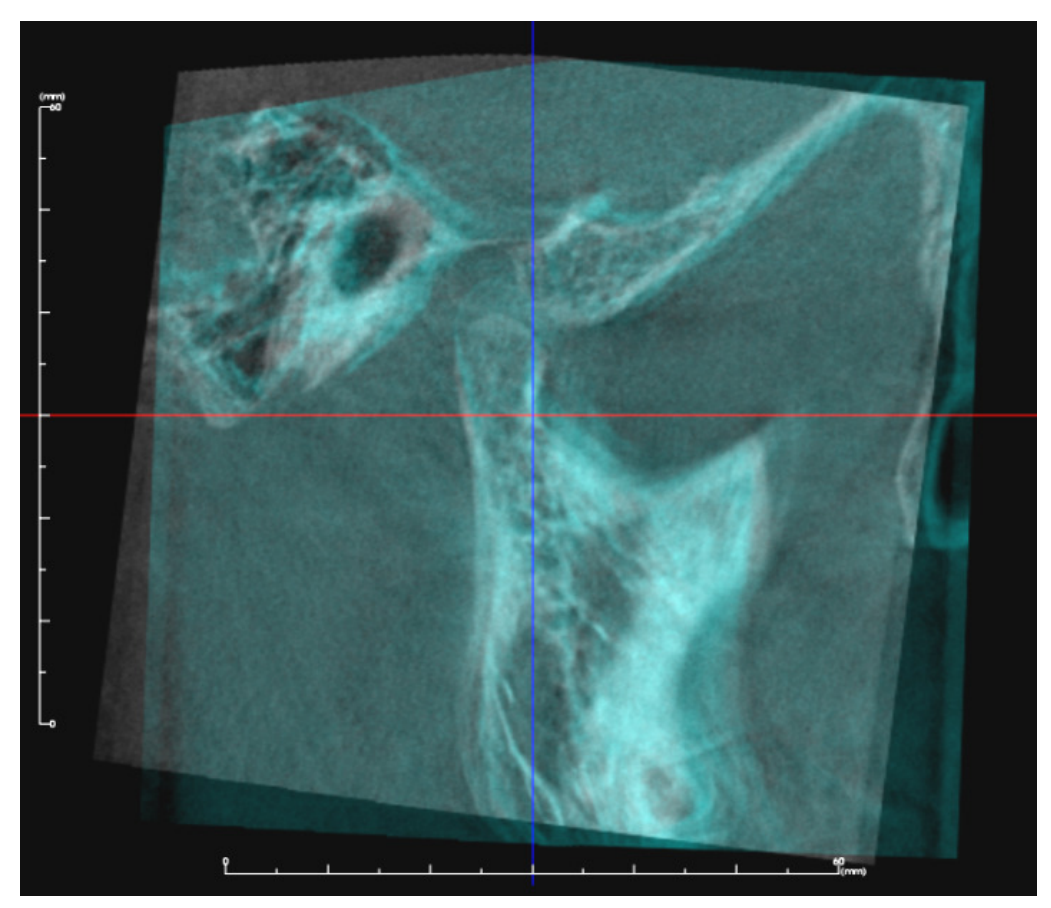

Figure 11. The mandibular condyle, superimposed

\section{Measuring the Mandibular Condyle (Sagittal Plane)}

The sagittal plane presents the condyle (either left or right) as if you are viewing from the same side (left condyle, left side of the face perspective). For example, for a left condyle, the right aspect of the FOV would be the anterior side and the left aspect of the FOV would be the posterior. The operator, after visually verifying the superimposition, will set the opacity of the T1 scan to $0 \%$ in order to mark the initial two points and then set the opacity to $100 \%$ to mark the third point in the T1 scan. After marking the three points, the opacity can be returned to $50 \%$ to visualize both T0 and T1 scans. In the sagittal plane field of view, the cortical outline of the two condyles should be visualized. Three referents will be selected to identify changes in the condyle: the most superior aspect of the condyle, the most anterior aspect of the condyle, and the most posterior aspect of the condyle. 
Measurements will be linear and angular using the Angle Measurement Tool of InVivoDental ${ }^{\mathrm{TM}}$. This tool requires three points to be selected (Figure 12). Start by identifying the specific point you wish to evaluate (e.g. the superior most aspect of the condyle). Click point \#1 to be directly above the point investigated. Click point \#2 to be the point investigated on the T0 scan. Click point \#3 to be the point investigated on the T1 scan. Each point can be individually moved by clicking and dragging the point to the appropriate locations. Please note that the vertical height of the first point is immaterial, as it is only to establish a line parallel to the vertical axis of the scan. Rationale: point \#1 and point \#2 make the initial segment parallel to the vertical axis of the scan, and the marking of point \#3 utilizes the point $\# 2$ as the apex of an angle. The tool will produce the length of each segment in millimeters. For orientation, all angular measurements in the posterior direction will be considered negative. All angular measurements in the anterior direction will be considered positive.

Once you have accomplished a measurement, record the linear length of change (distance between point \#2 and point \#3) and the direction (angle of points \#1, \#2, and \#3) (Figure 12). Once this measurement has been recorded, you can erase the measurement and continue to the second and third referent. 


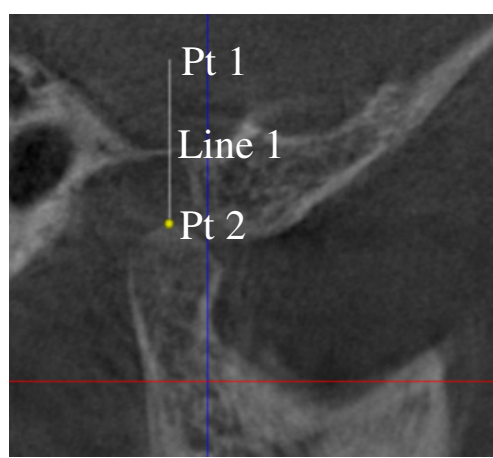

A

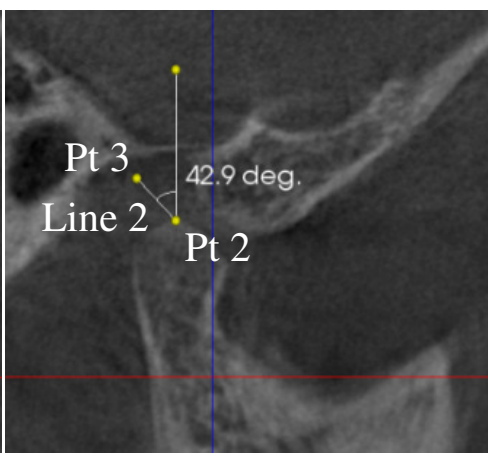

B

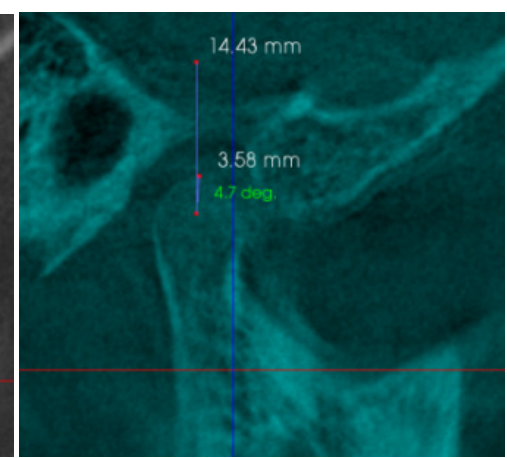

$\mathrm{C}$

Figure 12. (A) Line \#1 parallel to vertical of FOV with Point \#2 on superior referent (sagittal) of T0 condyle. (B) Lines \#1 and \#2 and Points \#1 and \#2 and an arbitrary Point \#3. (C) Point \#3 moved to superior referent of T1 condyle. Degree measurement and length of Line \#2 recorded into spreadsheet.

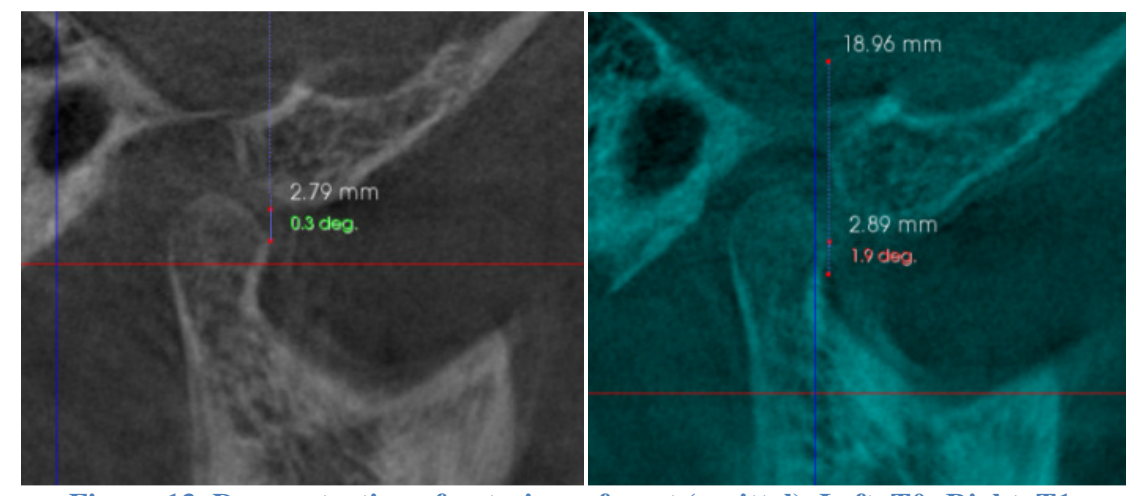

Figure 13. Demonstration of anterior referent (sagittal). Left, T0; Right, T1

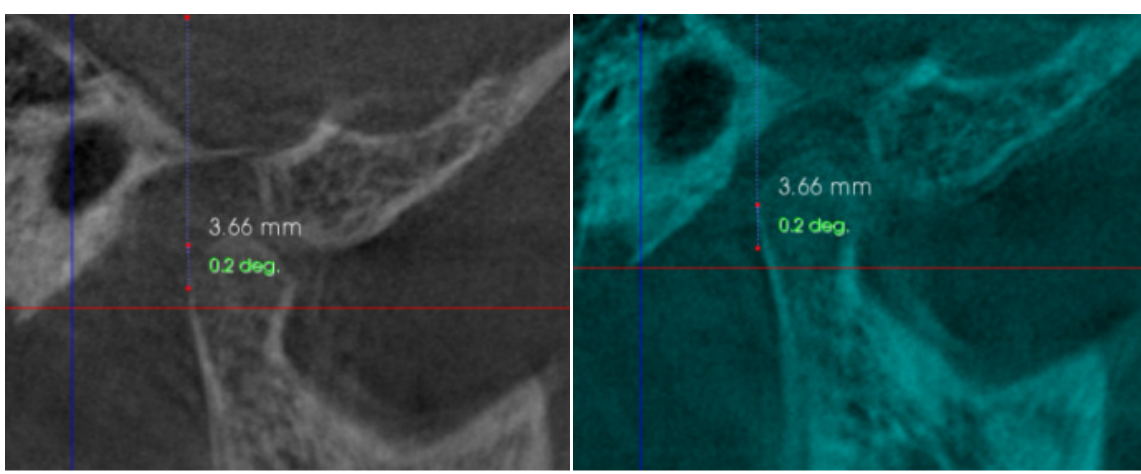

Figure 14. Demonstration of posterior referent (sagittal). Left, T0; Right, T1

\section{Measuring the Mandibular Condyle (Coronal Plane)}

The coronal plane presents the condyle (either left or right) as if you are looking face to face. For example, for a left condyle, the right side of the field of view (FOV) 
would be the medial side and the left aspect of the FOV would be lateral. The operator, after visually verifying the superimposition, will set the opacity of the T1 scan to $0 \%$ in order to mark the initial two points and then set the opacity to $100 \%$ to mark the third point. After marking the three points, the opacity can be returned to $50 \%$ to visualize both T0 and T1 scans. In the coronal plane field of view, the cortical outline of the two condyles should be visualized. Three referents will be selected to identify changes in the condyle: the most superior aspect of the condyle, the most lateral aspect of the condyle, and the most medial aspect of the condyle.

Measurements will be linear and angular using the Angle Measurement Tool of InVivoDental ${ }^{\mathrm{TM}}$. This tool requires three points to be selected. Start by identifying the specific point you wish to evaluate (e.g. the superior most aspect of the condyle). Click point \#1 to be directly above the point investigated. Click point \#2 to be the point investigated on the T0 scan. Click point \#3 to be the point investigated on the T1 scan. Each point can be individually moved by clicking and dragging the point to the appropriate locations. Please note that the vertical height of the first point is immaterial, as it is only to establish a line parallel to the vertical axis of the scan. Rationale: point \#1 and point \#2 make the initial segment parallel to the vertical axis of the scan, and the marking of point \#3 utilizes the point \#2 as the apex of an angle. The tool will produce the length of each segment in millimeters. For orientation, all angular measurements in the lateral direction will be considered negative. All angular measurements in the medial direction will be considered positive.

Once you have accomplished a measurement, record the linear length of change (distance between point \#2 and point \#3) and the direction (angle of points \#1, \#2, and 
\#3). Once this measurement has been recorded, you can erase the measurement and continue to the second and third referent.

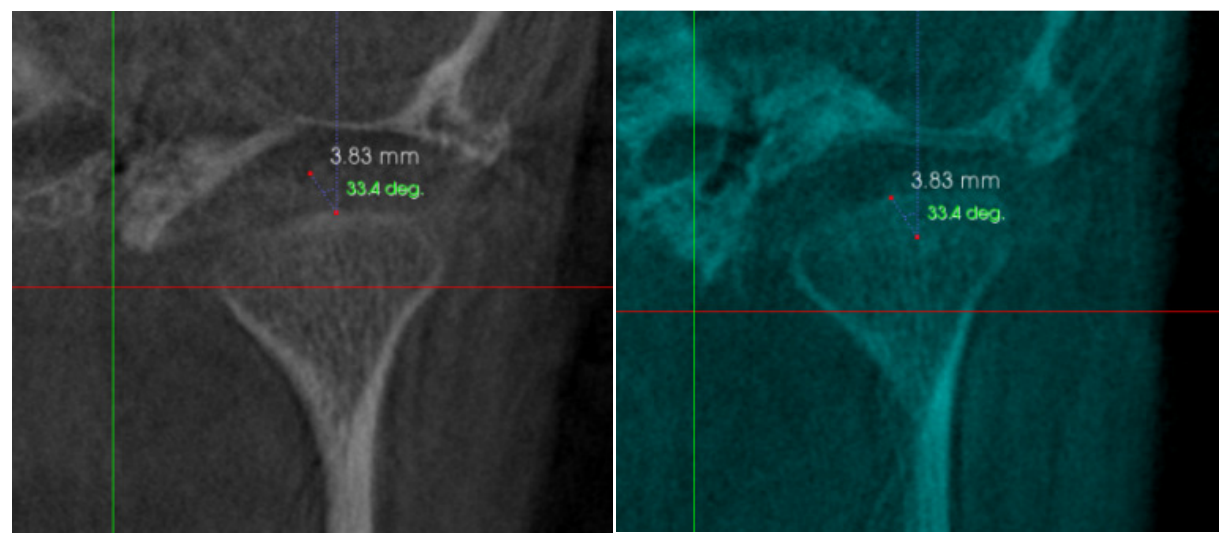

Figure 15. Demonstration of superior referent (coronal). Left, T0; Right, T1

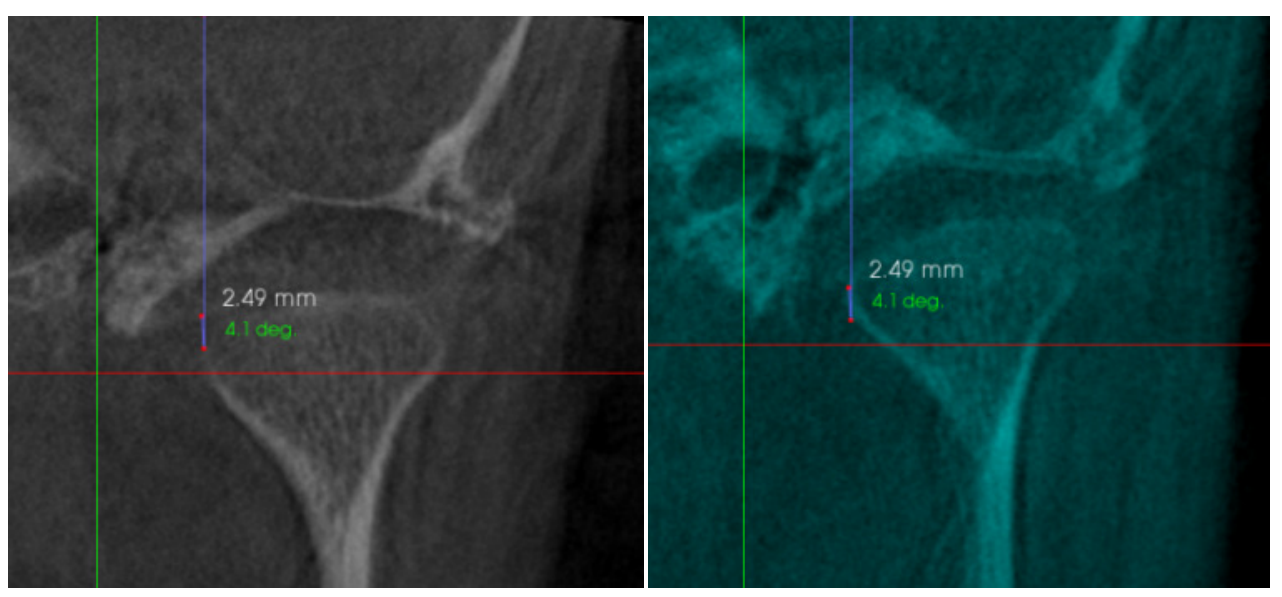

Figure 16. Demonstration of medial referent (coronal). Left, T0; Right, T1
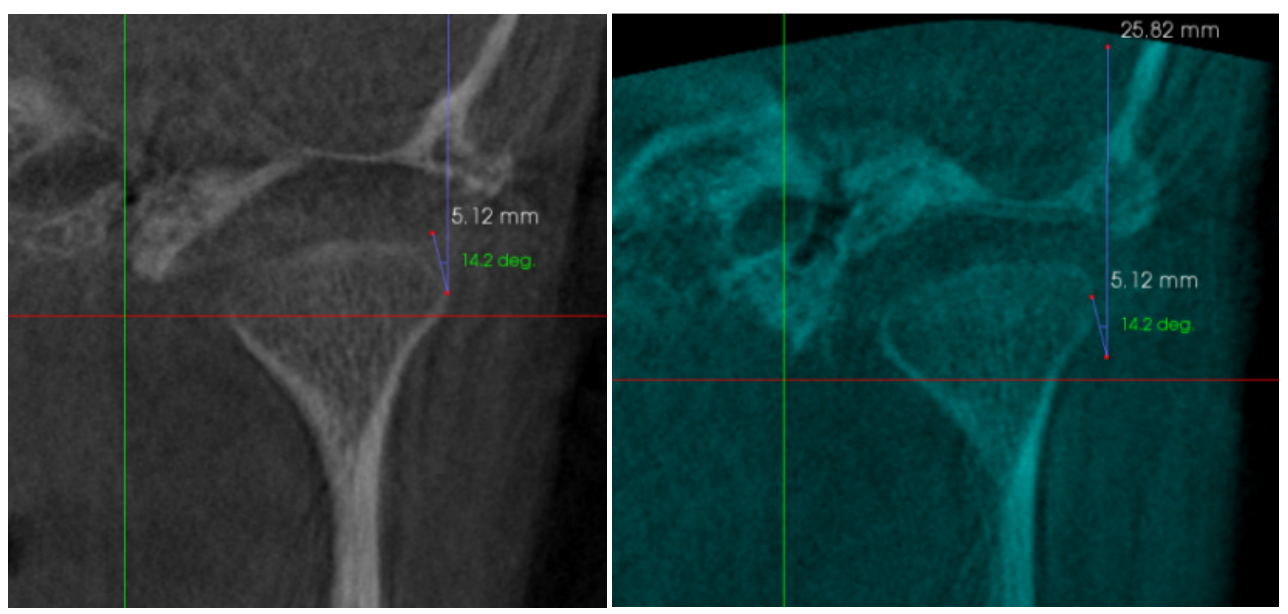

Figure 17. Demonstration of lateral referent (coronal). Left, T0; Right, T1 


\section{Image Orientation of the Glenoid Fossa}

Likewise for the condyle, when superimposing the glenoid fossa, the T0 image orientation is standardized. The coronal view is used to identify the external auditory meatus and ear canal air space. The most superior aspect of the bony canal floor (indicated by the arrow in Figure 18) is used to identify the inferior aspect of the external auditory meatus. The sagittal plane is then rotated about the inferior aspect of the external auditory meatus until it is horizontal with the articular eminence. The axial plane is oriented to be parallel with the long axis of the upper glenoid fossa (Figure 19).

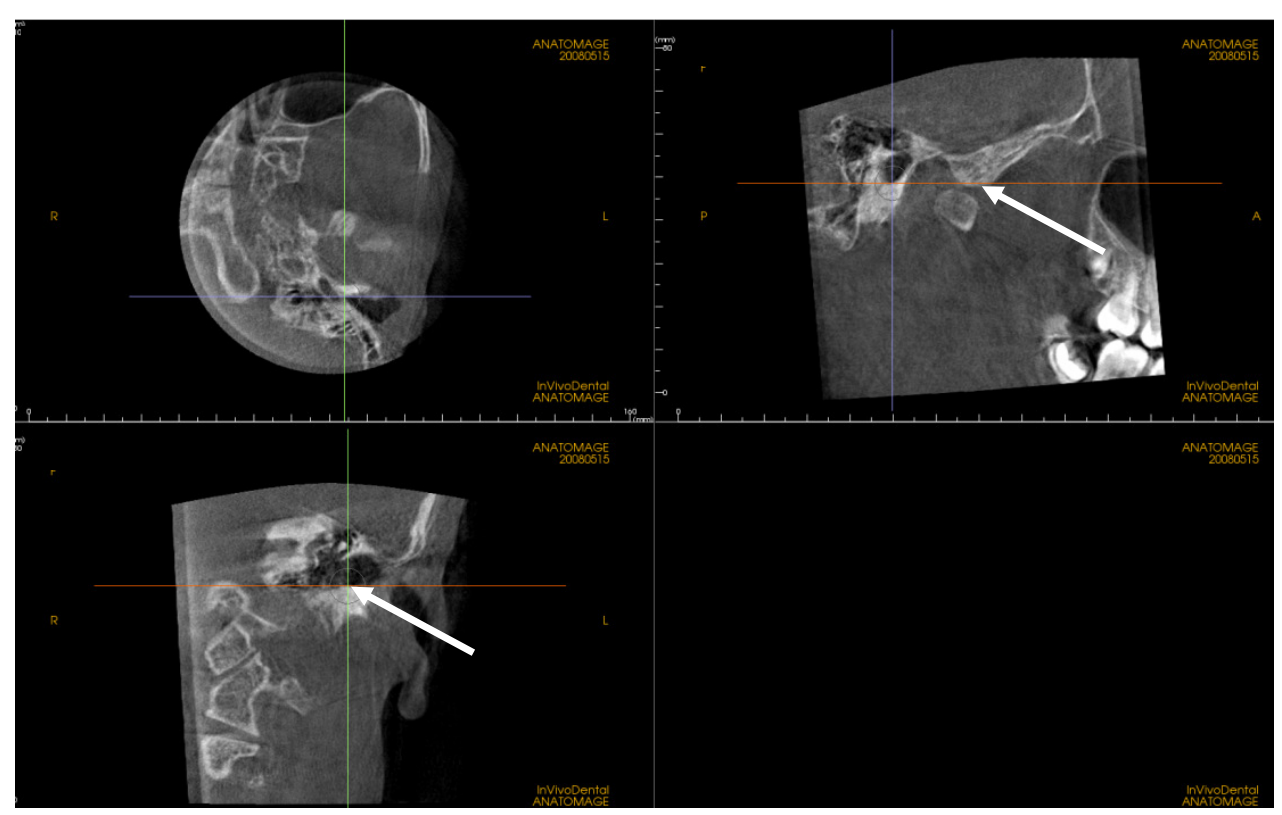

Figure 18. Standardizing the orientation of the T0 image for superimposition of the glenoid fossa. Arrows indicate the most superior aspect 


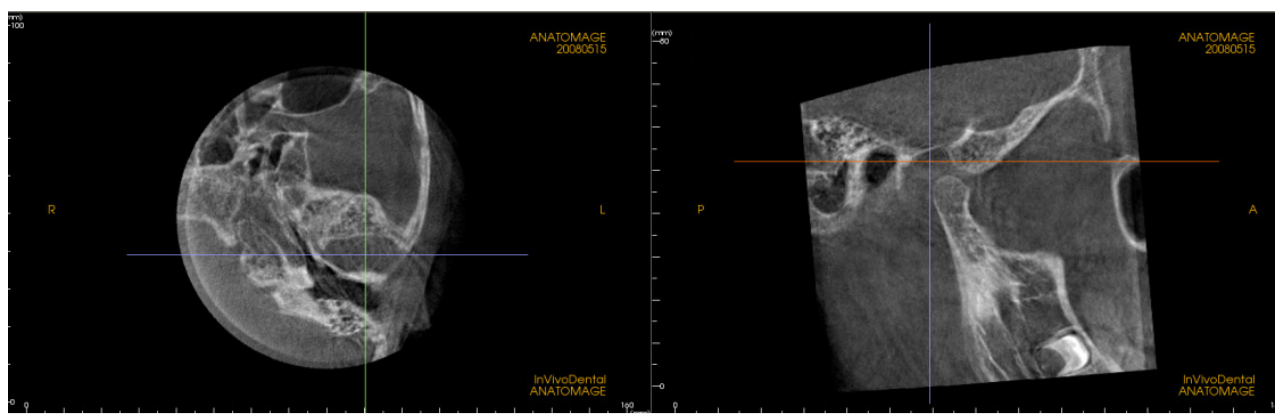

Figure 19. Orienting the sagittal plane to be parallel with the long axis of the upper fossa in the axial FOV.

\section{Superimposing the Glenoid Fossa}

There may be minor differences in the position of the mandible in relation to the glenoid fossa area between the T0 and T1 scans. Therefore, no single bony structure can be successfully used to register the superimposition of the entire scan (encompassing both the glenoid fossa and the mandible). Both the condyle and the glenoid fossa must be superimposed and inspected independently. The auto-registration landmarks selected will be superior and inferior external auditory meatus, the height of contour of the articular eminence, the inferior surface of the cranial base, the zygomatic arch, and lower orbit (Figure 20). Visual verification of the cranial base surface alignment ensures adequate superimposition for the analysis (Figure 21). 


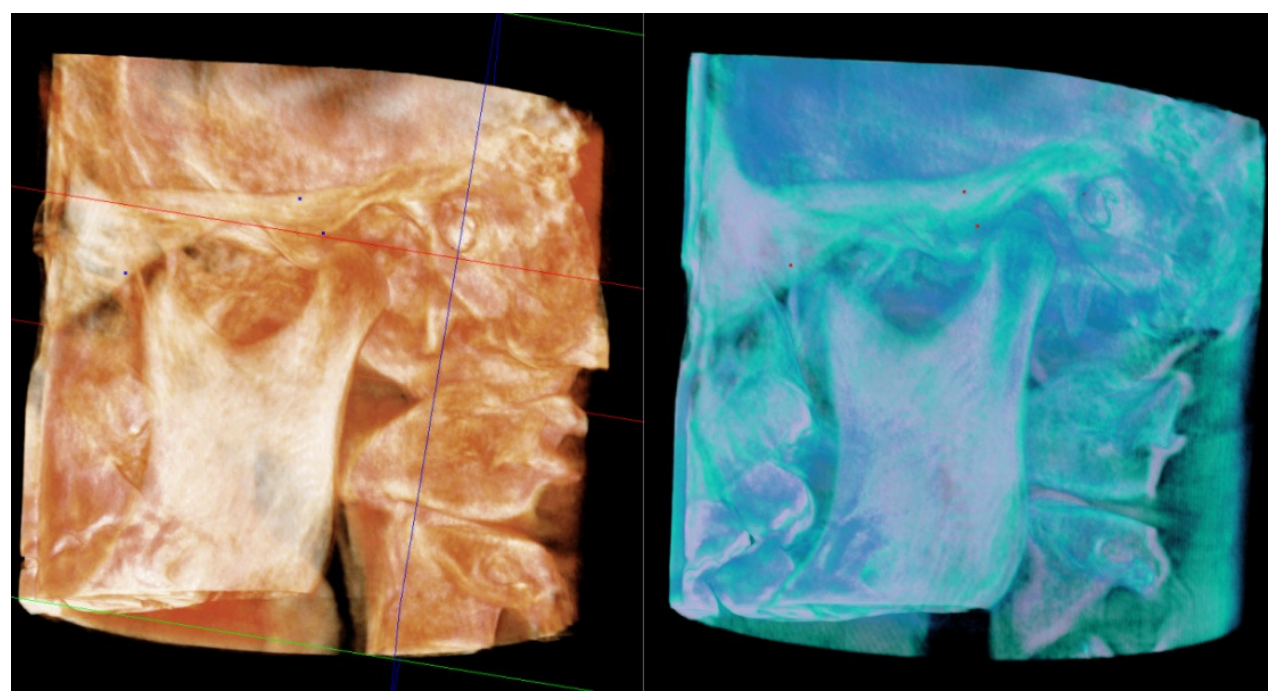

Figure 20. Auto-registration for superimposing the glenoid fossa

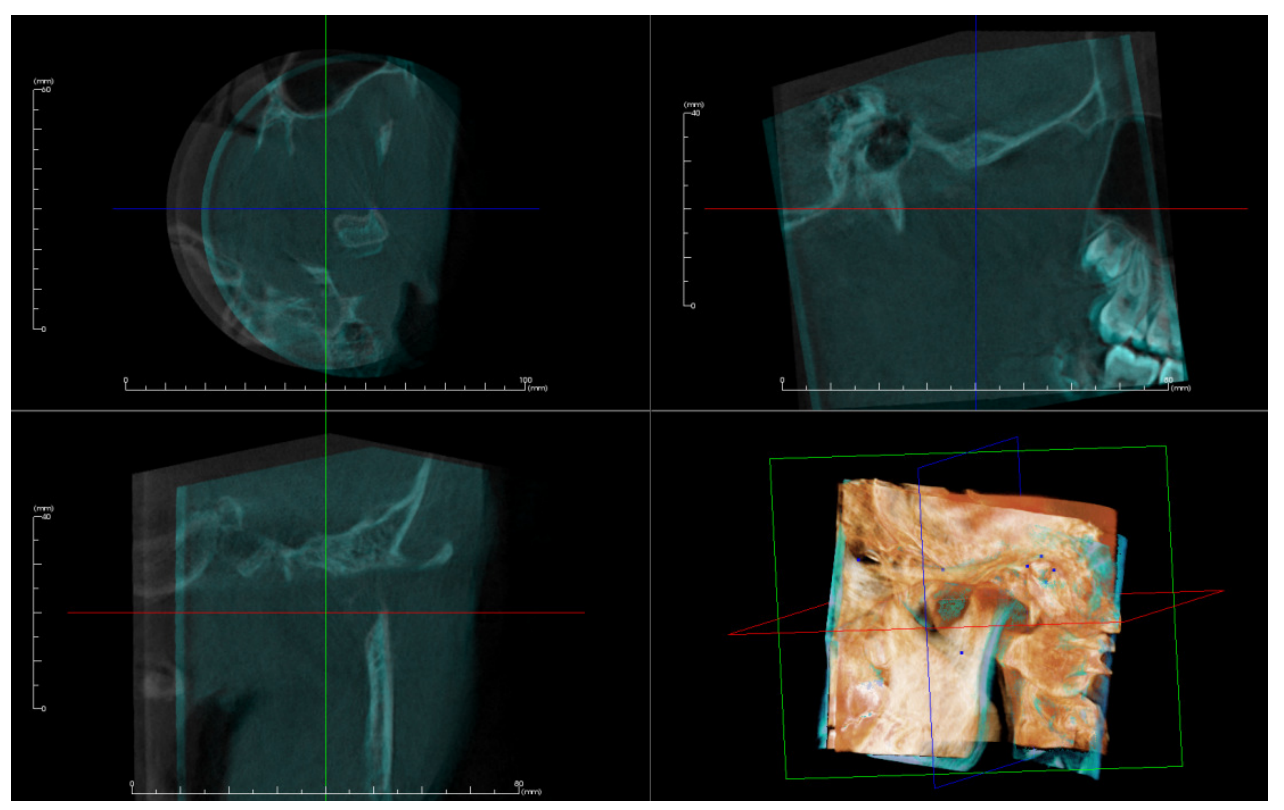

Figure 21. The glenoid fossa, superimposed.

\section{Measuring the Glenoid Fossa (Sagittal Plane)}

Identify the midline of the glenoid fossa by scrolling to that plane sagittally. Note that when the image was oriented, the long axis (mediolaterally) of the fossa is oriented 
to be parallel with the coronal plane (Figure 22). This axial FOV can be used to gauge the fossa center, lateral third, and medial third.

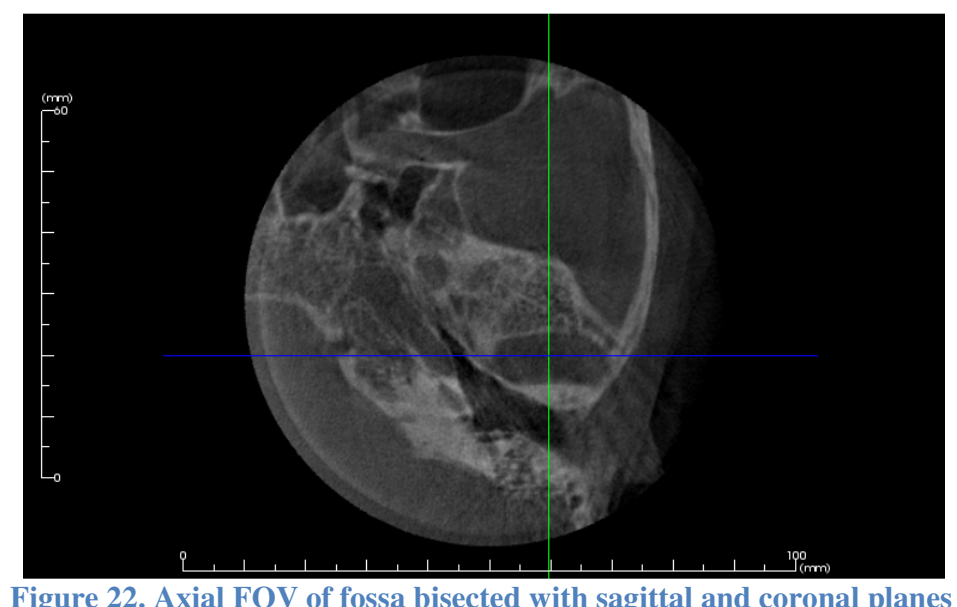

The sagittal plane presents the glenoid fossa (either left or right) as if you are viewing from the same side (left condyle, left side of the face perspective). For example, for a left glenoid fossa, the right aspect of the FOV would be the anterior side and the left aspect of the FOV would be the posterior. The operator, after visually verifying the superimposition, will set the opacity of the T1 scan to $0 \%$ in order to mark the initial two points and then set the opacity to $100 \%$ to mark the third point in the T1 scan. After marking the three points, the opacity can be returned to $50 \%$ to visualize both $\mathrm{T} 0$ and $\mathrm{T} 1$ scans. In the sagittal plane field of view, the cortical outline of the two glenoid fossa should be visualized. This may be difficult to visualize if there is little or no change. Three referents will be selected to identify changes in the glenoid fossa: the most superior aspect of the fossa, bisection of the anterior contour of the fossa, and bisection of the posterior contour of the fossa. These referents will represent the articulating surfaces of the fossa which are being investigated. The inferior limit of the fossa in that particular 
plane will be a line parallel to the axial plane at the height of the articular eminence (Figure 23).

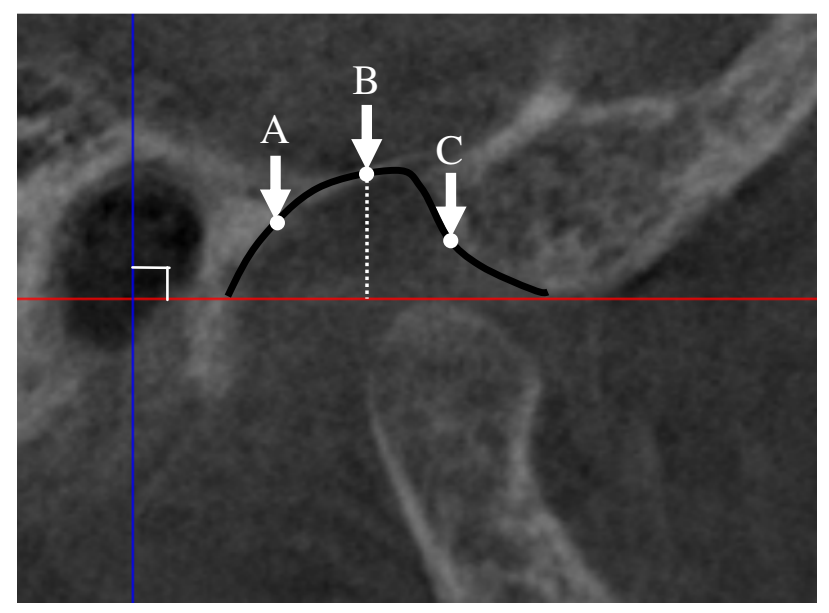

Figure 23. (A) Posterior bisection; (B) superior aspect of the fossa; (C) anterior bisection

To simplify the three-dimensional measurement process, the fossa measurements will be sampled from three slices (center, medial, and lateral) in the sagittal plane. The medial and lateral samples will be measured from a bisection of the medial and lateral halves, respectively. The symmetry of the glenoid fossa can be realized by bringing the axial plane to the most inferior level of the fossa where it is circumferentially outlined by cortical bone (Figure 24). 


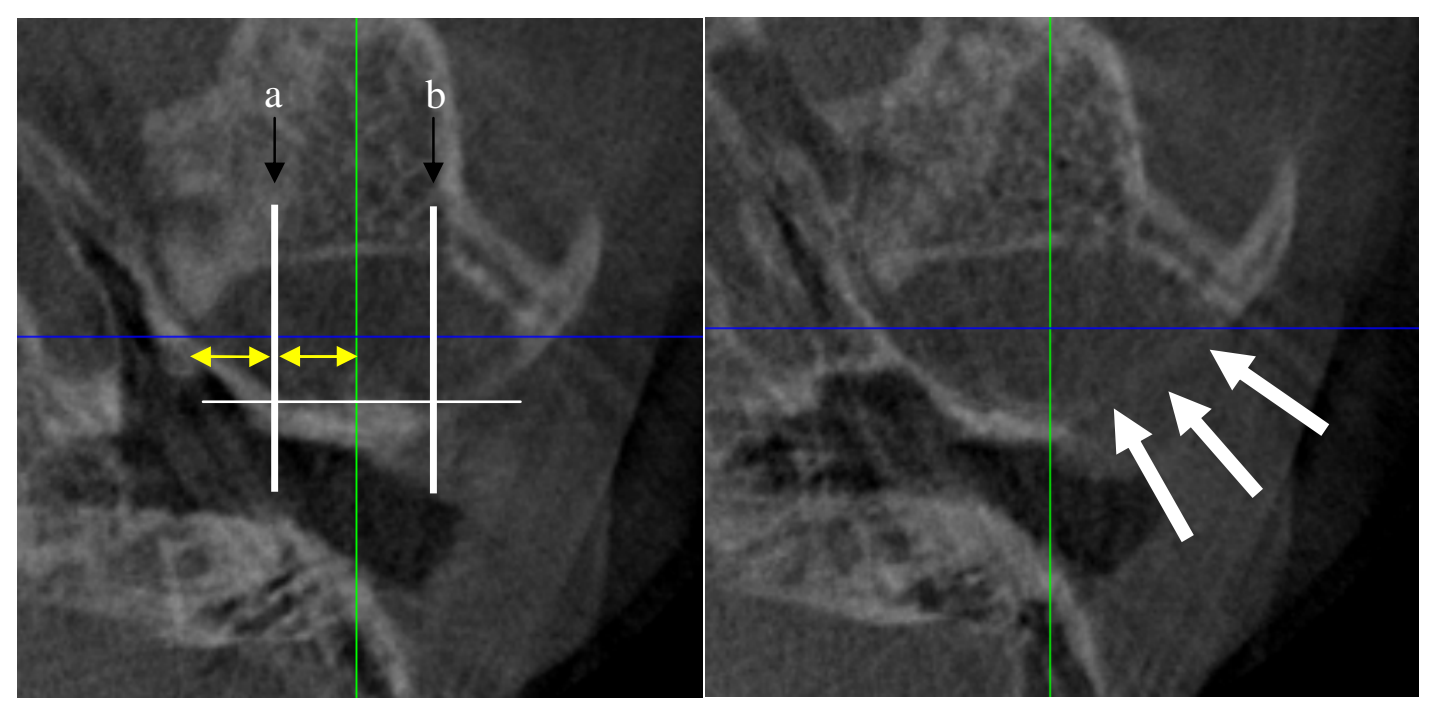

A

B

Figure 24. (A) Glenoid fossa at the most inferior level with bone still circumferential. Bisect medial (a) and lateral (b) halves for measurement sampling. (B) Axial plane too inferior, where bone does not completely surround the fossa (arrows).

Measurements will be linear and angular using the Angle Measurement Tool of InVivoDental ${ }^{\mathrm{TM}}$. This tool requires three points to be selected (Figure 25). Start by identifying the specific point you wish to evaluate (e.g. the superior most aspect of the condyle). Click point \#1 to be directly above the point investigated. Click point \#2 to be the point investigated on the T0 scan. Click point \#3 to be the point investigated on the T1 scan. Each point can be individually moved by clicking and dragging the point to the appropriate locations. Please note that the vertical height of the first point is immaterial, as it is only to establish a line parallel to the vertical axis of the scan. Rationale: point \#1 and point \#2 make the initial segment parallel to the vertical axis of the scan, and the marking of point \#3 utilizes the point \#2 as the apex of an angle. The tool will produce the length of each segment in millimeters. For orientation, all angular measurements in the posterior direction will be considered negative. All angular measurements in the anterior direction will be considered positive. 
Once you have accomplished a measurement, record the linear length of change (distance between point \#2 and point \#3) and the direction (angle of points \#1, \#2, and \#3) (Figure 25). Once this measurement has been recorded, you can erase the measurement and continue to the second and third referent.

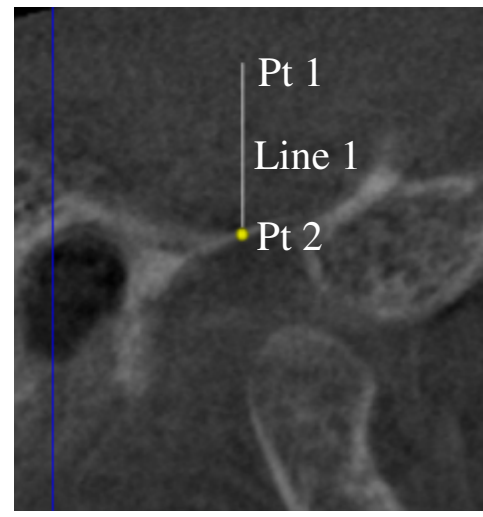

A

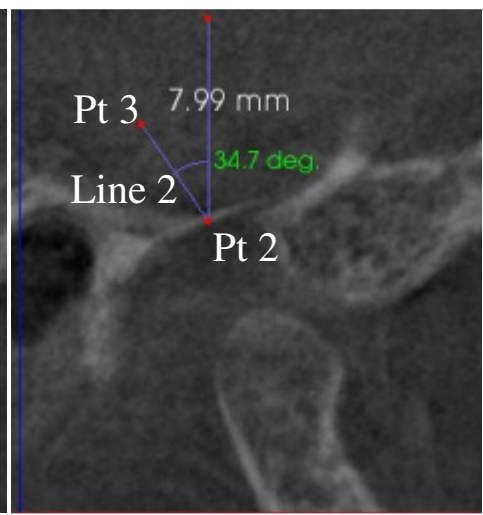

B

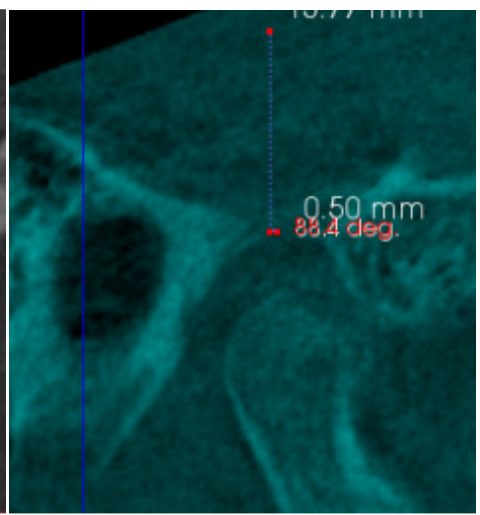

$\mathrm{C}$

Figure 25. (A) Line \#1 parallel to vertical of FOV with Point \#2 on superior referent (sagittal) of T0 fossa. (B) Lines \#1 and \#2 and Points \#1 and \#2 and an arbitrary Point \#3. (C) Point \#3 moved to superior referent of T1 fossa. Degree measurement and length of Line \#2 recorded into spreadsheet.

\section{Data Collection}

The measurements from the mandibular condyle and glenoid fossa will be recorded in a spreadsheet (Table 2, Table 3, Table 4, Table 5, and Table 6) with linear measurements separated from angular measurements.

\begin{tabular}{|l|l|l|l|l|l|}
\hline \multicolumn{5}{|c|}{ Mandibular Condyle L or R } \\
\hline \multicolumn{5}{|c|}{ Coronal Plane } \\
\hline Medial (mm) & Medial $\left({ }^{\circ}\right)$ & Superior $(\mathrm{mm})$ & Superior $\left({ }^{\circ}\right)$ & Lateral $(\mathrm{mm})$ & Lateral $\left({ }^{\circ}\right)$ \\
\hline & & & & & \\
\hline
\end{tabular}

Table 2. Data collection table for the mandibular condyle (coronal plane)

\begin{tabular}{|l|l|l|l|l|l|}
\hline \multicolumn{5}{|c|}{ Mandibular Condyle L or R } \\
\hline \multicolumn{5}{|c|}{ Sagittal Plane } \\
\hline Posterior $(\mathrm{mm})$ & Posterior $\left({ }^{\circ}\right)$ & Superior $(\mathrm{mm})$ & Superior $\left({ }^{\circ}\right)$ & Anterior $(\mathrm{mm})$ & Anterior $\left({ }^{\circ}\right)$ \\
\hline & & & & & \\
\hline
\end{tabular}

Table 3. Data collection table for the mandibular condyle (sagittal plane) 


\begin{tabular}{|l|l|l|l|l|l|}
\hline \multicolumn{5}{|c|}{ Glenoid Fossa L or R } \\
\hline \multicolumn{7}{|c|}{ Sagittal Plane (Medial) } \\
\hline Posterior $(\mathrm{mm})$ & Posterior $\left({ }^{\circ}\right)$ & Superior $(\mathrm{mm})$ & Superior $\left({ }^{\circ}\right)$ & Anterior $(\mathrm{mm})$ & Anterior $\left({ }^{\circ}\right)$ \\
\hline & & & & & \\
\hline
\end{tabular}

Table 4. Data collection table for the glenoid fossa (medial sample)

\begin{tabular}{|l|l|l|l|l|l|}
\hline \multicolumn{5}{|c|}{ Glenoid Fossa L or R } \\
\hline \multicolumn{5}{|c|}{ Sagittal Plane (Center) } \\
\hline Posterior $(\mathrm{mm})$ & Posterior $\left({ }^{\circ}\right)$ & Superior $(\mathrm{mm})$ & Superior $\left({ }^{\circ}\right)$ & Anterior $(\mathrm{mm})$ & Anterior $\left({ }^{\circ}\right)$ \\
\hline & & & & & \\
\hline
\end{tabular}

Table 5. Data collection table for the glenoid fossa (center sample)

\begin{tabular}{|l|l|l|l|l|l|}
\hline \multicolumn{5}{|c|}{ Glenoid Fossa L or R } \\
\hline \multicolumn{5}{|c|}{ Sagittal Plane (Lateral) } \\
\hline Posterior $(\mathrm{mm})$ & Posterior $\left({ }^{\circ}\right)$ & Superior $(\mathrm{mm})$ & Superior $\left({ }^{\circ}\right)$ & Anterior $(\mathrm{mm})$ & Anterior $\left({ }^{\circ}\right)$ \\
\hline & & & & & \\
\hline
\end{tabular}

Table 6. Data collection table for the glenoid fossa (lateral sample)

These data tables provide the investigator with detail as to which direction and magnitude the referents are moving between the T0 and T1 scans. Each individual referent can be observed, or with the help of Microsoft Excel ${ }^{\mathrm{TM}}$, an average can be calculated. It is important to note the vector information given by the degree measurement. Since the initial line of the angle (Figure 12, for example) is oriented to be parallel with the vertical axis of the field of view, $0^{\circ}$ is in the superior direction. InVivoDental ${ }^{\mathrm{TM}}$ also only reports the inferior angle (for example, instead of reporting $270^{\circ}$, it will report $90^{\circ}$ ). Therefore, care must be taken to ensure that measurements are transcribed correctly. In this methodology, negative values are prescribed to posterior, lateral, and inferior movements and positive values are prescribed to anterior, medial, and superior movements (Figure 26 and Figure 27). For example: Instead of $\mathbf{2 7 0}^{\circ}$, the software will report $90^{\circ}$ which, if indicating a posterior direction on a sagittal plane, 
should be recorded as $\mathbf{- 9 0}^{\circ}$. Keeping this angle prescription also eliminates the need to differentiate direction orientation between left and right sides of a subject.

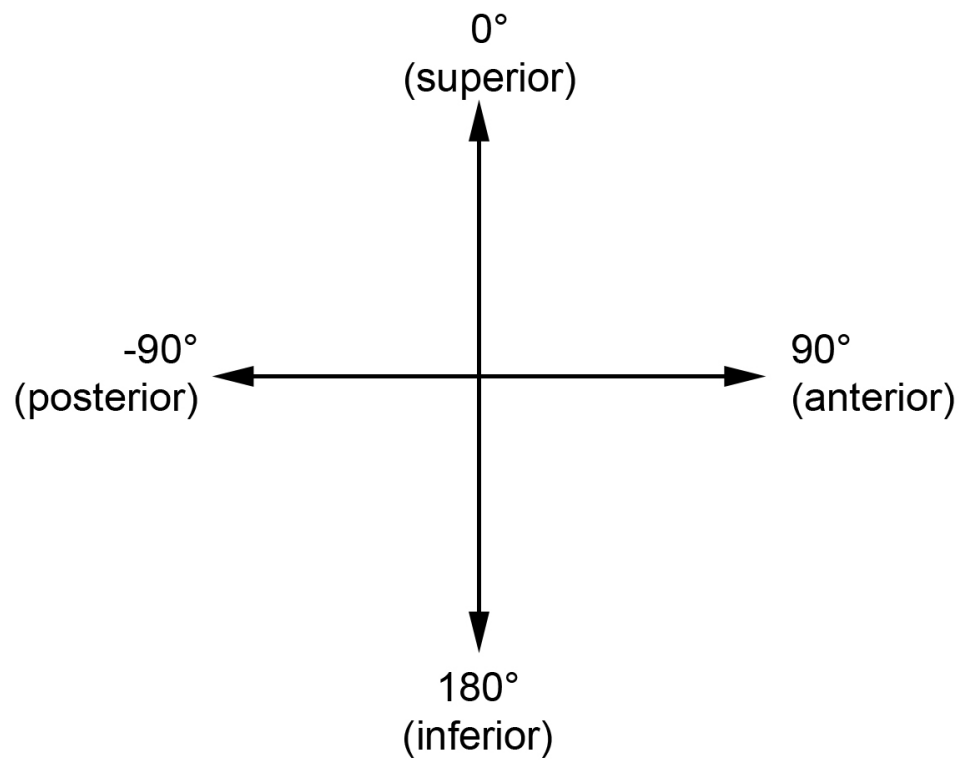

Figure 26. Compass view of directions in the sagittal plane

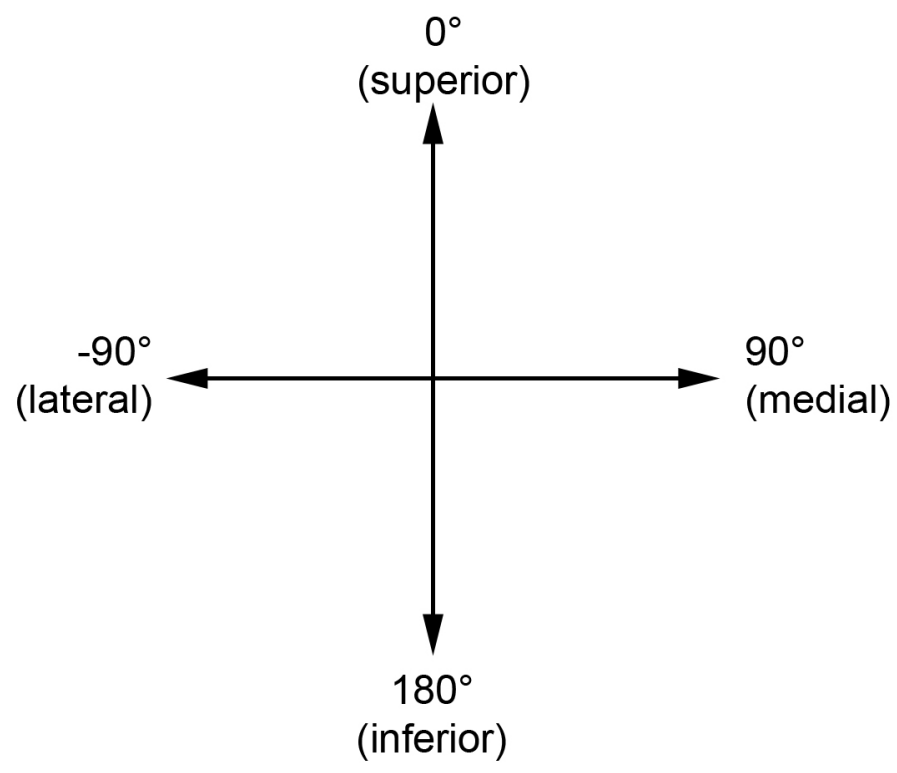

Figure 27. Compass view of directions in the coronal plane

In Microsoft Excel ${ }^{\mathrm{TM}}$, a formula can be derived to automatically calculate the direction in the sagittal and coronal planes (Table 7 and Table 8): 


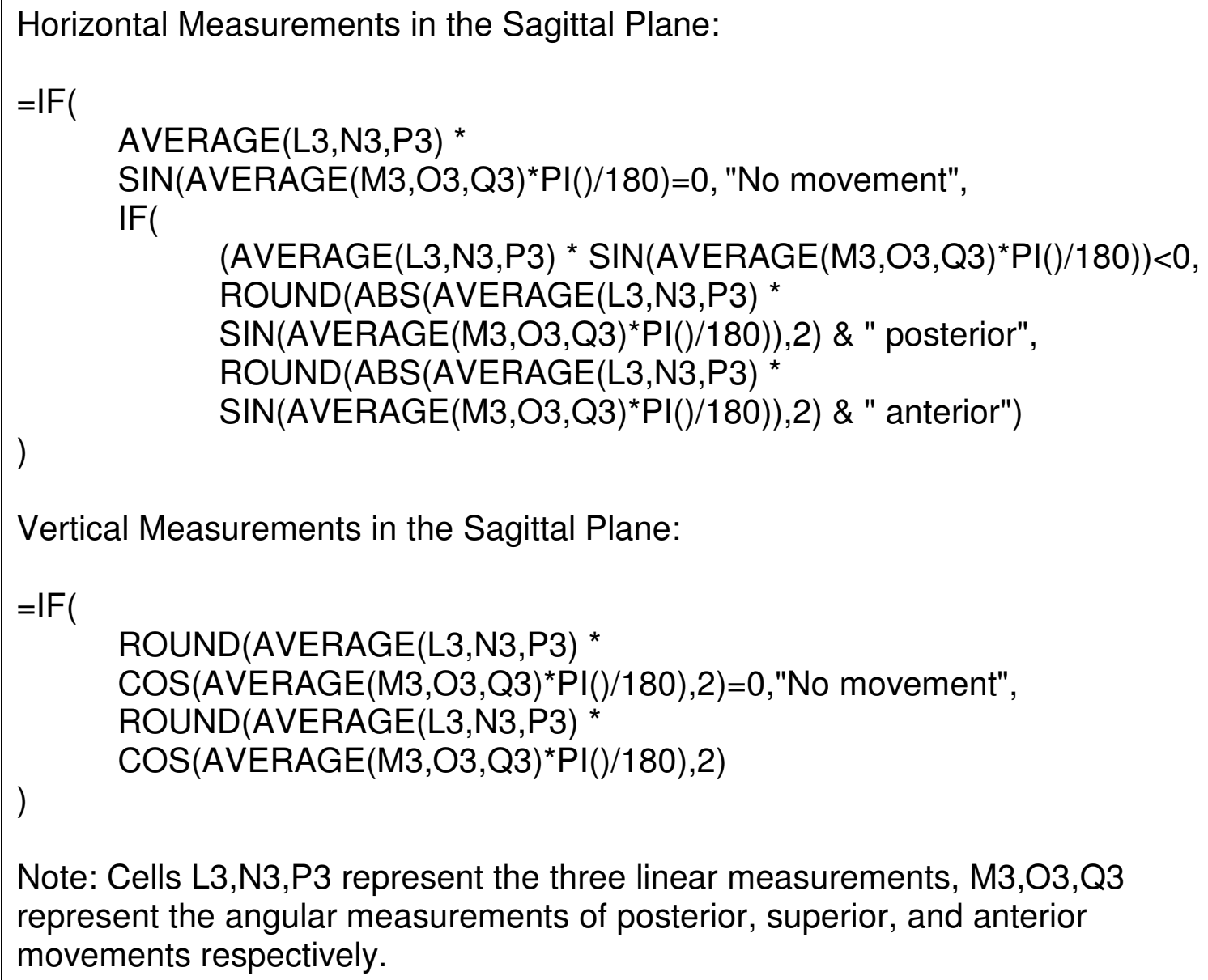

Note: Cells L3,N3,P3 represent the three linear measurements, M3,O3,Q3 represent the angular measurements of posterior, superior, and anterior movements respectively.

Table 7. Microsoft Excel ${ }^{\mathrm{TM}}$ formula for summarizing direction of movement in the sagittal plane 


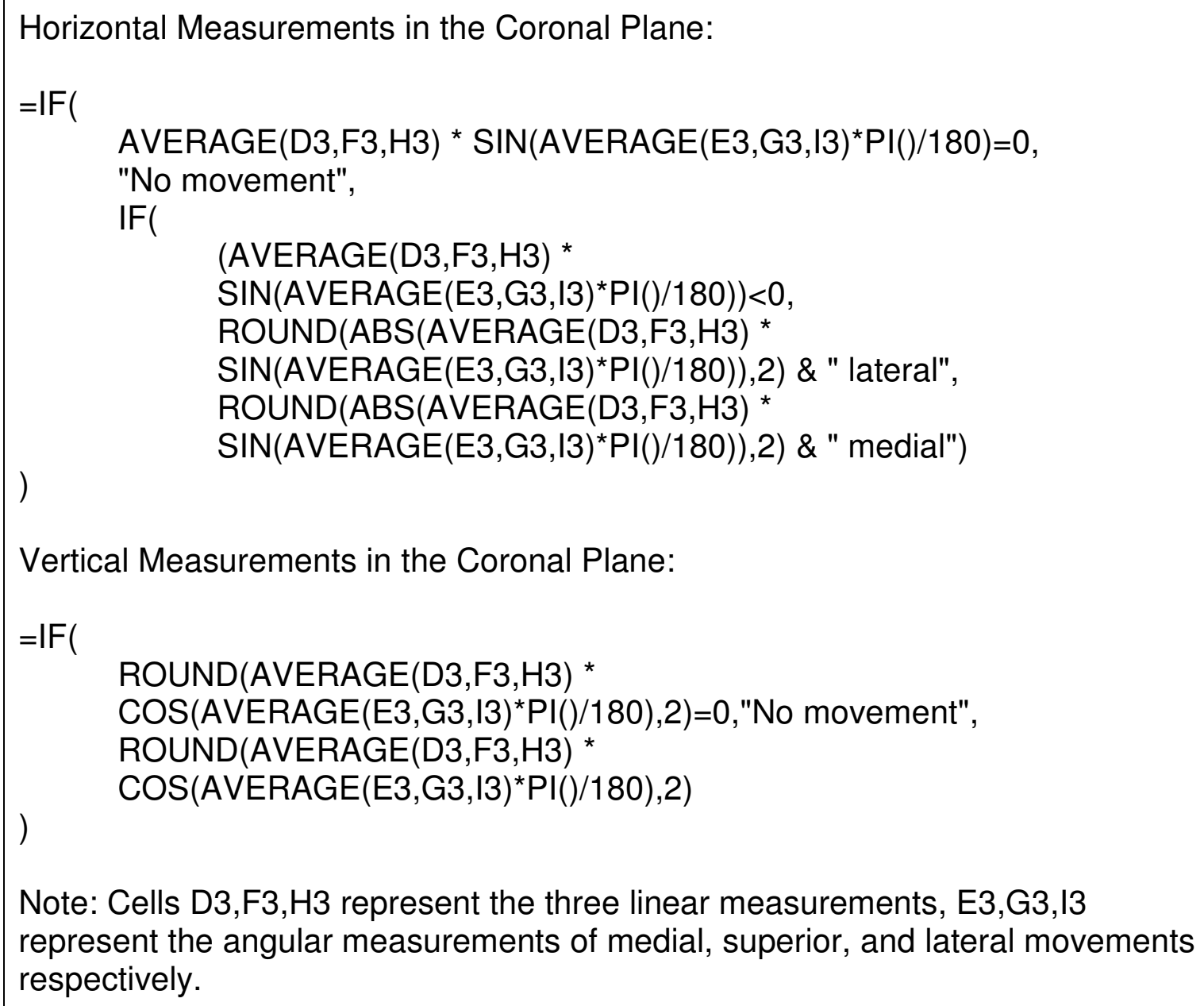

Note: Cells D3,F3,H3 represent the three linear measurements, E3,G3,13 represent the angular measurements of medial, superior, and lateral movements respectively.

Table 8. Microsoft Excel ${ }^{\mathrm{TM}}$ formula for summarizing direction of movement in the coronal plane

These Excel ${ }^{\mathrm{TM}}$ formulas will average the lengths and angles to provide a composite value consisting of components of a vector (horizontal change and vertical change). The $\sin$ of the angle will give the transverse movement (anterior/posterior on a sagittal view or medial/lateral on a coronal view). The cos of the angle will give the vertical movement (superior/inferior).

For example: An investigator found a composite measurement on a sagittal field of view indicating that three referents of a right condyle resulted in an average change of 
$3 \mathrm{~mm}$ at $-75^{\circ}$. The $\sin$ of the measurement indicates a $2.9 \mathrm{~mm}$ posterior movement and the cos indicates a $0.78 \mathrm{~mm}$ positive vertical (superior) movement (Figure 28).

Likewise for the composite measurement, if desired, the same mathematics can be applied to each individual referent to see what happens to a more specific part of the TMJ.

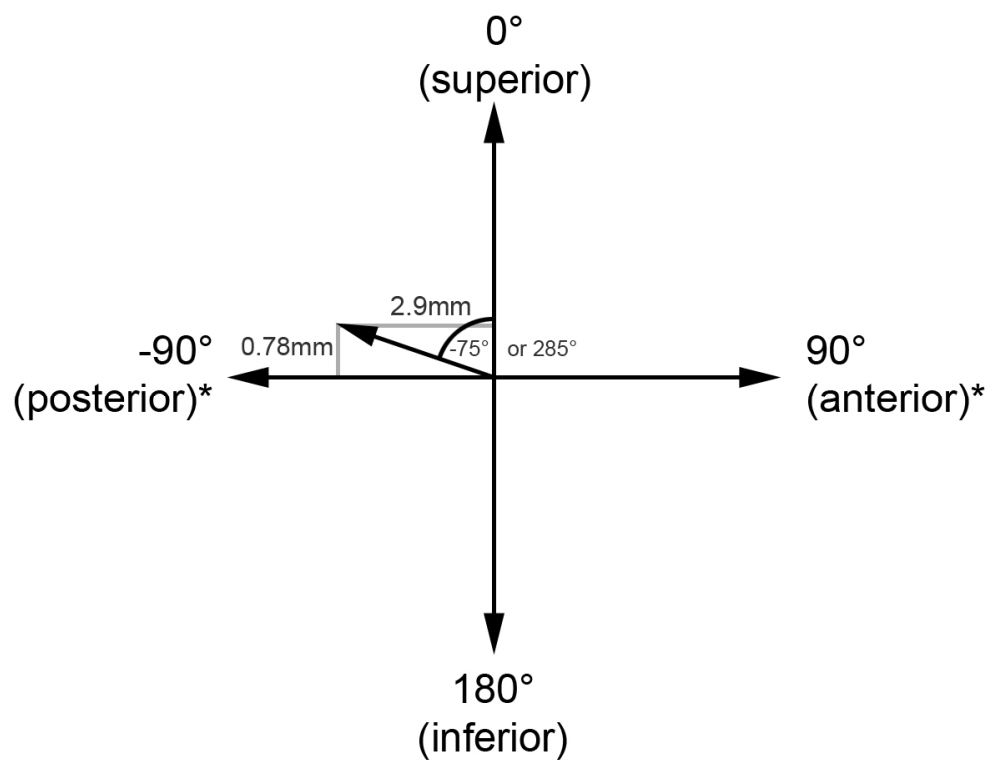

Figure 28. Compass diagram of the above example

\section{Method Error}

The reliability of this novel three-dimensional analytic approach was tested by investigating the error in locating, superimposing, and measuring the changes of all landmarks. All subjects were analyzed a second time two weeks after the initial tracing. For all variables, differences between the measurements recorded at the first analysis and measurements recorded at the second analysis were compared for each individual. A matched-pairs reliability test was used to statistically analyze each measurement to establish a coefficient of reliability to determine the degree of reliability of the analysis. 


\section{CHAPTER 4: RESULTS AND DISCUSSION}

The sample size included 20 subjects ( 9 female, 11 male) containing right and left TMJ scans that were taken 9 months between pre and post Herbst treatment. Some of the subjects did not have a subsequent post-treatment cone beam scan or were only left or only right scans. Also, some subjects' radiographic field of view did not contain sufficient structures to be able to be superimposed. With all subjects, there was not a sufficient amount of stable cranial base structures to superimpose for glenoid fossa measurements. Therefore, glenoid fossa measurements were not performed in this study. To maximize the number of usable pre and post treatment radiographs, only right-side scans of sufficient diagnostic quality were used which totaled 10 subjects.

The measurements in this study were grouped into two categories: sagittal and coronal. Within each category, the measurements were grouped into subcategories: linear, direction (degrees), and component average.

\section{Distribution of Condyle Measurements (Sagittal)}

The average change of the condyle in the sagittal direction was $2.64 \mathrm{~mm}$ (posterior referent), $2.85 \mathrm{~mm}$ (superior referent), and $2.47 \mathrm{~mm}$ (anterior referent). The component averages were a posterior $1.59 \mathrm{~mm}$ horizontal change and a superior $1.80 \mathrm{~mm}$ vertical change (Table 9). 


\begin{tabular}{|c|c|c|c|c|c|c|c|c|}
\hline \multicolumn{9}{|c|}{ Condyle Measurements (Sagittal) } \\
\hline Subject & $\begin{array}{c}\text { Cond/Sag } \\
\text { Avg AP }\end{array}$ & $\begin{array}{c}\text { Cond/Sag } \\
\text { Avg } \\
\text { Vertical }\end{array}$ & $\begin{array}{c}\text { Cond/Sag } \\
\text { Posterior } \\
(\mathrm{mm})\end{array}$ & $\begin{array}{c}\text { Cond/Sag } \\
\text { Posterior } \\
\left({ }^{\circ}\right)\end{array}$ & $\begin{array}{c}\text { Cond/Sag } \\
\text { Superior } \\
(\mathrm{mm})\end{array}$ & $\begin{array}{c}\text { Cond/Sag } \\
\text { Superior } \\
\left({ }^{\circ}\right)\end{array}$ & $\begin{array}{c}\text { Cond/Sag } \\
\text { Anterior } \\
(\mathrm{mm})\end{array}$ & $\begin{array}{c}\text { Cond/Sag } \\
\text { Anterior } \\
\left({ }^{\circ}\right)\end{array}$ \\
\hline 1 & -2.36 & 1.70 & 2.63 & -36.70 & 2.97 & -64.30 & 3.14 & -61.80 \\
\hline 2 & -1.89 & 2.35 & 3.22 & -43.70 & 3.31 & -39.80 & 2.52 & -33.00 \\
\hline 3 & -1.80 & 2.02 & 2.63 & -37.90 & 3.03 & -29.70 & 2.45 & -57.50 \\
\hline 4 & -1.77 & 1.40 & 2.59 & -29.50 & 2.45 & -73.70 & 1.74 & -51.60 \\
\hline 5 & -1.66 & 2.02 & 2.14 & -36.80 & 3.44 & -41.50 & 2.26 & -39.70 \\
\hline 6 & 0.23 & 3.70 & 4.85 & 6.00 & 3.29 & 6.70 & 2.98 & -1.80 \\
\hline 7 & -0.76 & 1.33 & 1.67 & -37.20 & 1.39 & -41.90 & 1.53 & -10.60 \\
\hline 8 & 0.27 & 1.01 & 0.36 & 30.70 & 1.59 & 4.00 & 1.20 & 10.10 \\
\hline 9 & -3.44 & 0.88 & 3.43 & -79.40 & 3.71 & -78.90 & 3.51 & -68.70 \\
\hline 10 & -2.71 & 1.61 & 2.85 & -42.30 & 3.27 & -58.10 & 3.33 & -77.30 \\
\hline Mean & -1.59 & 1.80 & 2.64 & -30.68 & 2.85 & -41.72 & 2.47 & -39.19 \\
\hline StDev & 1.20 & 0.81 & 1.17 & 29.74 & 0.79 & 29.38 & 0.79 & 29.83 \\
\hline Min & -3.44 & 0.88 & 0.36 & -79.40 & 1.39 & -78.90 & 1.20 & -77.30 \\
\hline Max & 0.27 & 3.70 & 4.85 & 30.70 & 3.71 & 6.70 & 3.51 & 10.10 \\
\hline
\end{tabular}

Table 9. Distribution of condyle measurements (sagittal plane)

\section{Distribution of Condyle Changes (Coronal)}

The average change of the condyle in the coronal direction was $2.45 \mathrm{~mm}$ (medial referent), $2.46 \mathrm{~mm}$ (superior referent), and $2.49 \mathrm{~mm}$ (lateral referent). The component averages were a lateral $0.64 \mathrm{~mm}$ horizontal change and a superior $2.19 \mathrm{~mm}$ vertical change (Table 10). 


\begin{tabular}{|c|c|c|c|c|c|c|c|c|}
\hline \multicolumn{9}{|c|}{ Condyle Measurements (Coronal) } \\
\hline Subject & $\begin{array}{l}\text { Cond/ } \\
\text { Coronal } \\
\text { Avg } \\
\text { Transverse } \\
\text { (mm) }\end{array}$ & $\begin{array}{c}\text { Cond/ } \\
\text { Coronal } \\
\text { Avg } \\
\text { Vertical } \\
(\mathrm{mm})\end{array}$ & $\begin{array}{l}\text { Cond/ } \\
\text { Coronal } \\
\text { Medial } \\
(\mathrm{mm}) \\
\end{array}$ & $\begin{array}{c}\text { Cond/ } \\
\text { Coronal } \\
\text { Medial }\left(^{\circ}\right)\end{array}$ & $\begin{array}{l}\text { Cond/ } \\
\text { Coronal } \\
\text { Superior } \\
(\mathrm{mm}) \\
\end{array}$ & $\begin{array}{c}\text { Cond/ } \\
\text { Coronal } \\
\text { Superior }\left({ }^{\circ}\right)\end{array}$ & $\begin{array}{l}\text { Cond/ } \\
\text { Coronal } \\
\text { Lateral } \\
(\mathrm{mm})\end{array}$ & $\begin{array}{c}\text { Cond/ } \\
\text { Coronal } \\
\text { Lateral }\left({ }^{\circ}\right)\end{array}$ \\
\hline 1 & -0.93 & 1.98 & 1.66 & -18.40 & 2.94 & -34.80 & 1.95 & -22.20 \\
\hline 2 & -0.57 & 2.67 & 3.37 & -18.60 & 3.22 & -9.50 & 1.60 & -7.90 \\
\hline 3 & -1.10 & 3.35 & 5.10 & -6.00 & 2.31 & -41.10 & 3.18 & -7.30 \\
\hline 4 & 1.80 & 2.05 & 1.72 & 12.70 & 3.06 & 39.60 & 3.41 & 71.60 \\
\hline 5 & -0.50 & 2.51 & 2.33 & -2.20 & 3.09 & -9.80 & 2.26 & -21.50 \\
\hline 6 & -1.31 & 4.25 & 4.41 & -11.00 & 3.83 & -22.10 & 5.09 & -18.30 \\
\hline 7 & -0.30 & 0.97 & 0.87 & -5.10 & 0.66 & 1.00 & 1.53 & -47.80 \\
\hline 8 & -1.01 & 1.94 & 1.94 & -21.80 & 1.60 & -29.70 & 3.02 & -31.40 \\
\hline 9 & -0.81 & 0.28 & 0.40 & -135.90 & 1.29 & -13.20 & 0.87 & -63.40 \\
\hline 10 & -1.58 & 1.88 & 2.70 & -7.20 & 2.64 & -25.10 & 2.03 & -88.00 \\
\hline Mean & -0.63 & 2.19 & 2.45 & -21.35 & 2.46 & -14.47 & 2.49 & -23.62 \\
\hline StDev & 0.94 & 1.12 & 1.49 & 41.46 & 0.99 & 22.94 & 1.21 & 42.15 \\
\hline Min & -1.58 & 0.28 & 0.40 & -135.90 & 0.66 & -41.10 & 0.87 & -88.00 \\
\hline Max & 1.80 & 4.25 & 5.10 & 12.70 & 3.83 & 39.60 & 5.09 & 71.60 \\
\hline
\end{tabular}

Table 10. Distribution of condyle measurements (coronal plane)

\section{Sagittal Linear Measurements}

In this study, the superior $(r=0.821)$ and posterior $(r=0.851)$ linear millimeter measurements were most reliable and showed a loose correlation and the anterior measurement $(\mathrm{r}=0.563)$ was the least reliable with little correlation (Table 11).

\begin{tabular}{|l|r|r|r|}
\hline Variable & Mean (1st) & Mean (2nd) & $\begin{array}{l}\text { Correlation } \\
\text { (r } \text { - value) }\end{array}$ \\
\hline Cond/Sag Anterior $(\mathrm{mm})$ & 2.47 & 2.69 & 0.563 \\
\hline Cond/Sag Superior $(\mathrm{mm})$ & 2.85 & 2.69 & 0.821 \\
\hline Cond/Sag Posterior $(\mathrm{mm})$ & 2.64 & 2.75 & 0.851 \\
\hline
\end{tabular}

Table 11. Reliability of condylar sagittal linear measurements 


\section{Sagittal Degree Measurements}

The sagittal directional measurements were not strongly correlated. Anterior $(\mathrm{r}=$ $0.434)$ and superior $(r=0.375)$ measurements were least reliable and the posterior measurement $(\mathrm{r}=0.803)$ was the most reliable (Table 12$)$.

\begin{tabular}{|l|c|c|c|}
\hline Variable & Mean (1st) & Mean (2nd) & $\begin{array}{l}\text { Correlation } \\
\text { ( } \mathbf{r} \text { - value) }\end{array}$ \\
\hline Cond/Sag Superior (deg) & -41.72 & -37.42 & 0.375 \\
\hline Cond/Sag Anterior (deg) & -39.19 & -31.77 & 0.434 \\
\hline Cond/Sag Posterior (deg) & -30.68 & -30.06 & 0.803 \\
\hline
\end{tabular}

Table 12. Reliability of condylar sagittal directional measurements

\section{Sagittal Component Average Measurements}

Directional measurements were anticipated to be highly variable. Therefore, the horizontal and vertical components were extracted by using the sin and $\cos$ of the linear and degree measurements. The anterior-posterior horizontal average $(r=0.803)$ was more reliable than the inferior-superior vertical average $(\mathrm{r}=0.636)($ Table 13).

\begin{tabular}{|l|r|r|r|}
\hline Variable & Mean (1st) & Mean (2nd) & $\begin{array}{l}\text { Correlation } \\
\text { (r } \text { - value) }\end{array}$ \\
\hline Cond/Sag Average Vertical $(\mathrm{mm})$ & 1.80 & 2.18 & 0.636 \\
\hline Cond/Sag Average AP $(\mathrm{mm})$ & -1.59 & -1.40 & 0.803 \\
\hline
\end{tabular}

Table 13. Reliability of condylar sagittal component average measurements

\section{Coronal Linear Measurements}

The lateral $(r=0.342)$ and superior $(r=0.412)$ measurements were least reliable and showed little correlation. The medial measurement $(\mathrm{r}=0.783)$ was the most reliable with a loose correlation (Table 14). 


\begin{tabular}{|l|r|r|r|}
\hline Variable & Mean (1st) & Mean (2nd) & $\begin{array}{l}\text { Correlation } \\
\text { ( } \text { - value) }\end{array}$ \\
\hline Cond/Coronal Lateral $(\mathrm{mm})$ & 2.49 & 2.90 & 0.342 \\
\hline Cond/Coronal Superior $(\mathrm{mm})$ & 2.46 & 2.50 & 0.412 \\
\hline Cond/Coronal Medial $(\mathrm{mm})$ & 2.45 & 2.68 & 0.783 \\
\hline
\end{tabular}

Table 14. Reliability of condylar coronal linear measurements

\section{Coronal Degree Measurements}

The medial measurement $(\mathrm{r}=-0.118)$ was the least reliable with no correlation. The lateral measurement $(\mathrm{r}=0.495)$ showed a loose correlation and low reliability, and the superior measurement $(\mathrm{r}=0.821)$ showed the most correlation and reliability (Table $15)$.

\begin{tabular}{|l|r|r|r|}
\hline Variable & Mean (1st) & Mean (2nd) & $\begin{array}{l}\text { Correlation } \\
\text { ( } \mathbf{r} \text { - value) }\end{array}$ \\
\hline Cond/Coronal Medial (deg) & -21.35 & -3.74 & -0.118 \\
\hline Cond/Coronal Lateral (deg) & -23.62 & 0.88 & 0.495 \\
\hline Cond/Coronal Superior (deg) & -14.47 & -13.22 & 0.821 \\
\hline
\end{tabular}

Table 15. Reliability of coronal directional measurements

\section{Coronal Component Average Measurements}

Directional measurements were anticipated to be highly variable. Therefore, the horizontal and vertical components were extracted by using the $\sin$ and $\cos$ of the linear and degree measurements. The inferior-superior vertical average $(\mathrm{r}=0.560)$ and transverse horizontal average $(\mathrm{r}=0.601)$ both showed a loose correlation and low reliability (Table 16). 


\begin{tabular}{|l|r|r|r|}
\hline Variable & Mean (1st) & Mean (2nd) & $\begin{array}{l}\text { Correlation } \\
\text { (r - value) }\end{array}$ \\
\hline Cond/Coronal Avg Vertical (mm) & 2.19 & 2.30 & 0.560 \\
\hline Cond/Coronal Avg Transverse (mm) & 2.90 & 2.49 & 0.601 \\
\hline
\end{tabular}

Table 16. Reliability of condylar coronal component average measurements

Overall, the method of three-dimensional cephalometric analysis used in this study including landmark identification, superimposition of radiographs, and measurements were determined to be only slightly reliable. The correlation coefficients ranged from $r=-0.118$ to $r=0.851$ with the majority being greater than $r>0.500$ (Table 17).

\begin{tabular}{|l|r|r|r|}
\hline Variable & Mean (1st) & Mean (2nd) & $\begin{array}{l}\text { Correlation } \\
\text { (r - value) }\end{array}$ \\
\hline Cond/Coronal Medial (deg) & -21.35 & -3.74 & -0.118 \\
\hline Cond/Coronal Lateral (mm) & 2.49 & 2.90 & 0.342 \\
\hline Cond/Sag Superior (deg) & -41.72 & -37.42 & 0.375 \\
\hline Cond/Coronal Superior (mm) & 2.46 & 2.50 & 0.412 \\
\hline Cond/Sag Anterior (deg) & -39.19 & -31.77 & 0.434 \\
\hline Cond/Coronal Lateral (deg) & -23.62 & 0.88 & 0.495 \\
\hline Cond/Coronal Avg Vertical (mm) & 2.19 & 2.30 & 0.560 \\
\hline Cond/Sag Anterior (mm) & 2.47 & 2.69 & 0.563 \\
\hline Cond/Coronal Avg Transverse (mm) & 2.90 & 2.49 & 0.601 \\
\hline Cond/Sag Average Vertical (mm) & 1.80 & 2.18 & 0.636 \\
\hline Cond/Coronal Medial (mm) & 2.45 & 2.68 & 0.783 \\
\hline Cond/Sag Posterior (deg) & -30.68 & -30.06 & 0.803 \\
\hline Cond/Sag Average AP (mm) & -1.59 & -1.40 & 0.803 \\
\hline Cond/Sag Superior (mm) & 2.85 & 2.69 & 0.821 \\
\hline Cond/Coronal Superior (deg) & -14.47 & -13.22 & 0.821 \\
\hline Cond/Sag Posterior (mm) & 2.64 & 2.75 & 0.851 \\
\hline
\end{tabular}

Table 17. Reliability of variables, ordered from least to most correlated 


\section{CHAPTER 5: SUMMARY, CONCLUSIONS, AND RECOMMENDATIONS}

\section{Summary}

The purpose of this study was to investigate the reliability of a novel approach to document three-dimensional changes in morphology of the temporomandibular joint by comparing a pre and post treatment cone beam radiograph. The approach to measuring these changes included plotting specific referents on the mandibular condyle and tracking them in magnitude $(\mathrm{mm})$ and direction $\left(^{\circ}\right)$ on a reference plane after superimposing the cone beams three-dimensionally on the inferior alveolar nerve canal and the lower contour of the third molar tooth germ ${ }^{93}$. Since a suitable control group could not be used, contribution of skeletal growth versus Herbst treatment effects could not be determined. Two sets of measurements were compared for reliability and each measurement (both linear and directional) showed varied correlation of coefficients. Linear measurements tended to be more reliable than average and directional measurements. Directional measurements were generally the least reliable. The varied reliability results are likely due to the difficulty in superimposing limited field of view cone beam radiographs because of inadequate structures that are able to be superimposed. The results of this study should provide important information on the effectiveness of superimposing threedimensionally and taking/comparing measurements in three planes of space, particularly in limited field of view radiographs which is present in a large number of private practice settings. 


\section{Conclusions}

Reliability determinations resulted in the following conclusions about superimposing three-dimensionally and plotting measurements in three planes of space:

1) There is no such control group to show the developing mandibular condyle and glenoid fossa in adolescents in three dimensions. Therefore no conclusions can be drawn in determining the skeletal component of change versus the component from Herbst treatment.

2) There was an insufficient amount of anatomic landmarks to superimpose predictably in a cone beam scan with a limited field of view due to the minimal presence of stable structures.

a. Anterior cranial base structures were not present on subjects' radiographs.

b. The mandibular symphysis was not present on the subjects' radiographs.

c. Only one posterior segment of the mandible was present on the subjects' radiographs.

3) The mandibular inferior alveolar nerve canal and third molar tooth germ on one side of a mandible is sufficient to superimpose in the sagittal dimension (e.g. in a two-dimensional lateral cephalometric radiograph), but insufficient in three dimensions due to difficulty in determining the canal space in three dimensions as well as minor changes within the developing third molar tooth bud.

4) Sagittal posterior and sagittal superior linear referents are most reliably identified on the condyle.

5) Sagittal posterior directional referents are most reliably identified on the condyle.

6) Coronal medial linear referents are most reliably identified on the condyle. 
7) Coronal superior directional referents are most reliably identified on the condyle.

8) Generally, sagittal referents are more reliable than coronal measurements.

9) Generally, linear referents are more reliable than directional measurements.

Overall, three-dimensional evaluation provides much more information than an evaluation obtained from a two-dimensional radiograph. Utilizing three dimensions will be an extremely valuable perspective in research when investigating changes in bony structure throughout growth or treatment.

\section{Recommendations}

Full field of view cone beam scans containing the anterior cranial base and the entire mandible will produce more predictable superimpositions due to surface anatomy registration ${ }^{94}$ on the anterior cranial base itself and on the lingual mandibular symphysis. Currently, the most practical method of comparing changes between multiple threedimensional radiographs is with color mapping technology as developed by the work of Cevidanes, et al ${ }^{94-97}$. With color mapping, varying intensities of color can describe the amount of change and all dimensions can be visualized at once for rapid consumption of data by the investigator. However, with color mapping, the data is qualitative and specific comparisons between different patients may be difficult to represent for research on a population of subjects.

Ideally, a future study can be conducted on full field of view CBCT radiographs using color mapping technology. However, medical ethics would prevent unnecessarily exposing untreated subjects to a higher dose of radiation from a CBCT machine strictly 
for research purposes. This is especially important to recognize in the establishment of a control group similar to catalogs of cephalometric radiographs in the Bolton-Brush study, for example. Perhaps in the future, non-ionizing radiation technologies (e.g. Magnetic Resonance Imaging) will become more practical and inexpensive in the threedimensional dental research arena. 


\section{Reference List}

1. Pancherz, H. \& nehus-Pancherz, M. The effect of continuous bite jumping with the Herbst appliance on the masticatory system: a functional analysis of treated class II malocclusions. Eur. J. Orthod. 4, 37-44 (1982).

2. Foucart, J. M., Pajoni, D., Carpentier, P. \& Pharaboz, C. [MRI study of temporomandibular joint disk behavior in chilren with hyperpropulsion appliances]. Orthod. Fr. 69, 79-91 (1998).

3. Hansen, K., Pancherz, H. \& Petersson, A. Long-term effects of the Herbst appliance on the craniomandibular system with special reference to the TMJ. Eur. J. Orthod. 12, 244-253 (1990).

4. Ruf, S. \& Pancherz, H. Does bite-jumping damage the TMJ? A prospective longitudinal clinical and MRI study of Herbst patients. Angle Orthodontist 70, 183-199 (2000).

5. Popowich, K., Nebbe, B. \& Major, P. W. Effect of Herbst treatment on temporomandibular joint morphology: a systematic literature review. Am. $J$. Orthod. Dentofacial Orthop. 123, 388-394 (2003).

6. Pancherz, H., Ruf, S. \& Thomalske-Faubert, C. Mandibular articular disk position changes during Herbst treatment: a prospective longitudinal MRI study. Am. J. Orthod. Dentofacial Orthop. 116, 207-214 (1999).

7. Larsen, C. S. Bioarchaeology: interpreting behavior from the human skeleton. Cambridge University Press, Cambridge, MA (1997).

8. Kingsley, N. W. Treatise on oral deformities as a branch of mechanical surgery. Appleton, New York (1880).

9. Angle, E. H. Treatment of malocclusion of teeth and fractures of the maxillae. SS White Dental Mfg. Co., Philadelphia (1900).

10. Profitt, W. R. \& Fields, H. W. Contemporary Orthodontics. Moseby, Inc., St. Louis (2000).

11. Kelly, J. E., Sanchez, M. \& Vankirk, L. E. An assessment of the occlusion of the teeth of children. DHEW Publication No. (HRA) 74-1612. 1973. Washington, DC, National Center for Health Statistics.

Ref Type: Report 
12. Kelly, J. E. \& Haskell, B. S. An assessment of the teeth of youths 12-17 years. DHEW Publication No. (HRA) 74-1612. 1977. Washington, DC, National Center for Health Statistics.

Ref Type: Report

13. McLain, J. B. \& Profitt, W. R. Oral Helath Status in the United States: Prevalence of Malocclusion. Journal of Dental Education 49, 386-396 (1985).

14. Enlow, D. H. Facial Growth. WB Saunders, Co., (1990).

15. McNamara, J. A. \& Brudon, W. Orthodontic and Orthopedic Treatment in the Mixed Dentition. Needham Press, Inc., Ann Arbor (1993).

16. McNamara, J. A., Jr. Components of Class II malocclusion in children 8-10 years of age. Angle Orthodontist 51, 177-202 (1981).

17. Ngan, P. W., Byczek, E. \& Scheick, J. Longitudinal evaluation of growth changes in Class II division 1 subjects. Semin. Orthod. 3, 222-231 (1997).

18. Wieslander, L. Intensive treatment of severe Class II malocclusion with a headgear-Herbst appliance in the early mixed dentition. American Journal of Orthodontics and Dentofacial Orthopedics 86, 1-13 (1984).

19. Ruf, S. \& Pancherz, H. Herbst/multibracket appliance treatment of Class II division I malocclusions in early and late adulthood. A prospective cephalometric study of consecutively treated subjects. Eur. J. Orthod. 28, 352-360 (2006).

20. Ruf, S. \& Pancherz, H. Temporomandibular joint remodeling in adolescents and young adults during Herbst treatment: a prospective longitudinal magnetic resonance imaging and cephalometric radiographic investigation. American Journal of Orthodontics and Dentofacial Orthopedics 115, 607-618 (1999).

21. Moore, R. N. Principles of Dentofacial ORthopedics. Seminars in Orthodontics 3, 212-221 (1997).

22. Weinberger, W. W. Orthodontics. A historical review of its origin and evolution. The Mosby Company, (1926).

23. Breitner, C. Veranderungen der mesiodistalen Beziehungen der oberen und untern Zahnreihen. Stomatol. 28, 620-635 (1930).

24. Andresen, V. \& Kaupl, K. Funktions-kieferorthopadie. Leipzig (1936). 
25. Balters, W. Die technik und ubung der allfemeinen und speziellen bionatortherapie. Quintessenz 1, 77 (1964).

26. Frankel, R. Funktionskeiferorthopadie und der mundhof als apparative basis. V.E.B. Verlag Volk \& Gesundheit, Berlin (1967).

27. Pancherz, H. The modern Herbst appliance. Moseby-Year Book, St. Louis (1997).

28. Nelson, C., Harkness, M. \& Herbison, P. Mandibular changes during functional appliance treatment. American Journal of Orthodontics and Dentofacial Orthopedics 104, 153-161 (1993).

29. Mills, J. R. The effect of functional appliances on the skeletal pattern. British Journal of Orthodontics 18, 267-275 (1991).

30. Teuscher, U. A growth-related concept for skeletal Class II treatment. American Journal of Orthodontics 74, 258-275 (1978).

31. Rudzki-Janson, I. Functional appliance therapy with the bionator. Seminars in Orthodontics 4, 33-45 (1998).

32. Aelbers, C. M. F. \& Dermault, L. R. Orthopedics in orthodontics: Part I, fiction or reality--a review of the literature. American Journal of Orthodontics and Dentofacial Orthopedics 110, 513-519 (1996).

33. O'Brien, K. Effectiveness of treatment for Class II malocclusion with the Herbst or twin-block appliances: A randomized, controller trial. American Journal of Orthodontics and Dentofacial Orthopedics 124, 128-137 (2003).

34. Pancherz, H. Treatment of Class II malocclusions by jumping the bite with the Herbst appliance: A cephalometric investigation. American Journal of Orthodontics 76, 423-442 (1979).

35. Pancherz, H. The mechanism of Class II correction in Herbst appliance treatment: A cephalometric investigation. American Journal of Orthodontics 82, 104-113 (1982).

36. Pancherz, H. Treatment of class II malocclusions by jumping the bite with the Herbst appliance. A cephalometric investigation. Am. J. Orthod. 76, 423-442 (1979). 
37. McNamara, J. A. Fabrication of the acrylic splint Herbst appliance. Am. J. Orthod. Dentofacial Orthop. 94, 10-18 (1988).

38. Burkhardt, D. R., McNamara, J. A. Jr. \& Baccetti, T. Maxillary molar disalization or mandibular enhancement: a cephalometric comparison of comprehensive orthodontic treatment including the pendulum and the Herbst appliances. American Journal of Orthodontics and Dentofacial Orthopedics 123, 108-116 (2003).

39. Dischinger, T. G. Edgewise bioprogressive Herbst appliance. Journal of Clinical Orthodontics 23, 608-617 (1989).

40. Langford, N. M. Jr. Updating fabrication of the Herbst appliance. Journal of Clinical Orthodontics 16, 173-174 (1982).

41. Schwarz, M. Erfahrungen mit dem herbstschen scharnier zur behandlung des distalbisses. Zahnarztl 43, 47-54 (1934).

42. Herbst, E. Dreissigjahridge Erfahrungen mit dem Retentionsscharnier. Zahnarztl 43, 1515-1524 (1934).

43. McNamara, J. A. Trotman C-A (ed.) (Center for Human Growth and Development, Ann Arbor,1997).

44. Sinha, P. K., Nanda, R. S. \& Fillingim, R. B. Psychologic issues related to orthodontics. Seminars in Orthodontics 6, (2000).

45. Jay, M. S. Compliance: the adolescent/provider partnership. Creating the compliant patient 33, 47-58 (1997).

46. Albino, J. E., Lawrence, S. D., Lopes, C. E., Nash, L. B. \& Tedesco, L. A. Cooperation of adolescents in orthodontic treatment. J. Behav. Med. 14, 53-70 (1991).

47. Klages, U., Sergl, H. G. \& Burucker, I. Relations between verbal behavior of the orthodontist and communicative cooperation of the patient in regular orthodontic visits. American Journal of Orthodontics and Dentofacial Orthopedics 102, 265-269 (1992).

48. Moss, M. L. The primacy of functional matrices in orofacial growth. Dent. Pract. Dent. Rec. 19, 65-73 (1968). 
49. Moss, M. L. \& Rankow, R. M. The role of the functional matrix in mandibular growth. Angle Orthod. 38, 95-103 (1968).

50. Broadie, A. G. On the growth pattern of the human head from third month to the eighth year of life. American Journal of Orthodontics 27, 633-647 (1941).

51. Jakobsson, S. O. Cephalometric evaluation of treatment effect on Class II, Division 1 malocclusions. American Journal of Orthodontics and Dentofacial Orthopedics 53, 446-457 (1967).

52. Baumrind, S., Korn, E. L. \& Isaacson, R. J. Quantitative analysis of the orthodontic and orthopedic effects of maxillary traction. American Journal of Orthodontics and Dentofacial Orthopedics 84, 384-398 (1983).

53. Croft, R. S., Buschang, P. H. \& English, J. D. A cephalometric and tomographic evaluation of Herbst treatment in the mixed dentition. American Journal of Orthodontics and Dentofacial Orthopedics 116, 435-443 (1999).

54. Cozza, P., Baccetti, T., Franchi, L., Toffol, L. D. \& McNamara, J. A. Mandibular changes produced by functional appliances in Class II malocclusion: A systematic review. American Journal of Orthodontics and Dentofacial Orthopedics 129, 599 (2006).

55. Von Bremen, J. \& Pancherz, H. Efficiency of early and late Class II Division 1 treatment. American Journal of Orthodontics and Dentofacial Orthopedics 121, 31-37 (2002).

56. Tulloch, J. F., Phillips, C. \& Profitt, W. R. Benefits of early Class II treatment: Progress report of a two-phase randomized clinical trial. American Journal of Orthodontics and Dentofacial Orthopedics 113, 62-72 (1998).

57. Tulloch, J. F., Profitt, W. R. \& Phillips, C. Outcomes in a 2-phase randomized controlled clinical trial of early Class II treatment. American Journal of Orthodontics and Dentofacial Orthopedics 125, 657-667 (2004).

58. Viazis, A. D. Efficient orthodontic treatment timing. American Journal of Orthodontics and Dentofacial Orthopedics 108, 560-561 (1995).

59. Ghafari, J. G. Emerging paradigms in orthodontics. American Journal of Orthodontics and Dentofacial Orthopedics 111, 573-580 (1997).

60. Nelson, G. Phase I treatment. American Journal of Orthodontics and Dentofacial Orthopedics 111, 239-240 (1997). 
61. Gianelly, A. A. Crowding: timing of treatment. Angle Orthodontist 64, 415-418 (1994).

62. Gianelly, A. A. One-phase versus two-phase treatment. American Journal of Orthodontics and Dentofacial Orthopedics 108, 556-559 (1995).

63. Tung, A. W. \& Kiyak, H. A. Psychological influences on the timing of orthodontic treatment. American Journal of Orthodontics and Dentofacial Orthopedics 113, 29-39 (1998).

64. O'Brien, K. et al. Effectiveness of early orthodontic treatment with the Twinblock appliance: a multicenter, randomized, controlled trial. Part 2: Psychosocial effects. Am. J. Orthod. Dentofacial Orthop. 124, 488-494 (2003).

65. McNamara, J. A., Jr. \& Carlson, D. S. Quantitative analysis of temporomandibular joint adaptations to protrusive function. Am. J. Orthod. 76, 593-611 (1979).

66. McNamara, J. A., Jr. Neuromuscular and skeletal adaptations to altered function in the orofacial region. Am. J. Orthod. 64, 578-606 (1973).

67. Xiong, H., Hagg, U., Tang, G. H., Rabie, A. B. \& Robinson, W. The effect of continuous bite-jumping in adult rats: a morphological study. Angle Orthod. 74, 86-92 (2004).

68. Chen, J. Y., Will, L. A. \& Niederman, R. Analysis of efficacy of functional appliances on mandibular growth. Am. J. Orthod. Dentofacial Orthop. 122, 470476 (2002).

69. Pancherz, H. \& Littmann, C. Somatische Reif und morphologische Veranderungen des Unterkiefers bei der Herbst-Behandlung. Inf. Orthod. Kieferorthop. 20, 455-470 (1988).

70. Pancherz, H. \& Littmann, C. Morphologie und Lage des Unferkiefers bei der Herbst-Behandlung. Eine kephalometriesche Analyse der Veranderungen bis zum Wachstumsabschluss. Inf. Orthod. Kieferorthop. 21, 493-513 (1989).

71. Voudouris, J. C. et al. Condyle-fossa modifications and muscle interactions during Herbst treatment, Part 2. Results and conclusions. Am. J. Orthod. Dentofacial Orthop. 124, 13-29 (2003). 
72. Araujo, A. M., Buschang, P. H. \& Melo, A. C. Adaptive condylar growth and mandibular remodelling changes with bionator therapy--an implant study. Eur. $J$. Orthod. 26, 515-522 (2004).

73. Paulsen, H. U., Karle, A., Bakke, M. \& Herskind, A. CT-scanning and radiographic analysis of temporomandibular joints and cephalometric analysis in a case of Herbst treatment in late puberty. Eur. J. Orthod. 17, 165-175 (1995).

74. Bakke, M. \& Paulsen, H. U. Herbst treatment in late adolescence: clinical, electromyographic, kinesiographic, and radiographic analysis of one case. Eur. $J$. Orthod. 11, 397-407 (1989).

75. Rabie, A. B. et al. Osteogenesis in the glenoid fossa in response to mandibular advancement. Am. J. Orthod. Dentofacial Orthop. 119, 390-400 (2001).

76. Rabie, A. B., Shum, L. \& Chayanupatkul, A. VEGF and bone formation in the glenoid fossa during forward mandibular positioning. Am. J. Orthod. Dentofacial Orthop. 122, 202-209 (2002).

77. Rabie, A. B., Wong, L. \& Hagg, U. Correlation of replicating cells and osteogenesis in the glenoid fossa during stepwise advancement. Am. J. Orthod. Dentofacial Orthop. 123, 521-526 (2003).

78. Honey, O. B. et al. Accuracy of cone-beam computed tomography imaging of the temporomandibular joint: comparisons with panoramic radiology and linear tomography. Am. J. Orthod. Dentofacial Orthop. 132, 429-438 (2007).

79. Carlton, K. L. \& Nanda, R. S. Prospective study of posttreatment changes in the temporomandibular joint. American Journal of Orthodontics and Dentofacial Orthopedics 122, 486-490 (2002).

80. Peltola, J. S., Kononen, M. \& Nystrom, M. A follow-up study of radiographic findings in the mandibular condyles of orthodontically treated patients and associations with TMD. Journal of Dental Research 74, 1571-1576 (1995).

81. Frederiksen, N. L. Oral Radiology: Principles and Interpretation., pp. 245-264 (Mosby, Philadelphia,2004).

82. Seren, E., Akan, H., Toller, M. O. \& Akyar, S. An evaluation of the condylar position of the temporomandibular joint by computerized tomography in Class III malocclusions: a preliminary study. Am. J. Orthod. Dentofacial Orthop. 105, 483488 (1994). 
83. Baba, R., Konno, Y., Ueda, K. \& Ikeda, S. Comparison of flat-panel detector and image-intensifier detector for cone-beam CT. Comput. Med. Imaging Graph. 26, 153-158 (2002).

84. Baba, R., Ueda, K. \& Okabe, M. Using a flat-panel detector in high resolution cone beam CT for dental imaging. Dentomaxillofac. Radiol. 33, 285-290 (2004).

85. ElSaid, K., Friedland, B., Scarfe, W. C. \& Graber, T. M. Conebeam. 2008. 4-242008.

Ref Type: Internet Communication

86. Moshiri, M. et al. Accuracy of linear measurements from imaging plate and lateral cephlometric images derived from cone-beam computed tomography. American Journal of Orthodontics and Dentofacial Orthopedics 465, 550-560 (2007).

87. Rustemeyer, P., Streubuhr, U. \& Suttmoeller, J. Low-dose dental computed tomography: significant dose reduction without loss of image quality. Acta Radiol. 45, 847-853 (2004).

88. Healthcare Human Factors Group. Computed Tomography Radiation Safety Issues in Ontario. 6-16-2006. Toronto, Centre for Global eHealth Innovation. Ref Type: Report

89. Scarfe, W. C., Farman, A. G. \& Sukovic, P. Clinical applications of cone-beam computed tomography in dental practice. J. Can. Dent. Assoc. 72, 75-80 (2006).

90. Christensen, G. Why switch to digital radiography? Journal of the American Dental Association 135, 1437-1439 (2004).

91. Frederiksen, N. L. X-Rays: What is the RIsk? Texas Dental Journal 112, 68-72 (1995).

92. Ricketts, R. M. Variations of the temporomandibular joint as revealed by cephalometric laminagraphy. Am. J. Orthod. 36, 877-898 (1950).

93. Bjork, A. Prediction of mandibular growth rotation. Am. J. Orthod. 55, 585-599 (1969).

94. Cevidanes, L. H. et al. Superimposition of 3D cone-beam CT models of orthognathic surgery patients. Dentomaxillofac. Radiol. 34, 369-375 (2005). 
95. Cevidanes, L. H., Styner, M. A. \& Proffit, W. R. Image analysis and superimposition of 3-dimensional cone-beam computed tomography models. Am. J. Orthod. Dentofacial Orthop. 129, 611-618 (2006).

96. Cevidanes, L. H. et al. Three-dimensional cone-beam computed tomography for assessment of mandibular changes after orthognathic surgery. Am. J. Orthod. Dentofacial Orthop. 131, 44-50 (2007).

97. Cevidanes, L. H., Heymann, G., Cornelis, M. A., DeClerck, H. J. \& Tulloch, J. F. Superimposition of 3-dimensional cone-beam computed tomography models of growing patients. Am. J. Orthod. Dentofacial Orthop. 136, $94-99$ (2009). 


\section{APPENDICES}




\section{Appendix A - IRB Exemption}

\begin{tabular}{|r|r|}
\hline & IRB PROTOCOL - Details \\
Tracking \# & H-22052 \\
PI & Ngan, Peter \\
Title & A PROPOSED METHOD FOR EVALUATION OF MORPHOLOGICAL CHANGES IN THE CONDYLE \\
& AND GLENOID FOSSA BY CONE BEAM COMPUTED TOMOGRAPHY \\
Version & 2 \\
Status & Exempt \\
Status Date & 11/10/2009 3:53:08 PM \\
Board & Board Blue \\
Meeting Date & \\
Approval Date & 11/10/2009 \\
Expiration Date &
\end{tabular}




\section{Appendix B - Permission to Use Radiographs}

ROBBERT C. BYRD

HEALTH SCIENCES CENTER

OP IYEST' VIROINIA UNIVERSITY

Schoul of Dentistry

Department of Osthodontics

Permisaion is granted to Dr, Michad Mum, Dr, Poter Ngan, and co-porkers to use the cophalometric radiographs provided by this offico for research and octucational purposes in the completion of the master's thesis "A PROPOSBD MBTHOD FOR BVALUATION OF MORPHOLOGICAL CHANGES MI THE CONDYLE APD GLENOID POBEA DY CONE BEAM COMPUTED TOMOGRAPHY".

Sincerely,

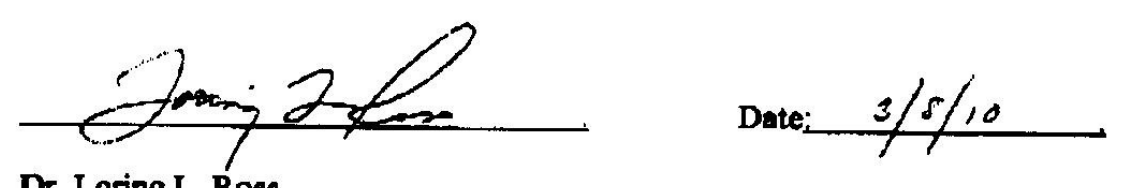

Dr. Loring L, Ross 


\section{Appendix C - Condylar Sagittal Measurements}

\begin{tabular}{|c|c|c|c|c|c|c|c|c|}
\hline \multicolumn{9}{|c|}{ First Measurement } \\
\hline Subject & $\begin{array}{l}\text { Cond/Sag } \\
\text { Avg AP }\end{array}$ & $\begin{array}{c}\text { Cond/ } \\
\text { Sag } \\
\text { Avg } \\
\text { Vertical }\end{array}$ & $\begin{array}{c}\text { Cond/ } \\
\text { Sag Post. } \\
(\mathrm{mm})\end{array}$ & $\begin{array}{c}\text { Cond// } \\
\text { Sag Post. } \\
\left({ }^{\circ}\right)\end{array}$ & $\begin{array}{c}\text { Cond/ } \\
\text { Sag } \\
\text { Superior } \\
(\mathrm{mm})\end{array}$ & $\begin{array}{c}\text { Cond// } \\
\text { Sag Sup. }\left({ }^{\circ}\right)\end{array}$ & $\begin{array}{c}\text { Cond/ } \\
\text { Sag Ant (mm) }\end{array}$ & $\begin{array}{c}\text { Cond/ } \\
\text { Sag Ant }\left({ }^{\circ}\right)\end{array}$ \\
\hline 1 & -2.36 & 1.70 & 2.63 & -36.70 & 2.97 & -64.30 & 3.14 & -61.80 \\
\hline 2 & -1.89 & 2.35 & 3.22 & -43.70 & 3.31 & -39.80 & 2.52 & -33.00 \\
\hline 3 & -1.80 & 2.02 & 2.63 & -37.90 & 3.03 & -29.70 & 2.45 & -57.50 \\
\hline 4 & -1.77 & 1.40 & 2.59 & -29.50 & 2.45 & -73.70 & 1.74 & -51.60 \\
\hline 5 & -1.66 & 2.02 & 2.14 & -36.80 & 3.44 & -41.50 & 2.26 & -39.70 \\
\hline 6 & 0.23 & 3.70 & 4.85 & 6.00 & 3.29 & 6.70 & 2.98 & -1.80 \\
\hline 7 & -0.76 & 1.33 & 1.67 & -37.20 & 1.39 & -41.90 & 1.53 & -10.60 \\
\hline 8 & 0.27 & 1.01 & 0.36 & 30.70 & 1.59 & 4.00 & 1.20 & 10.10 \\
\hline 9 & -3.44 & 0.88 & 3.43 & -79.40 & 3.71 & -78.90 & 3.51 & -68.70 \\
\hline 10 & -2.71 & 1.61 & 2.85 & -42.30 & 3.27 & -58.10 & 3.33 & -77.30 \\
\hline Mean & -1.59 & 1.80 & 2.64 & -30.68 & 2.85 & -41.72 & 2.47 & -39.19 \\
\hline StDev & 1.20 & 0.81 & 1.17 & 29.74 & 0.79 & 29.38 & 0.79 & 29.83 \\
\hline Min & -3.44 & 0.88 & 0.36 & -79.40 & 1.39 & -78.90 & 1.20 & -77.30 \\
\hline Max & 0.27 & 3.70 & 4.85 & 30.70 & 3.71 & 6.70 & 3.51 & 10.10 \\
\hline \multicolumn{9}{|c|}{ Second Measurement } \\
\hline Subject & $\begin{array}{l}\text { Cond/Sag } \\
\text { Avg AP }\end{array}$ & $\begin{array}{l}\text { Cond/ } \\
\text { Sag } \\
\text { Avg } \\
\text { Vertical }\end{array}$ & $\begin{array}{c}\text { Cond/ } \\
\text { Sag Post. } \\
\text { (mm) }\end{array}$ & $\begin{array}{c}\text { Cond/ } \\
\text { Sag Post. } \\
\left(^{\circ}\right)\end{array}$ & $\begin{array}{c}\text { Cond/ } \\
\text { Sag } \\
\text { Superior } \\
(\mathrm{mm})\end{array}$ & $\begin{array}{c}\text { Cond/ } \\
\text { Sag Sup. }\left(^{\circ}\right)\end{array}$ & $\begin{array}{c}\text { Cond/ } \\
\text { Sag Ant (mm) }\end{array}$ & $\begin{array}{c}\text { Cond/ } \\
\text { Sag Ant }\left({ }^{\circ}\right)\end{array}$ \\
\hline 1 & -2.14 & 1.20 & 2.44 & -38.00 & 2.79 & -67.10 & 2.14 & -77.20 \\
\hline 2 & -0.49 & 2.29 & 2.44 & -29.10 & 2.37 & -10.30 & 2.22 & 3.30 \\
\hline 3 & -1.73 & 3.04 & 3.38 & -35.80 & 3.34 & -21.50 & 3.76 & -31.70 \\
\hline 4 & -1.83 & 2.34 & 3.07 & -37.20 & 2.98 & -41.30 & 2.88 & -35.60 \\
\hline 5 & -2.07 & 1.89 & 2.79 & -34.60 & 2.80 & -57.60 & 2.81 & -50.40 \\
\hline 6 & -0.01 & 3.51 & 4.75 & 5.50 & 3.09 & -5.80 & 2.69 & 0.00 \\
\hline 7 & -0.72 & 1.67 & 1.14 & -41.60 & 1.74 & -22.10 & 2.57 & -6.30 \\
\hline 8 & -0.74 & 0.93 & 1.44 & -12.50 & 1.29 & -57.80 & 0.84 & -45.00 \\
\hline 9 & -2.46 & 2.49 & 3.02 & -43.80 & 3.54 & -48.10 & 3.93 & -42.20 \\
\hline 10 & -1.77 & 2.41 & 3.00 & -33.50 & 2.92 & -42.60 & 3.05 & -32.60 \\
\hline Mean & -1.40 & 2.18 & 2.75 & -30.06 & 2.69 & -37.42 & 2.69 & -31.77 \\
\hline StDev & 0.83 & 0.79 & 1.01 & 15.18 & 0.70 & 21.30 & 0.87 & 24.94 \\
\hline Min & -2.46 & 0.93 & 1.14 & -43.80 & 1.29 & -67.10 & 0.84 & -77.20 \\
\hline Max & -0.01 & 3.51 & 4.75 & 5.50 & 3.54 & -5.80 & 3.93 & 3.30 \\
\hline
\end{tabular}




\section{Appendix D - Condylar Coronal Measurements}

\begin{tabular}{|c|c|c|c|c|c|c|c|c|}
\hline \multicolumn{9}{|c|}{ First Measurement } \\
\hline Subject & $\begin{array}{c}\text { Cond/ } \\
\text { Coronal } \\
\text { Avg } \\
\text { Transv. } \\
\text { (mm) } \\
\end{array}$ & $\begin{array}{c}\text { Cond/ } \\
\text { Coronal } \\
\text { Avg } \\
\text { Vertical } \\
(\mathrm{mm}) \\
\end{array}$ & $\begin{array}{c}\text { Cond/ } \\
\text { Coronal } \\
\text { Medial } \\
(\mathrm{mm})\end{array}$ & $\begin{array}{c}\text { Cond/ } \\
\text { Coronal } \\
\text { Medial }\left({ }^{\circ}\right)\end{array}$ & $\begin{array}{l}\text { Cond/ } \\
\text { Coronal } \\
\text { Superior } \\
(\mathrm{mm})\end{array}$ & $\begin{array}{c}\text { Cond/ } \\
\text { Coronal } \\
\text { Superior }\left({ }^{\circ}\right)\end{array}$ & $\begin{array}{c}\text { Cond/ } \\
\text { Coronal Lateral } \\
(\mathrm{mm})\end{array}$ & $\begin{array}{c}\text { Cond/ } \\
\text { Coronal } \\
\text { Lateral }\left({ }^{\circ}\right)\end{array}$ \\
\hline 1 & -0.93 & 1.98 & 1.66 & -18.40 & 2.94 & -34.80 & 1.95 & -22.20 \\
\hline 2 & -0.57 & 2.67 & 3.37 & -18.60 & 3.22 & -9.50 & 1.60 & -7.90 \\
\hline 3 & -1.10 & 3.35 & 5.10 & -6.00 & 2.31 & -41.10 & 3.18 & -7.30 \\
\hline 4 & 1.80 & 2.05 & 1.72 & 12.70 & 3.06 & 39.60 & 3.41 & 71.60 \\
\hline 5 & -0.50 & 2.51 & 2.33 & -2.20 & 3.09 & -9.80 & 2.26 & -21.50 \\
\hline 6 & -1.31 & 4.25 & 4.41 & -11.00 & 3.83 & -22.10 & 5.09 & -18.30 \\
\hline 7 & -0.30 & 0.97 & 0.87 & -5.10 & 0.66 & 1.00 & 1.53 & -47.80 \\
\hline 8 & -1.01 & 1.94 & 1.94 & -21.80 & 1.60 & -29.70 & 3.02 & -31.40 \\
\hline 9 & -0.81 & 0.28 & 0.40 & -135.90 & 1.29 & -13.20 & 0.87 & -63.40 \\
\hline 10 & -1.58 & 1.88 & 2.70 & -7.20 & 2.64 & -25.10 & 2.03 & -88.00 \\
\hline Mean & -0.63 & 2.19 & 2.45 & -21.35 & 2.46 & -14.47 & 2.49 & -23.62 \\
\hline StDev & 0.94 & 1.12 & 1.49 & 41.46 & 0.99 & 22.94 & 1.21 & 42.15 \\
\hline Min & -1.58 & 0.28 & 0.40 & -135.90 & 0.66 & -41.10 & 0.87 & -88.00 \\
\hline Max & 1.80 & 4.25 & 5.10 & 12.70 & 3.83 & 39.60 & 5.09 & 71.60 \\
\hline \multicolumn{9}{|c|}{ Second Measurement } \\
\hline Subject & $\begin{array}{c}\text { Cond/ } \\
\text { Coronal } \\
\text { Avg } \\
\text { Transv. } \\
\text { (mm) }\end{array}$ & $\begin{array}{c}\text { Cond/ } \\
\text { Coronal } \\
\text { Avg } \\
\text { Vertical } \\
(\mathrm{mm}) \\
\end{array}$ & $\begin{array}{l}\text { Cond/ } \\
\text { Coronal } \\
\text { Medial } \\
(\mathrm{mm})\end{array}$ & $\begin{array}{l}\text { Cond/ } \\
\text { Coronal } \\
\text { Medial }\left({ }^{\circ}\right)\end{array}$ & $\begin{array}{l}\text { Cond/ } \\
\text { Coronal } \\
\text { Superior } \\
(\mathrm{mm}) \\
\end{array}$ & $\begin{array}{c}\text { Cond/ } \\
\text { Coronal } \\
\text { Superior }\left({ }^{\circ}\right)\end{array}$ & $\begin{array}{c}\text { Cond/ } \\
\text { Coronal Lateral } \\
(\mathrm{mm})\end{array}$ & $\begin{array}{c}\text { Cond/ } \\
\text { Coronal } \\
\text { Lateral }\left({ }^{\circ}\right)\end{array}$ \\
\hline 1 & -0.09 & 1.07 & 1.79 & -27.30 & 0.47 & -63.40 & 0.97 & 76.90 \\
\hline 2 & -1.69 & 3.32 & 3.47 & -17.00 & 3.76 & -20.90 & 3.95 & -42.90 \\
\hline 3 & -0.52 & 3.13 & 3.31 & -39.80 & 3.25 & -32.50 & 2.96 & 43.80 \\
\hline 4 & 1.41 & 0.41 & 1.29 & 89.50 & 1.22 & 54.20 & 1.90 & 78.30 \\
\hline 5 & -1.76 & 2.74 & 2.75 & 2.80 & 3.15 & -30.00 & 3.88 & -70.80 \\
\hline 6 & -1.31 & 4.02 & 4.20 & -28.90 & 4.00 & -35.20 & 4.48 & 9.90 \\
\hline 7 & 0.70 & 1.78 & 2.14 & 10.60 & 1.42 & 53.10 & 2.18 & 0.30 \\
\hline 8 & -2.00 & 1.23 & 2.34 & -61.80 & 1.92 & -55.50 & 2.80 & -57.80 \\
\hline 9 & 0.94 & 2.19 & 2.16 & 36.00 & 2.29 & 12.40 & 2.70 & 21.20 \\
\hline 10 & -1.25 & 3.10 & 3.31 & -1.50 & 3.50 & -14.40 & 3.21 & -50.10 \\
\hline Mean & -0.56 & 2.30 & 2.68 & -3.74 & 2.50 & -13.22 & 2.90 & 0.88 \\
\hline StDev & 1.24 & 1.16 & 0.89 & 42.90 & 1.21 & 40.96 & 1.05 & 54.98 \\
\hline Min & -2.00 & 0.41 & 1.29 & -61.80 & 0.47 & -63.40 & 0.97 & -70.80 \\
\hline Max & 1.41 & 4.02 & 4.20 & 89.50 & 4.00 & 54.20 & 4.48 & 78.30 \\
\hline
\end{tabular}




\section{Appendix E - Reliability Data}

\begin{tabular}{|l|r|r|c|}
\hline Component Averages (Sagittal) & Mean (1st) & Mean (2nd) & Correlation \\
\hline Cond/Sag Average Vertical (mm) & 1.80 & 2.18 & 0.636 \\
\hline Cond/Sag Average AP (mm) & -1.59 & -1.40 & 0.803 \\
\hline Linear (Sagittal) & Mean (1st) & Mean (2nd) & Correlation \\
\hline Cond/Sag Anterior (mm) & 2.47 & 2.69 & 0.563 \\
\hline Cond/Sag Superior (mm) & 2.85 & 2.69 & 0.821 \\
\hline Cond/Sag Posterior (mm) & 2.64 & 2.75 & 0.851 \\
\hline Directional (Sagittal) & Mean (1st) & Mean (2nd) & Correlation \\
\hline Cond/Sag Superior (deg) & -41.72 & -37.42 & 0.375 \\
\hline Cond/Sag Anterior (deg) & -39.19 & -31.77 & 0.434 \\
\hline Cond/Sag Posterior (deg) & -30.68 & -30.06 & 0.803 \\
\hline Component Averages (Coronal) & Mean (1st) & Mean (2nd) & Correlation \\
\hline Cond/Coronal Avg Vertical (mm) & 2.19 & 2.30 & 0.560 \\
\hline Cond/Coronal Avg Transverse (mm) & 2.90 & 2.49 & 0.601 \\
\hline Linear (Coronal) & Mean (1st) & Mean (2nd) & Correlation \\
\hline Cond/Coronal Lateral (mm) & 2.49 & 2.90 & 0.342 \\
\hline Cond/Coronal Superior (mm) & 2.46 & 2.50 & 0.412 \\
\hline Cond/Coronal Medial (mm) & 2.45 & 2.68 & 0.783 \\
\hline Directional (Coronal) & -14.47 & -13.22 & 0.821 \\
\hline Cond/Coronal Medial (deg) & & & \\
\hline Cond/Coronal Lateral (deg) & -21.35 & -3.74 & -0.118 \\
\hline Cond/Coronal Superior (deg) & -23.62 & 0.88 & 0.495 \\
\hline
\end{tabular}




\section{CURRICULUM VITAE}

Name:

Date of Birth:

Place of Birth:

Education:

August 1999 - May 2003

June 2003 - May 2007

July 2007 - Present
Michael R. Munn, D.M.D.

March 5, 1981

West Columbia, SC
Bob Jones University

Greenville, South Carolina

Bachelor of Science, Pre-med/Biology

Medical University of South Carolina

College of Dental Medicine

Charleston, South Carolina

Doctorate of Dental Medicine

West Virginia University

School of Dentistry

Department of Orthodontics

Morgantown, West Virginia

Master of Science (anticipated May 2010)

\section{Professional Memberships:}

June 2003 - May 2007

May 2007 - Present

July 2007 - Present
American Student Dental Association

American Dental Association

American Association of Orthodontists

\section{Publications:}

"Comparing digital serial cephalogram images for growth or treatment changes" American Journal of Orthodontics \& Dentofacial Orthopedics; Volume 128, Issue 2, Pages 161-62 (August 2005) 